\title{
Die Funktion von NLP1 im CRM1- abhängigen Protein-Export aus dem Zellkern
}

\author{
Dissertation \\ zur Erlangung des mathematisch-naturwissenschaftlichen \\ Doktorgrades \\ „Doctor rerum naturalium“ \\ der Georg-August-Universität Göttingen
}

vorgelegt von

Inga Mareike Waldmann

aus Aurich

Göttingen 2011 
Mitglieder des Betreuungsausschusses:

Referent:

\section{PD Dr. Ralph Kehlenbach}

Zentrum für Biochemie und Molekulare Zellbiologie, Abteilung

Biochemie I der Georg-August-Universität Göttingen

Korreferent:

Prof. Dr. Ralf Ficner

Institut für Mikrobiologie und Genetik, Abteilung für Molekulare Strukturbiologie der Georg-August-Universität Göttingen

Tag der mündlichen Prüfung: 10. Mai 2011 
INHALTSVERZEICHNIS

ZUSAMMENFASSUNG

SUMMARY
1. EINLEITUNG

1.1. Transportfaktoren und ihre Signale

1.2. Der Ran-Zyklus

1.3. CRM1-abhängiger Protein-Export

1.4. Die Kernpore 20

1.5. Transport-Modelle 22

1.6. Spezifische Funktionen einzelner Nucleoporine im Transport von 23 Proteinen

1.7. hCG1/NLP1 24

1.8. Zielsetzung der Arbeit 26

2. ERGEBNISSE

2.1. CRM1 ist für den CRM1-abhängigen Export von Proteinen aus dem 27 Zellkern limitierend

2.2. Intrazelluläre Lokalisation von NLP1 29

2.2.1. Generierung von $\alpha$ NLP1-Antikörpern 29

2.2.2. Untersuchung der intrazellulären Lokalisation von NLP1 31

2.2.3. NLP1 unterliegt nicht CRM1-abhängigem Export und ist im Kern 33 mobil

2.3. Biochemische Charakterisierung von NLP1 35

2.3.1. NLP1 kann Komplexe mit CRM1, RanGTP und einem Exportsubstrat 35 bilden

2.3.2. NLP1-Komplexe sind gegenüber RanGAP1-induzierter GTP-Hydrolyse 38 insensitiv

2.3.3. NLP1-Komplexe können durch RanBP1 dissoziiert werden

2.3.4. Identifizierung der CRM1-Bindestelle in NLP1

2.3.5. Das virale Protein HIV-Rev kann sowohl direkt als auch über CRM1 mit NLP1 interagieren

2.3.6. NLP1 kann in vitro nicht $O$-glykosyliert werden 
2.3.7. Nup214 konkurriert mit NLP1 um die Komplexbildung mit CRM1

2.3.8. Der mRNA-Exportfaktor TAP interagiert direkt mit NLP1 und 48 konkurriert nicht mit CRM1

2.4. Funktionelle Charakterisierung von NLP1 50

2.4.1. Überexpression von RFP-NLP1 inhibiert den poly(A)-mRNA-Export in HeLa Zellen

2.4.2 NLP1 fördert den Export von GFP-Snurportin1

2.4.3. Der Export von NC2ß-GFP 2 ist durch $C R M 1$ limitiert und wird durch NLP1 gefördert

2.4.4. NLP1 erhöht den Export von GFP-NFAT in vitro

2.4.5. Die Depletion von NLP1 inhibiert den Export von NC2 $\beta$

61

2.4.6. Die Depletion von NLP1 inhibiert den Export von GFP-NFAT

\section{DISKUSSION}

3.1. Die zelluläre CRM1-Konzentration ist für den Protein-Export limitierend

3.2. Die Lokalisation von NLP1

3.3. Die Rolle von NLP1 im poly(A)mRNA-Export

3.4. Biochemische Charakterisierung von NLP1

3.5. NLP1 fördert den Export verschiedener Exportsubstrate

3.5.1. Dissoziation der NLP1-Komplexe

4.3. Verbrauchsmaterialien 
4.10. Software 85

4.11. zur Verfügung gestellte Vektoren 86

4.12. zur Verfügung gestellte Plasmide 86

4.13. Selbst klonierte Plasmide 87

4.14. Durch „direkte in vitro Mutagenese“ erstellte Plasmide 88

4.15. Oligonukleotide für Klonierungen 88

4.16. Oligonukleotide für Mutagenesen 89

4.17. Oligonukleotide für Sequenzierungen 89

4.18. Oligonukleotide für Fluoreszenz-in situ-Hybridisierung 90

4.19. SiRNAs 90

4.20. Selbst hergestellte Proteine 90

4.21. Zur Verfügung gestellte Proteine $\quad 91$

4.22. Primärantikörper 92

4.23. Sekundärantikörper 92

5. METHODEN

5.1. Molekularbiologische Methoden 93

5.1.1. Transformation chemisch kompetenter Bakterien 93

5.1.2. Plasmid-Aufreinigung (Minipräparation) 93

5.1.3. DNA-Konzentrationsmessung 94

5.1.4. Agarosegelelektrophorese 94

5.1.5. Isolation von DNA aus Agarosegel 94

5.1.6. DNA-Verdauung durch Endonucleasen 94

5.1.7. Ligation $\quad 95$

5.1.8. Sequenzierung von Plasmiden 95

5.1.9. Polymerase-Kettenreaktion (PCR) 96

5.1.10. Gerichtete in vitro Mutagenese

5.2. Biochemische Methoden $\quad 97$

5.2.1. Trennung von Proteinen mittels SDS-Polyacrylamid- $\quad 97$ Gelelektrophorese (SDS-PAGE)

5.2.2. Coomassiefärbung 98 
5.2.3. Colloidale Coomassie-Färbung 98

5.2.4. Proteintransfer mittels Western Blot mit anschließendem 98 immunologischem Nachweis

5.2.5. Expression rekombinanter Bakterien 99

5.2.6. Dialyse aufgereinigter Proteine 100

5.2.7. Reinigung MBP-fusionierter NLP1-Proteine 100

5.2.8. Reinigung GST-fusionierter NLP1-Proteine 100

5.2.9. Reinigung von His-NLP1 1-204 100

$\begin{array}{ll}\text { 5.2.10. Reinigung von His-Snurportin1 } & 101\end{array}$

$\begin{array}{ll}\text { 5.2.11. Reinigung von GST-Ran } & 101\end{array}$

$\begin{array}{ll}\text { 5.2.12. Reinigung von GST-NC2 } \beta & 102\end{array}$

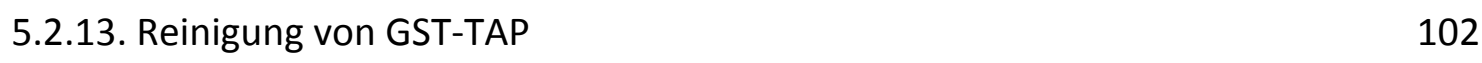

$\begin{array}{ll}\text { 5.2.14. Reinigung von CRM1-His } & 102\end{array}$

5.2.16. Reinigung von RanQ69L 102

5.2.17. in vitro O-Glykosylierung von GST-p62 und MBP-NLP1 102

5.2.18. Bindungsstudien mit MBP-oder GST-fusionierten Proteinen 103

5.2.19. Enzymgekoppelter Immunadsorptionstest 103

5.2.20. Beladung von Ran mit GTP/GDP oder $\left[\gamma^{32}\right.$ P]GTP 104

$\begin{array}{ll}\text { 5.2.21. RanGAP1-Assay } & 104\end{array}$

5.2.22. Affinitäsaufreinigung polyclonaler Antikörper 105

5.3. Zellbiologische Methoden 106

5.3.1. Kultivierung adhärenter HeLa-Zellen 106

5.3.2. Beschichten der Deckgläschen mit Poly-L-Lysin 106

5.3.3. Transiente Transfektion mittels Calcium-Phosphat-Methode 107

5.3.4. Transiente Transfektion mittels Polyfect 107

5.3.5. Überexpression und Detektion fluoreszierender Proteine 107

$\begin{array}{ll}\text { 5.3.6. Indirekte Immunfluoreszenz } & 108\end{array}$

$\begin{array}{ll}\text { 5.3.7. Fluoreszenz-in situ-Hybridisierung (FISH) } & 108\end{array}$

5.3.8. Transfekion von siRNAs mit Oligofectamin (Invitrogen) in HeLaP4- 109 Zellen

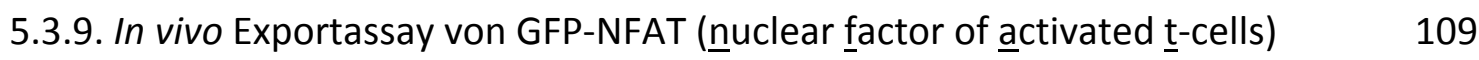

$\begin{array}{ll}\text { 5.3.10. In vitro Exportassay } & 110\end{array}$ 
5.3.11. FLIP (fluorescence loss in photobleaching)

5.3.12. FRAP (fluorescence recovery after photobleaching)

6.1. Proteinsequenz von NLP1

\section{ABKÜRZUNGEN}

7.1. Symbole für Aminosäuren

7.2. Allgemeine Abkürzungen 199

8. LITERATURVERZEICHNIS

CURRICULUM VITAE

DANKSAGUNG 


\section{ZUSAMMENFASSUNG}

Der Export der meisten Proteine aus dem Zellkern ins Cytosol erfolgt unter Beteiligung des Exportfaktors CRM1. Dieser erkennt einen hydrophoben Bereich des zu exportierenden Proteins (NES = nuclear export signal), bindet ihn in Gegenwart von RanGTP und vermittelt anschließend den Durchtritt durch die Kernpore. Die meisten NES-Substrate besitzen eine relativ geringe Affinität zu CRM1. In den letzten Jahren wurden jedoch Proteine entdeckt, die als Hilfsfaktoren für den Export fungieren indem sie die Bindungsaffinität zwischen CRM1, RanGTP und dem Exportsubstrat erhöhen.

Ein Ziel dieser Doktorarbeit war es herauszufinden, warum in der Zelle Hilfsfaktoren für den CRM1-abhängigen Export vorhanden sind. In vivo-Analysen basierend auf der Überexpression unterschiedlicher Reporterproteine in humanen Zellen zeigten, dass die Exporteffizienz dieser Proteine in Zellen, die mit CRM1 co-transfiziert waren, signifikant erhöht war. Dieses Ergebnis deutet darauf hin, dass die Konzentration des Exportfaktors CRM1 für den CRM1-vermittelten Proteinexport limitierend ist und leitet zu der Annahme, dass Hilfsfaktoren den Export deshalb unterstützen können.

Schwerpunkt der vorliegenden Arbeit war die Analyse des Proteins NLP1 (nucleoporin like protein 1). Da andere Gruppen mittels Hefe-zwei-Hybrid-Analysen eine Interaktion zwischen CRM1 und NLP1 nachgewiesen hatten, sollte nun die Funktion von NLP1 im CRM1-abhängigen Proteinexport näher untersucht werden. Es konnte in vivo mittels konventioneller Mikroskopie und FLIP-Analysen gezeigt werden, dass die Überexpression von NLP1 in humanen Zellen eine Verstärkung des Exports verschiedener Reporterproteine hervorrief, während die Depletion von NLP1 zu einer Verminderung des Exports führte. Auch in vitro verstärkte die Zugabe von rekombinantem NLP1 den Export von GFP-NFAT in Digitonin-permeabilisierten Zellen. Somit konnte NLP1 erstmals eine fördernde Rolle im CRM1-abhängigen Proteinexport zugeordnet werden. Hinweise darauf, wie NLP1 den Export von Substraten fördern kann, gaben biochemische Analysen. Sie zeigten, dass NLP1 trimere bzw. tetramere Komplexe mit CRM1 und RanGTP in An- oder Abwesenheit eines Exportsubstrates bilden kann. Dies förderte zum einen die Bindung von CRM1 zu RanGTP und verstärkte zusätzlich die Interaktion zwischen CRM1 und dem Exportsubstrat.

Die Ergebnisse dieser Arbeit weisen NLP1 eine stimulierende Funktion im CRM1abhängigen Export von Proteinen zu, die der Zelle Möglichkeiten zur Regulation dieses Transportweges eröffnen könnte. 


\section{SUMMARY}

Export of most proteins from the nucleus to the cytosol is mediated by the export factor CRM1. In the presence of RanGTP CRM1 binds to a hydrophobic region within the cargo protein, the NES (nuclear export signal), and mediates the passage through the nuclear pore. Most NES-containing proteins have a relatively low binding affinity to CRM1. Work in recent years revealed the existence of proteins which support CRM1-mediated export by facilitating the interaction betweeen CRM1, RanGTP and the cargo.

One part of this thesis dealt with the question why cells contain such supporting factors. In vivo analyses based on overexpression of different reporter proteins in human cells revealed a significant increase in the export-efficiencies of the reporter proteins upon CRM1-cotransfection. This result suggests that the concentration of CRM1 is rate limiting for CRM1-dependent export and leads to the assumption that transport might be supported by accessory factors.

The main focus of this work was to investigate the function of the protein NLP1 (nnucleoporin like protein $\underline{1}$ ). Since work from other groups indicated that NLP1 interacts with CRM1 in yeast two hybrid assays, a possible implication of NLP1 in CRM1-dependent protein export should now be analyzed in more detail. In vivo analyses by conventional microscopy and FLIP analyses revealed that overexpression of NLP1 increases the export of reporter proteins, whereas depletion of NLP1 inhibited the export. In line with this finding, the addition of recombinant NLP1 to digitonin-permeabilized cells enhanced nuclear export. Furthermore, biochemical analyses indicated that NLP1 can form complexes with CRM1 and RanGTP in the presence or absence of cargo proteins. This enhanced the binding of CRM1 to RanGTP as well as the cargo protein and thereby reveals a possible mechanism of how NLP1 supports the export of CRM1-substrates.

The results of this work clearly assign NLP1 a stimulating function on CRM1dependent export of proteins, which might open new possibilities of regulating this intracellular transport pathway. 


\section{EINLEITUNG}

Ein wesentlicher Unterschied zwischen Prokaryoten und Eukaryoten besteht in der räumlichen Trennung von DNA-Replikation und RNA-Biogenese von der Translation. Die DNA und sämtliche transkriptiven Prozesse sind im Zellkern lokalisiert, welcher durch eine Doppelmembran, die Kernhülle (nuclear envelope, NE), vom Cytoplasma räumlich abgetrennt ist. Die Separation von Transkription und Translation bietet Eukaryoten durch die Erfordernis eines kontrollierten Austausches von Molekülen zwischen Zellkern und Cytoplasma vielfältige Regulationsmöglichkeiten der Proteinbiogenese, welche Prokaryoten verwehrt bleiben. Während zum Beispiel verschiedene RNA-Moleküle (mRNA, tRNA, snRNA...) aus dem Zellkern exportiert werden sollen, müssen Proteine wie Histone und Polymerasen in den Zellkern importiert werden. Andere Proteine, wie spezifische Transkriptionsfaktoren, unterliegen einem dynamischen, beidseitig gerichteten In- und Export aus dem Zellkern.

Der Übergang zwischen Kern und Cytoplasma wird durch Kernporenkomplexe ermöglicht (NPC = nuclear pore complexes), die in der Kernmembran verankert sind und sie tunnelartig durchspannen. Diese Kernporen bilden eine Barriere zwischen Kern und Cytoplasma und sind für den selektiven Austausch von Makromolekülen verantwortlich. Während kleinere Moleküle wie Ionen, Wasser-, Zucker-Moleküle und zum Teil einige Proteine frei durch die Pore diffundieren können, ist den meisten Proteinen der Durchtritt durch die Pore verwehrt. Sie können die Kernpore nur mit Hilfe von sogenannten Transportrezeptoren passieren.

Neben Transportrezeptoren und Kernporenkomplexen spielen viele weitere Faktoren wie zum Beispiel Energie in Form von GTP, GTPasen usw. beim gerichteten Import oder Export von Proteinen in den Zellkern eine Rolle (zusammengefasst in Fried et al, 2003 [1]; Weis et al 2003 [2]; Mosammaparast et al., 2004 [3], Cook et al, 2007 [4], Wente et al., 2010 [5]).

Auf die für den Transport von Proteinen wichtigsten Faktoren soll in den nächsten Abschnitten der Einleitung etwas näher eingegangen werden. 


\subsection{Transportfaktoren und ihre Signale}

Der Kerntransport von Proteinen ist ein hochspezifischer Prozess, der auf Erkennung verschiedener spezifischer Signale sowohl für den Import (NLS = nuclear import signal), als auch für den Export (NES = nuclear export signal) beruht. Transportrezeptoren, auch Karyopherine genannt, können dabei entweder direkt oder indirekt über ein Adapterprotein mit ihrem jeweiligen Protein interagieren (zusammengefasst in Weis et al., 2003 [2]; Fried et al., 2003 [1]; Cook et al., 2007; Wente et al., 2010 [5]).

Die meisten Transportrezeptoren gehören zur Importin- $\beta$-Familie, von der bis jetzt circa 20 Mitglieder bekannt sind. Zu Ihnen gehören neben Importrezeptoren wie zum Beispiel Transportin, Importin $\beta$, Importin 4, 5, 7, 8, 9 auch Rezeptoren, die ausschließlich für den Export von Proteinen zuständig sind, zum Beispiel CRM1 und CAS. Charakteristische Merkmale der Importin $\beta$-Familie sind eine $\mathrm{N}$-terminale RanGTP-Bindedomäne, ein saurer isoelektrischer Punkt ( $\mathrm{pH}$ 4.6-5.9), vergleichbare Molekulargewichte von 95-145 kDa und eine sehr ähnliche Tertiärstruktur aus sogenannten „HEAT-Repeats“ (zusammengefasst in Fried et al. 2003 [1], Pemberton et al., 2005 [6]; Cook et al, 2007 [4]). Ein HEAT-Repeat besteht aus zwei $\alpha$-Helices, die über eine Schleife miteinander verbunden sind. Der Name HEAT-Repeat stammt von den ersten Proteinen, in denen dieses Motiv entdeckt wurde Huntingtin, Elongation factor 3, the $\underline{\mathbf{A}}$ subunit of protein phosphatase 2A und IOR1 (Andrade et al., 1995 und $2001[7,8])$.

Proteine, die in den Kern importiert werden sollen, werden über ihre NLS von Importrezeptoren erkannt. Zu den am besten untersuchten NLS gehören die klassischen Importsignale (cNLS). Hierbei wird das cNLS durch Importin $\alpha$ erkannt, das dann über seine IBB-Domäne (Importin $\underline{\boldsymbol{\beta}} \underline{\mathbf{b}}$ inding domain) eine Verbindung zum Importrezeptor Importin $\beta$ herstellt (zusammengefasst in Pemberton et al., 2005 [6]). Bei der klassischen NLS handelt es sich um mehrere basische Aminosäuren (Arginine oder Lysine) die entweder wie im „Simian Virus 40 large-T Antigen“ als eine einzige basische Region (monopartite cNLS) oder wie in "Nukleoplasmin" als zweigeteilte basische Region, unterbrochen von nichtbasischen Aminosäuren, vorliegen kann (Dingwall et al., 1982 [9]; Kalderon et al., 1984 [10]; Robbins et al., 
1988 [11]) . Ein anderes Beispiel für Adapter-vermittelten Transport ist der Import von UsnRNAs. UsnRNAs sind kurze 100-300 Basen lange RNA-Moleküle des Spleißosoms. Die $m_{3}$ Cap-Struktur dieser RNAs wird durch den Adapter Snurportin1 (SPN1) gebunden, der dann mit Importin $\beta$ interagiert (Huber et al., 1998, [12]).

Sehr viele Proteine werden direkt von ihrem Importrezeptor gebunden. Ein Beispiel hierfür ist hnRNPA1, dessen Glycin und Asparagin-reiche NLS (M9-Sequenz) direkt durch Transportin erkannt wird (Michael et al., 1995 [13]; Siomi et al., 1995 [14]; Pollard et al., [15]; Bonifaci et al., 1997 [16]).

Der Export der meisten aus dem Zellkern zu exportierenden Proteine wird durch den Exportfaktor CRM1 (́hromosome region maintainence $\underline{1}$ ) vermittelt, der ebenfalls zur Importin $\beta$-Familie gehört (Fornerod et al., 1997 [17]; Stade et al., 1997 [18]; Hutten et al., 2007 [19]). Dieser erkennt sein Substrat an einem spezifischen Export-Signal (NES). Neben dem Export von Proteinen ist CRM1 auch für den Export verscheidener RNAs (rRNAs, U-snRNAs, SRP RNAs, virale RNAs und spezifische mRNAs) aus dem Zellkern verantwortlich (zusammengefasst in Hutten et al., 2007 [20]). Da CRM1 nicht direkt an RNA binden kann, sind hierfür Adapterproteine notwendig. Die Cap-Struktur von splicoßomsalen U-snRNAs wird zum Beispiel von den beiden Adapterproteinen CBC (çap binding complex) und PHAX (phosphorylated adapter for RNA export) erkannt. PHAX enthält eine NES, die von CRM1 in Anwesenheit von RanGTP gebunden werden kann (Ohno et al., 2000 [21]). Auch die viralen mRNAs des HI-Virus 1 werden über CRM1 aus dem Zellkern exportiert. Das hierzu notwendige Adapterprotein ist das viruseigene Protein HIV-1 Rev (Regulator of virion expression) (zusammengefasst in Groom et al., 2009 [22]). Die größten aus dem Zellkern zu exportierenden Ribonucleoproteine sind wohl die 405 und 605 ribosomalen Untereinheiten. Ihre Bindung an CRM1 wird durch das Protein Nmd3 in Anwesenheit von RanGTP vermittelt (Thomas et al., 2003 [23]).

Ein Beispiel für „nicht-CRM1-vermittelten Protein-Export“ ist der Export des Adapterproteins Importin $\alpha$ durch seinen eigenen Exportfaktor CAS (C̄ellular Apoptosis S Susceptibility gene) (Kutay et al., 1997 [24]), der ebenfalls zur Importin $\beta$ Familie gehört. CAS scheint hierbei keine spezifische Exportsequenz sondern viele unterschiedliche Bereiche von Importin $\alpha$ zu erkennen (zusammengefasst in Cook et al., 2007 und $2010[4,25])$. 
Der Export der meisten mRNAs wird über das Heterodimer TAP/p15 vermittelt. Sowohl TAP als auch p15 gehören nicht zur Importin $\beta$-Familie. Auch hier spielen Adapterproteine, die den Kontakt zwischen mRNA und Exportfaktor herstellen, eine Rolle (zusammengefasst in Stewart et al., 2010 [26]).

\subsection{Der Ran-Zyklus}

Transportrezeptoren binden ihr Substrat auf der einen Seite der Kernhülle, durchqueren die Kernpore, entlassen es auf der anderen Seite und kehren zu ihrem ursprünglichen Kompartiment zurück. Das Model des RanGTP-Gradienten (Ran = Ras related nuclear protein) gibt eine plausible Erklärung dafür, wie dieser asymmetrische Transportmechanismus funktionieren kann. Die Richtung des Transports wird durch unterschiedliche RanGTP-Konzentrationen im Cytoplasma und Kern vorgegeben. Nachdem Importine ihr Substrat im Cytoplasma gebunden haben, vermitteln sie den Transport durch die Kernpore in den Kern, wo eine hohe RanGTP-Konzentration vorherrscht. Auf der nucleoplasmatischen Seite der Pore führt die Bindung von RanGTP an den Importrezeptor zur Freilassung des Substrats in den Zellkern (Siehe Abbildung 1.2., Schritt 1 und 2) (Rexach et al., 1995 [27], Görlich et al., 1996 [28]). Im Gegensatz zu den Importinen können Exportine ihr Substrat im Zellkern nur im Komplex mit RanGTP binden (Fornerod et al., 1997 [17]; Kutay et al., 1997 [24]).

Ran gehört zur Familie der Ras ähnlichen GTPasen, die sowohl in GTP- als auch in GDP-gebundener Form vorliegen können. Da die intrinsische GTPase-Aktivität von Ran nur sehr gering ist, benötigt es Hilfsfaktoren zur Hydrolyse des GTPs. Auf der cytoplasmatischen Seite der Kernpore unterstützen RanBP1 (ㅁan $\underline{b} i n d i n g$ protein $\underline{1}$ ) oder RanBP2 (Nup358) sowie RanGAP1 (ㅁaㅁTPase activating protein) die GTPaseAktivität. Die Rolle von RanBP1 oder den Ran-bindenen Domänen von RanBP2 ist hierbei, RanGTP von den Transportrezeptoren abzulösen oder ihre Interaktion zu destabilisieren, sodass RanGAP1 die intrinsiche GTPase-Aktivität von Ran aktivieren kann (zusammengefasst in Wente et al., 2010 [5]). Dabei kann RanGAP1 die GTP- 
Hydrolyserate von Ran um das $10^{5}$-fache erhöhen (Bischoff et al., 1994 [29]). Das entstehende RanGDP wird durch seinen eigenen Importfaktor NTF2 in den Kern importiert (Abb. 1.2. Schritt 6) (Ribbeck et al., 1998). Hier findet mit Hilfe von RanGEF/RCC1 (ㅁan guanosine nucleotide exchange factor/regulator of chromosome condensation $\underline{\mathbf{1}}$ ), welches an den Chromosomen lokalisiert ist, ein Nucleotidaustausch von GDP zu GTP statt (Bischoff et al., 1991 [30]; Klebe et al., 1995 [31]; Nemergut et al., 2001 [32]).

Der Ran-Gradient, der für den gerichteten Import und Export von Proteinen verantwortlich ist, kommt also aufgrund der räumlichen Trennung von GTPHydrolyse (unterstützt durch RanBP1 und RanGAP1) im Cytoplasma und des Nucleotidaustauschs von GDP zu GTP (durch RanGEF) im Zellkern zustande.

\subsection{CRM1-abhängiger Protein-Export}

Damit Proteine CRM1-abhängig aus dem Zellkern exportiert werden, müssen sie im Zellkern zuerst Komplexe mit CRM1 und RanGTP eingehen (siehe Abbildung 1.2. Schritt 4). Hierbei scheint es sich um ein kooperatives Bindeverhalten zu handeln, in dem die Bindung von RanGTP an CRM1 die Bindung des Exportsubstrates begünstigt (Fornerod et al., 1997 [17]). Strukturanalysen von trimeren Exportkomplexen bestehend aus CRM1, RanGTP und Snurportin1 zeigen, dass CRM1 aus 21 HEATRepeats besteht, die eine Ring-ähnliche Struktur bilden (Abb. 1.1.A) (Monecke et al., 2009 [33]). RanGTP ist im Inneren des Rings lokalisiert und interagiert mit verschiedenen Stellen von CRM1. Es wird angenommen, dass nicht nur die Bindung von RanGTP an CRM1 dessen Substratbindung durch Stabilisierung einer bevorzugten Konformation fördert, sondern dass sich auch die Substratbindung positiv auf die RanGTP-CRM1-Interaktion auswirkt (Monecke et al., 2009 [33]). Das Exportsubstrat Snurportin1 (SPN1) interagiert an drei verschiedenen Stellen mit der äußeren konvexen Oberfläche von CRM1. Der N-Terminus von Snurportin1, der die eigentliche NES enthält, bindet an eine hydrophobe Spalte, die von den HEATRepeats 11 und 12 gebildet wird (Abb. 1.1). Dieser Bereich ist zwischen 
verschiedenen Spezies hoch konserviert. (Dong et al., 2009 [34]; Monecke et al., 2009 [33]; Güttler et al., 2010 [35]).

Die kovalente Bindung des antifungalen Antibiotikums Leptomycin B (LMB) an ein spezielles Cystein (C528) in dieser hydrophoben Spalte führt zum Ausschluss der Bindung von Exportsubstraten an CRM1 und somit zur Inhibition des CRM1abhängigen Exports von Proteinen aus dem Zellkern (Kudo et al., 1998 und 1999 [36, 37], zusammengefasst in Hutten et al., 2007 [20]).

Generell erkennt CRM1 ein hydrophobes, meist Leucin-reiches Kernexportsignal (LR-NES), das zuerst in HIV-1-Protein Rev und in PKI ( CAMP-dependent protein ḱinase inhibitor) identifiziert wurde (Fischer et al., 1995 [38], Wen et al., 1995 [39]). Durch viele Mutationsstudien und Computer-gestützte Analysen konnte eine Consensussequenz für viele bekannte hydrophobe Kernexportsignale erstellt werden: $\Phi \mathrm{X}_{2-3} \Phi \mathrm{X}_{2-3} \Phi \times \Phi$, wobei $\Phi$ für L;l;V;F;M steht (Engelsma et al., 2004 [40]). Neueste strukturelle und biochemische Analysen geben Hinweise darauf, dass diese Consensussequenz um eine hydrophobe Aminosäure erweitert werden muss (Güttler et al., 2010 [35]). Strukturelle Untersuchungen der Bindung von REV-NES, PKI-NES oder dem N-Terminus von SPN1 an CRM1 zeigten, dass je 5 hydrophobe Aminosäuren der jeweiligen NES mit 5 Bindetaschen der hydrophoben Spalte interagieren (Abb. 1.1.B). Dabei bleibt die Struktur der hydrophoben Spalte auch bei Bindung unterschiedlichster NES starr (Güttler et al., 2010 [35]).

Die Bindungsaffinität von CRM1 zu verschiedenen NES-Substraten variiert und ist meistens eher gering. Neben der direkten Affinität der NES-Sequenz spielt hierbei auch der Gesamtkontext des Proteins, in dem sich die NES befindet, für die Affinität zu CRM1 eine Rolle (zusammengefasst in Kutay et al., 2005 [41]). Das Rev-NESPeptid hat zum Beispiel eine geringere Affinität zu CRM1 als das komplette RevProtein (Paraskeva et al., 1999 [42]). 
A

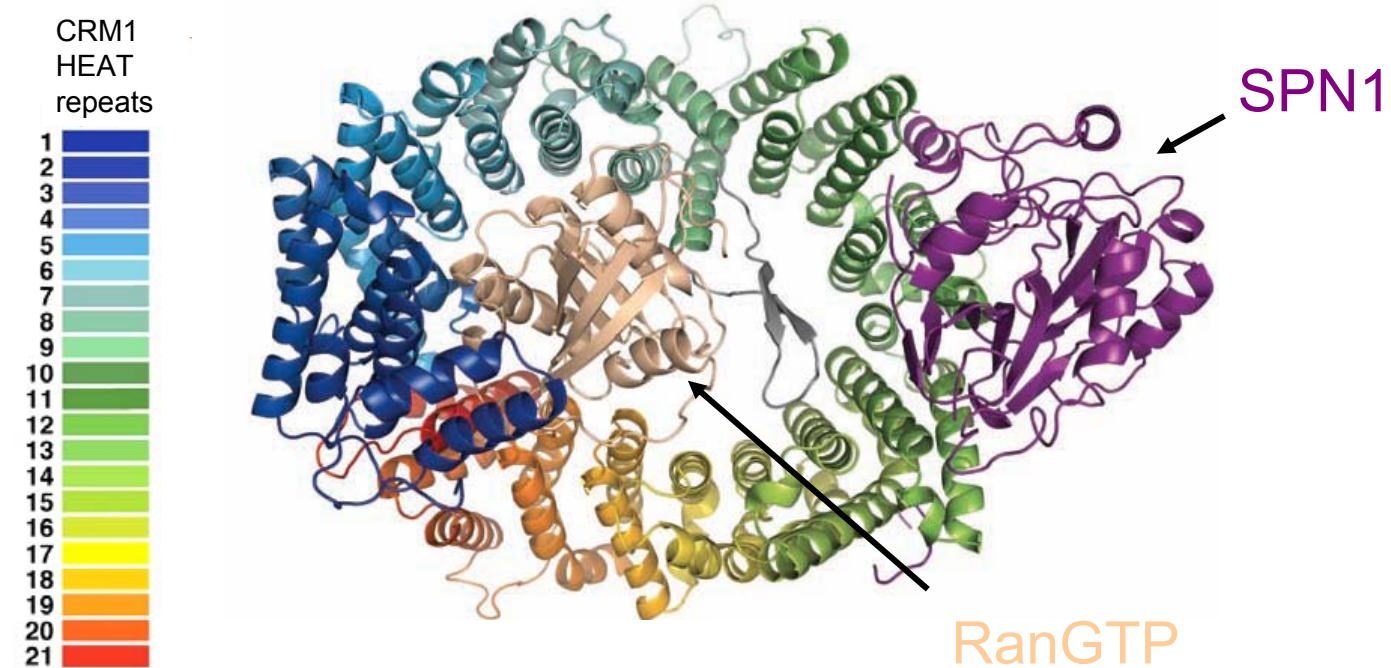

B

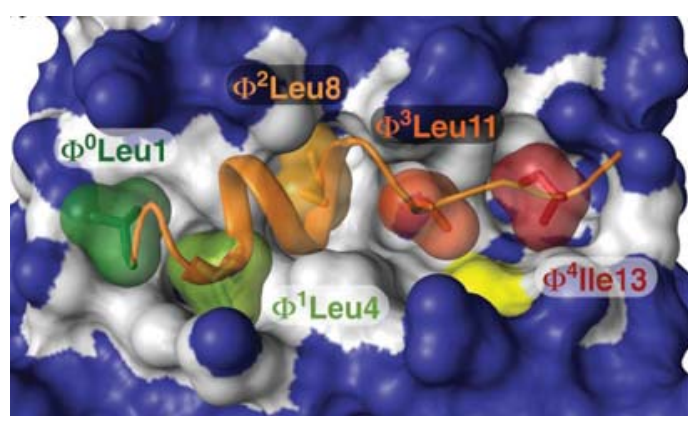

Abbildung 1.1 Strukturelle Abbildungen von CRM1 (verändert aus Monecke et al., 2009 [33] und Güttler et al., 2010 [35])

A) zeigt die Sruktur des CRM1-RanGTP-SPN1-Exportkomplexes. B) zeigt die Oberfläche der NESbindenen Region von CRM1, die mit der PKI-NES (orange) interagiert. Blau makiert sind hydrophile und weiß hydrophobe Bereiche der hydrophoben Spalte. Gelb ist das Cystein 528 dargestellt, an das LMB kovalent binden kann.

Aufgrund der niedrigen Bindungsaffinität von vielen Substraten zu CRM1 ist es nicht verwunderlich, dass Faktoren entdeckt wurden, die die Interaktion von Substrat mit CRM1 verstärken. Einer dieser Hilfsfaktoren ist zum Beispiel RanBP3. RanBP3 fördert die Bindung zwischen Exportfaktor und Substrat gleich auf zweierlei Weise: Einerseits rekrutiert RanBP3 CRM1 zu RanGEF. Die Bindung von RanBP3 an RanGEF führt zu einer Aktivierung des Nukleotidaustausches von GDP zu GTP bei Ran, sodass sich die RanGTP-Konzentration im CRM1 umgebenden Milieu erhöht (Nemergut et al., 2002 [43]). Andererseits erhöht die Bindung von RanBP3 an CRM1 dessen Affinität für Exportsubstrate und RanGTP (Lindsay et al., 2001 [44]; Engelmeier et al., 2001 [45]). 
Eine weitere Rolle scheint an dieser Stelle das Nucleoporin Nup98 zu spielen, das ebenfalls Komplexe mit CRM1, RanGTP und einem NES-Substrat in An- oder Abwesenheit von RanBP3 eingehen kann (Oka et al., 2010 [46]). Antikörper gegen Nup98, die in den Kern injiziert wurden, inhibierten den CRM1-abhängigen Export. Welche Aufgabe Nup98 allerdings genau hat, ist zu diesem Zeitpunkt noch unklar. Nachdem sich der Exportkomplex im Zellkern gebildet hat, wird der Durchtritt durch die Kernpore durch CRM1 vermittelt. Abschnitt. 1.5. gibt verschiedene Modelle für die Durchquerung der Kernpore wieder. Die Interaktion des CRM1-Exportkomplexes mit der Hauptkomponente der nucleären Filamente TPR könnte der initiale Schritt für die Translokation sein. TPR interagiert direkt mit einem trimeren Exportkomplex bestehend aus CRM1-RanGTP und einem NES-Substrat (Ben-Efraim et al., 2009 [47]). Außerdem inhibierte die Mikroinjektion eines Antikörpers gegen TPR den CRM1-abhängigen Export verschiedener Proteine (Frosst et al., 2002).

Als terminale Bindestation des Exportkomplexes an der Pore wird das Nucleoporin 214 (Nup214) vermutet, welches auf der cytoplasmatischen Seite der Kernpore lokalisiert ist (Kraemer et al., 1994 [48]) und eine hohe Affinität zu CRM1Exportkomplexen hat (Fornerod et al., 1997 [49]; Kehlenbach et al., 1999 [50]). Verschiedene Bindungsstudien zeigen in vitro, dass Nup214 mit CRM1, RanGTP und NES-Substrat (und auch RanBP3) Komplexe eingehen kann, die RanGAP1-Hydrolyseresistent sind. (Kehlenbach et al., 1999 [50], Lindsay et al., 2001 [44]; Hutten et al.,2006 [51]). Die Depletion von Nup214 führte in verschiedenen Studien jedoch zu kontroversen Ergebnissen. Während einerseits die Depletion von Nup214 zur starken Inhibition des Exports zweier Reporterproteine (GFP-NFAT und Rev-GR-GFP) führte (Hutten et al.,2006 [51]), wurde der Export der ribosomalen Untereinheit 60S durch Nup214 Depletion zwar inhibiert, der Export von einfachen Shuttlekonstrukten wurde andererseits allerdings nur sehr gering beeinflusst (Bernad et al., 2006 [52]). Eine Vermutung hier ist, dass die Interaktion von Nup214 mit den Exportkomplexen substratspezifisch sein könnte und dass die Größe der Substrate dabei vielleicht eine wichtige Rolle spielt.

Der letzte Schritt des Exports ist die Ablösung des CRM1-Komplexes von der Pore und seine Dissoziation durch GTP-Hydrolyse (Abb.1.2 Schritt 5). Da Komplexe aus CRM1, RanGTP und NES-Substrat (sowie Nup214) gegenüber RanGAP1-induzierter 
Hydrolyse resistent sind, werden zusätzliche Faktoren benötigt. Mit Hilfe des im Cytoplasma löslich vorliegenden RanBP1 oder den Ran-bindenen Domänen von Nup358 wird der Exportkomplex von der Kernpore dissoziiert, das Substrat vom CRM1-RanGTP-Komplex abgelöst (Koyama et al., 2010 [53]) und die Interaktion von Exportrezeptor und RanGTP so destabilisiert, dass RanGAP1 die GTPHydrolyseaktivität von Ran induzieren kann und es zur Dissoziation des gesamten Exportkomplexes und darauf zur Freilassung des Exportsubstrates im Cytoplasma kommt (zusammengefasst in Hutten et al., 2007 [20]). 


\section{IMPORT}

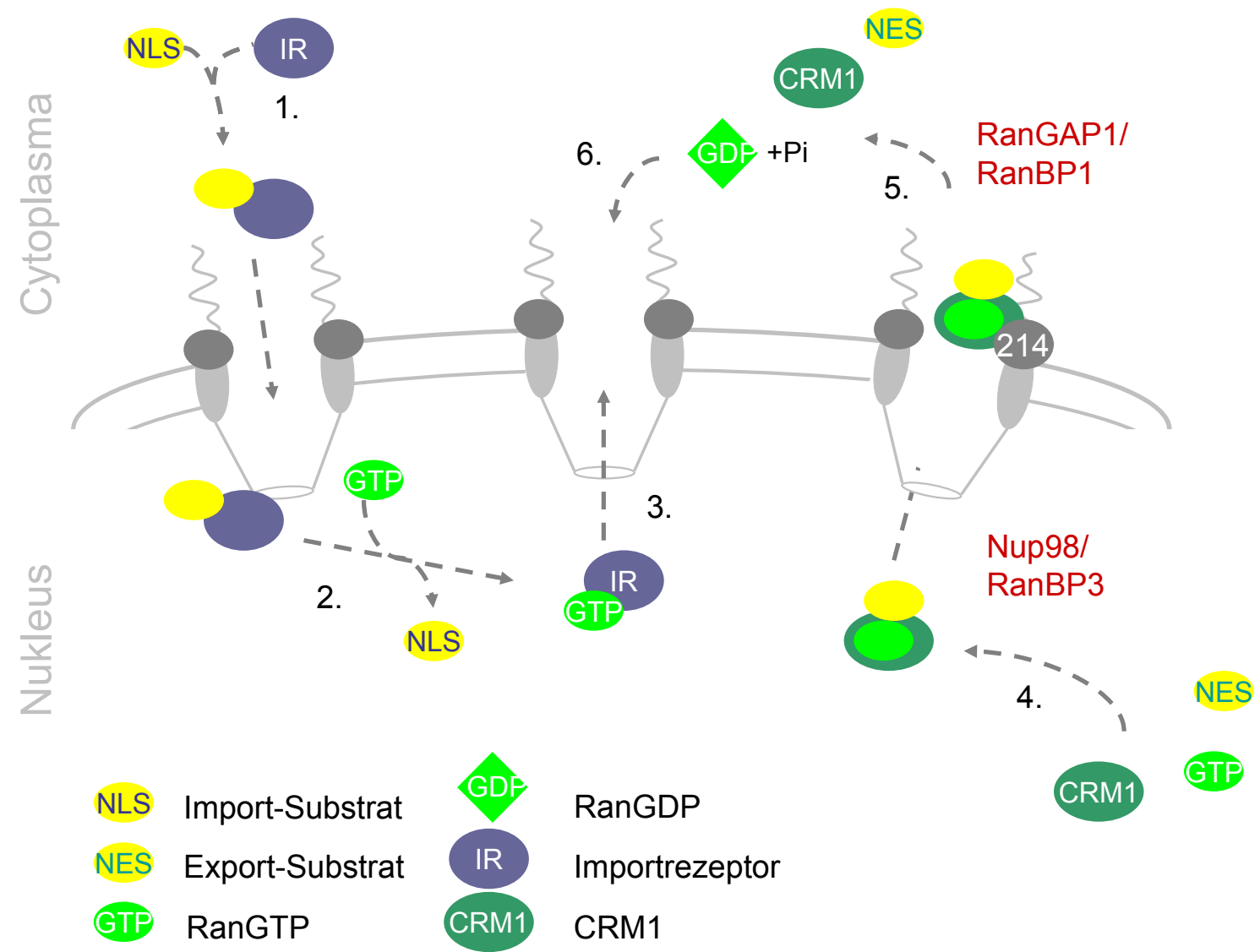

\section{Abbildung 1.2. Schematische Darstellung des Imports und Exports von Proteinen}

IMPORT: Importsubstrate binden im Cytoplasma über ihre spezifische NLS entweder direkt an den jeweiligen Importrezeptor (Abbildung 1.2.-1) oder über ein Adapterprotein. Der Importrezeptor vermittelt den Transport durch die Kernpore. Auf der nukleoplasmatischen Seite der Pore führt die Bindung von RanGTP an den Importrezeptor zur Dizzoziation des Importkomplexes (1.2.-2). Das Dimer aus Importrezeptor und RanGTP gelangt durch die Kernpore zurück ins Cytoplasma (1.2.-3), wo es durch die Hilfe von RanBP1 und RanGAP1-induzierter Hydrolyse von RanGTP zu RanGDP dissoziiert wird. Der Importrezeptor steht nun einem neuen Importzyklus zur Verfügung. EXPORT: Nachdem sich der Exportkomplex aus CRM1, RanGTP und NES-Substrat mit Hilfe von RanBP3 und Nup98 im Zellkern gebildet hat (1.2.-4), kann der Exportkomplex die Kernpore passieren. Auf der cytoplasmatischen Seite der Pore wird der Komplex mit Hilfe von RanBP1 oder den Ran-bindenen Domänen von Nup358 und RanGAP1 von der Kernpore abgelöst und dissoziiert (1.2.-5). Das dabei entstehende RanGDP wird durch seinen eigenen Importfaktor NTF2 wieder in den Kern importiert (1.2.-6) ( zusammengefasst in Weis et al., 2003 [2]; Fried et al., 2003 [1]; Stewart, 2007 [54]; Cook et al., 2007 [4]). 


\subsection{Die Kernpore}

Die Kernporenkomplexe gehören zu den größten Proteinkomplexen in eukaryotischen Zellen. Anzahl und Größe der NPCs variiert zwischen unterschiedlichen Spezies. Während in Saccharomyces cerevisiae pro Zellkern ca 200-500 Kernporen mit einer Größe von 50 MDa vorkommen, sind in Vertebraten ca 2000-5000 NPCs mit einer durchschnittlichen Größe von 60-125 MDa zu finden (Maul et al., 1977 [55]; Cordes et al.,1995 [56]). Trotz dieser starken Varianz zwischen den Spezies ist die generelle Struktur doch stark konserviert (zusammengefasst in Fried et al., 2003 [1]; Wente et al., 2010 [5]). Im Wesentlichen kann die Struktur einer Kernpore als Komplex mit achtfacher Rotationssymetrie beschrieben werden: Ein ringförmiger Kanal, der die Kernmembranen durchspannt, ist zwischen einem cytoplasmatischen und einem nucleären Ring eingebettet (siehe Abbildung 1.3.). Sowohl vom cytoplasmatischen als auch vom nucleären Ring gehen acht flexible Filamente aus, die auf der nucleären Seite der Kernpore in einem distalen Ring enden und somit eine Korb-ähnliche Struktur bilden (Fahrenkrog 2001, [57]; Terry et al., 2009 [58]; Wälde et al., 2010 [59]).

Insgesamt besteht der Kernporenkomplex aus nur $~ 30$ verschiedenen Proteinen, die Nucleoporine oder Nups genannt werden. Viele Nucleoporine sind symmetrisch in der Kernpore angeordnet, einige sind allerdings auch asymmetrisch verteilt und nur in den cytoplasmatsichen (Nup214, Nup358) oder nucleoplasmatischen Filamenten (TPR) zu finden (Rout et al., 2000 [60]; Crownshaw et al., 2002 [61]). Etwa ein Drittel aller Nucleoporine enthält Phenylalanin-Glycin-Wiederholungen (FG-Repeats). Elektronenmikroskopische Untersuchuchungen haben gezeigt, dass die FG-Repeat-Domänen der Nucleoporine sowohl das Innere der Kernpore ausfüllen, als auch auf der cytoplasmatischen und nucleoplasmatischen Oberfläche der Kernpore zu finden sind (Rout et al., 2000 [60]; Grote et al., 1995 [62]). Die FGRepeat-Domänen an sich scheinen keine übergeordnete Struktur zu haben (Bayliss et al., 2000 [63]; Denning et al. 2003 [64]). Das Fehlen einer festen Sekundär- oder Tertiärstruktur ist wahrscheinlich der Grund der hohen Flexibilität der FGNucleoporine. Das Nucleoporin 153 ist ein Beispiel dafür: Während der N-Terminus am nuclären Korb bindet, ist der C-Terminus nicht nur am Korb, sondern sogar an 
der cytoplasmatischen Peripherie der Pore detektiert worden (Fahrenkrog et al., 2002[65]). Auch der C-Terminus von Nup214 scheint sehr beweglich zu sein. (zusammengefasst in Fahrenkrog et al., 2003 [66]; Paulillo et al. 2005 [67]).

Die Phenylalanin- Reste der FG-Repeats interagieren, wenn auch nur schwach, mit hydrophoben Vertiefungen auf der Oberfläche von Transportrezeptoren und spielen daher eine große Rolle beim Rezeptor-vermittelten, aktiven Transport durch die Kernpore (Bayliss et al., 1999, 2000, 2002 [63, 68, 69]; Fribourg et al., 2001 [70]; Grant et al., 2003[71]; Liu et al., 2005 [72]).

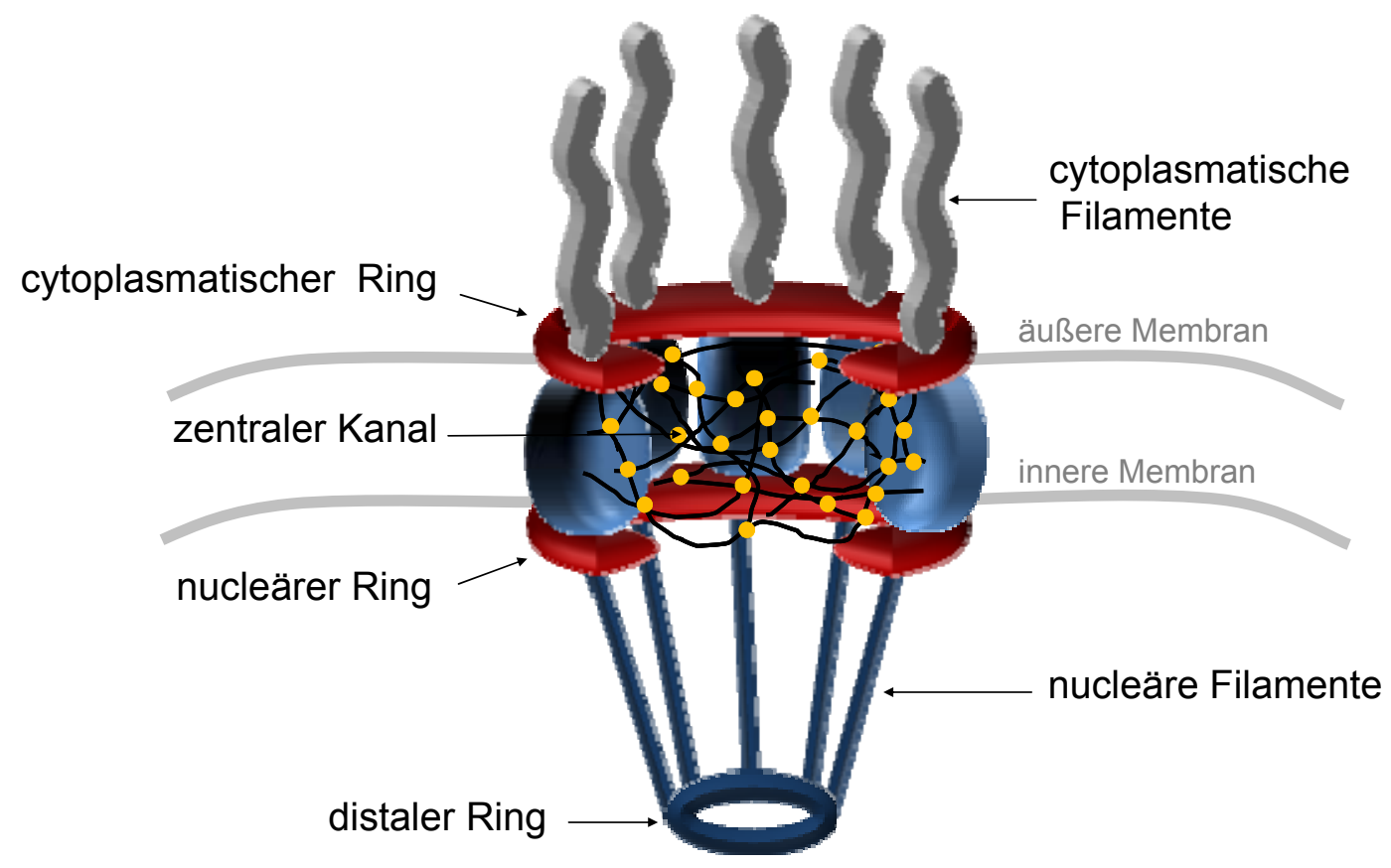

Abbildung 1.3 Strukturelle Darstellung der Kernpore, verändert aus Wälde et al. 2010.

Die gelben Punkte sollen Interaktionen zwischen FG-Repeats darstellen.

Die Kernpore hat, je nach Organismus, einen Durchmesser von circa 100-130 nm. Der zentrale Kanal der Kernpore ist ca $60 \mathrm{~nm}$ lang und der Durchmesser beträgt 40-50 nm (zusammengefasst in Brohawn et al., 2009 [73]; Elad et al., 2009 [74]). Die bis zu $50 \mathrm{~nm}$ langen, cytoplasmatischen Filamente sind am cytoplasmatischen Ring befestigt. Vom nucleären Ring ragen die Filamente bis zu $100 \mathrm{~nm}$ ins Nucleoplasma (zusammengefasst in Suntharalingam et al., 2003 [75]). 


\subsection{Transport-Modelle}

Wie der Durchtritt des Rezeptor-Substrat-Komplexes durch die Pore genau funktioniert, ist immer noch Gegenstand intensiver Forschung. Verschiedene Modelle versuchen den Sachverhalt zu klären (zusammengefasst in Peters 2009 [76] und Wälde et al., 2010 [59]):

Das Model „Selektive Phase“ geht davon aus, dass die FG-Nucleoporine in der Kernpore miteinander über ihre FG-Repeats interagieren und ein „dreidimensionals molekulares Sieb“ bilden, das Molekülen und kleineren Proteinen den Durchtritt durch die Pore erlaubt. Größere Proteine können diese Barriere nur mit Hilfe von Transportfaktoren, die mit den FG-Repeats interagieren und somit den Durchtritt durch die Pore ermöglichen, überwinden (Frey et al., 2006, 2007, 2009 [77-79]; Ribbeck et al., 2002 [80]).

Das „virtual gate model“ geht davon aus, dass das Innere der Pore mit FG-Repats gefüllt ist und somit eine entropische Barriere bildet. Die Energie zur Überwindung dieser Barriere liefert hier die freie Gibbs'sche Energie, die bei der Bindung von Transportrezeptoren an FG-Repeats frei wird (Rout et al., [81]). Einen ähnlichen Ansatz verfolgt das „polymer brush model“ (Lim et al., 2006 [82]). Es geht ebenfalls davon aus, dass die FG-Nucleoporine eine Art entropische Barriere bilden. Die Annahme ist, dass die FG-Nucleoporine „bürstenartig" von ihrer Verankerung in der Pore in den inneren Kanal und nach außen reichen. Bindet ein Rezeptor-Komplex an die FG-Repeats einer Außenseite, kollabieren die FG-Nucleoporine und ziehen den Transportkomplex in die Kernpore. Durch Interaktion mit weiteren FGNucleoporinen kann der Komplex auf die andere Seite der Pore gelangen

Bei dem „reduction of dimensionality model“ wird davon ausgegangen, dass alle FG-Repeats in der Kernpore den Rand des Kernporenkanals auskleiden, komplett mit Transportfaktoren besetzt sind und kollabiert vorliegen (Peters et al., 2009 [76]). Transportrezeptoren oder -Komplexe, die die Pore durchqueren wollen, verdrängen hierbei andere Transportfaktoren von ihrem Platz, die wiederum andere verdrängen.

Neben den gerade beschriebenen Modellen gibt es verschiedene weitere, in denen auch immer wieder FG-Repeats eine Hauptrolle spielen. 


\subsection{Spezifische Funktionen einzelner Nucleoporine im Transport von Proteinen}

Neben der Barriere-bildenden Funktion haben einige FG-enthaltende Nucleoporine spezielle Aufgaben beim Import oder Export von Proteinen. Einige dieser Nucleoporine und ihre spezifischen Aufgaben sollen in diesem Abschnitt vorgestellt werden.

Das Nucleoporin Nup50 spielt zum Beispiel eine Rolle beim Importin $\alpha / \beta$ vermittelten Import von Proteinen (Matsuura et al., 2005 [83]). Es kann direkt an Importin $\alpha$ binden, was die Dissoziation von Importsubstrat und Rezeptor zur Folge hat. Nup153 scheint ebenfalls eine wichtige Rolle bei diesem Importweg zu spielen. Die Depletion von Nup153 führte zu einer Inhibition des Importin $\alpha / \beta$-vermittelten-, nicht aber des Transportin-vermittelten Imports von Proteinen (Walther et al., 2001 [84]).

Der Transportin-vermittelte Import scheint durch Nup98 beeinflusst zu sein, das selbst eine M9-Sequenz enthält und mit Transportin-Substraten um die Bindung an den Rezeptor in Konkurrenz steht (Fontoura et al., 2000 [85]).

Das Nucleoporin Nup358, das die cytoplasmatischen Filamente der Kernpore bildet (Wu et al., 1995 [86]), interagiert mit CRM1 (Singh et al., 1999 [87]), Importin $\beta$ (Delpheen et al., [88]), Ran (Wu et al., 1995 [86]; Yaseen et al., 1999 [89]) und RanGAP1 (Mahajan et al., 1997 [90]; Matunis et al., 1998 [91]). Obwohl in Nup358depletierten Xenopus Oocyten in vitro gezeigt wurde, dass Nup358 für den ProteinImport verzichtbar ist (Walther et al., 2002 [92]), konnte in HeLa-Zellen in vivo gezeigt werden, dass Nup358 sowohl den Transportin- als auch den Importin $\alpha / \beta$ vermittelten Import von Proteinen fördert (Hutten et al., 2008 und 2009 [93, 94]). Es wird vermutet, dass Nup358 die Konzentration von Transportrezeptoren an der Kernpore erhöht, da Nup358-Depletionseffekte auf Proteinimport durch Überexpression von Importrezeptoren rückgängig gemacht werden konnten (Hutten et al., 2008 und 2009 [93, 94]).

Nucleoporine, die in den Export von Proteinen involviert sind, sind zum Beispiel Nup214, TPR und Nup98. Ihre jeweilige Rolle, wurde im Abschnitt über den CRM1abhängigen Export (Abschnitt 1.3.) näher erläutert. 
Die Rolle von vielen anderen Nucleoporinen im Kerntransport von Proteinen ist noch weitgehend unklar. Hierzu gehört unter anderem NLP1 (nuucleoporin like protein 1), der Hauptgegenstand dieser Doktorarbeit, welches ursprünglich als hCG1 beschrieben wurde.

\section{7. hCG1/NLP1}

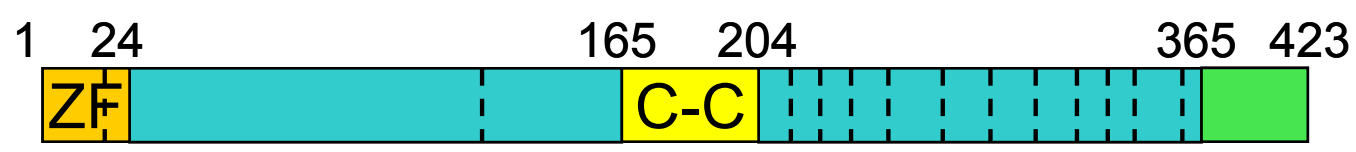

Abbildung 1.3. Schematische Darstellung von NLP1 ZF = Zinkfinger, C-C = Coiled-Coil-Domäne. Die gepunkteten Linien stellen FG-Repeats dar.

hCG1/NLP1 (human candidate gene 1) ist ein 423 Aminosäuren großes Protein, dessen Sequenz zuerst in einem Screen für Proteine auftauchte, die an der Krankheit DFNA5 (autosomal dominant progressive sensorineural hearing loss) beteiligt sind. Eine Funktion konnte hCG1 hier allerdings nicht zugesprochen werden (Van Laer et al., 1995 ([95]). Später wurde hCG1 fast zeitgleich als Interaktionspartner in 2 unterschiedlichen „Hefe-zwei-Hybrid“-Untersuchen mit HIV-1-Rev (Farjot et al., 1999 [96]) oder dem mRNA-Exportfaktor Gle1 (Strahm et al., 1999 [97]) als „Köder“, entdeckt.

Aufgrund seiner 12 FG-Repeats, die hauptsächlich im C-Terminus des Proteins lokalisiert sind, bekam das Protein seinen zweiten Namen: Nucleoporin like protein 1. Neben einem putativen Zinkfinger am N-Terminus (AS 1-24) ist in der Mitte eine putative Coiled-Coil-Domäne (As 165-204) zu finden (Kendirgi et al., 2005 [98]) (siehe Abbildung 1.3.). Lokalisationsstudien von überexprimiertem NLP1 zeigten, dass NLP1 sowohl im Zellkern, mit Aussparung der Nucleoli (Farjot et al., 1999 [96]), als auch an der Kernhülle zu finden ist (Rouzic et al., 2002 [99]; Kendirgi et al., 2005[98]). Die letzten 58 Aminsäuren von NLP1 (AS 366-423) sind notwendig, um NLP1 an die Kernhülle zu binden (Kendirgi et al., 2005 [98]). Untersuchungen des NLP1-Sequenzhomologs (55\%-Homologie) aus Saccharomyces cerevisiae RIP1p/Nup42 (ㄹev interacting protein 1) zeigten, dass Nup42 im Nucleoplasma sowie an den cytoplasmatischen und nucleoplasmatischen Fibrillen der Kernpore 
lokalisiert (Strahm et al., 1999 [97]). Kontrovers zu Strahms Ergebnissen sind die Ergebnisse von Rout et al. (2000 [60]), die Nup42 nur an den cytoplasmatischen Fibrillen der Kernpore finden. Bis heute ist die Lokalisation von NLP1 noch nicht eindeutig geklärt.

Sowohl NLP1, als auch Nup42 scheinen eine wichtige Rolle beim Export von Hitzeinduzierten mRNAs zu spielen (Saavedra et al., 1997 [100], Strahm et al., 1999 [97]; Rollenhagen et al., 2004 [101]; Kendirgi et al., 2005 [98]). Die Depletion von Nup42 in Hefe führt bei $42^{\circ} \mathrm{C}$ zu einer Inhibition des Exports von HitzeschockproteinmRNAs, die sich durch die Transformation von humanem NLP1 rückgängig machen lässt. NLP1 ist also ein funktionelles Homolog von Nup42 (Strahm et al., 1999 [97]). Auch der Export vieler mRNAs, die nicht für Hitzeschock-Proteine codieren, scheint bei $42{ }^{\circ} \mathrm{C}$ in Nup42-depletierten Hefezellen beeinflusst zu sein (Vainberg et al., 2000 [102]). Die Depletion von NLP1 in HeLa-Zellen führte zur Inhibition des Exports der mRNA des Hitzeschockproteins 70 aus dem Zellkern (Kendirgi et al., 2005 [98]). Hinweise auf eine generelle Funktion von NLP1 im mRNA-Export liegen nicht vor. In „Hefe-zwei-Hybrid-Studien“ konnte gezeigt werden, dass Nup42 und NLP1 nicht nur mit einer Reihe von mRNA-Exportfaktoren interagieren (TAP (Katahira et al., 1999 [103]) , Gle1 (Strahm et al., 1999) und HIV-Rev (Stutz et al., 1995 [104], Strahm et al., 1999 [97], Rouzic et al., 1999 [99], Farjot et al., 1999 [96])), sondern auch mit dem Proteinexportfaktor CRM1 (Strahm et al., 1999 [97]). Nup42 und CRM1 bildeten in Anwesenheit von RanGTP Komplexe, was allerdings die Bindung des CRM1-Exportsubstrates HIV-1-REV ausschloss. Der trimere Komplex aus Nup42, Crm1, und RanGTP, war RanGAP1 und RanGEF insensitiv (Floer et al., 1999 [105]). Die Depletion von Nup42 hatte interessanterweise keinen Einfluss auf den Export von Proteinen (Stade et al., 1997 [18]).

Obwohl CRM1 den wichtigsten Exportfaktor für Proteine darstellt, wurden bisher keine funktionellen und biochemischen Analysen zur Interaktion mit NLP1 vorgenommen. Welche Bedeutung die Interaktion zwischen CRM1 und NLP1 für den Proteinexport hat, ist bis heute daher noch völlig unklar. Die Zielsetzung dieser Arbeit ist es daher, die Relevanz der NLP1-CRM1 Interaktion in biochemischen und funktionellen Studien zu untersuchen. 


\subsection{Zielsetzung der Arbeit}

NLP1 ist ein Protein, das aufgrund seiner vielen FG-Repeats große Ähnlichkeit mit Nucleoporinen, insbesondere mit dem C-Terminus von Nup214 (Katahira et al., 1999 [103]), aufweist. Der C-Terminus von Nup214 hat eine hohe Affinität zu CRM1Exportkomplexen und ist wahrscheinlich die terminale "Dockingstation“, bevor diese von der Pore abgelöst werden (Hutten et al., 2006 [51]). In verschiedenen „Hefe-2-Hybrid-Studien“ stellte sich heraus, dass NLP1 nicht nur mit mRNAExportfaktoren, sondern, wie Nup214 auch, mit dem Proteinexportfaktor CRM1 interagiert.

Zunächst soll die Lokalisation von endogenem NLP1 näher untersucht werden. Hierzu ist die Herstellung eines Antikörpers gegen endogenes NLP1 notwendig. Mittels FLIP (fluorescence loss in photobleaching) und FRAP (fluorescence recovery after photobleaching) soll die Beweglichkeit von überexprimertem NLP1 in der Zelle analysiert werden.

Der Focus dieser Arbeit soll auf der Untersuchung der Funktion von NLP1 im CRM1abhängigen Export von Proteinen liegen. Hierzu soll die Interaktion von CRM1 und NLP1 in vitro, mittels rekombinanter Proteine verifiziert und näher charakterisiert werden. In vivo Studien von verschiedenen Substraten mit überexprimiertem oder depletiertem NLP1 sollen ebenfalls Antworten zur Funktion von NLP1 liefern. Hierbei soll nicht nur konventionelle Mikroskopie, sondern auch „life cell imaging“ und FLIP-Analysen angewandt werden, um Export-Kinetiken der zu untersuchenden Proteine zu erstellen.

Außerdem soll auch die Rolle von NLP1 im generellen mRNA-Export analysiert werden. Hierzu soll NLP1 in menschlichen Zellen überexprimiert oder NLP1depletiert und die Lokalisation des gesamt mRNA-Poos mittels FISH (fluorescence in situ hybridisation) untersucht werden.

Ein weiteres Ziel dieser Doktorarbeit ist es herauszufinden, warum in der Zelle Hilfsfaktoren wie RanBP3 und Nup98 für den CRM1-abhängigen Export vorhanden sind. 


\section{ERGEBNISSE}

\subsection{CRM1 ist für den CRM1-abhängigen Export von Proteinen aus dem Zellkern limitierend}

Der CRM1-abhängige Export von Proteinen aus dem Zellkern wird durch verschiedene Co-Faktoren wie zum Beispiel RanBP3 unterstützt. Die direkte Bindung von RanBP3 an CRM1 erhöht die Affinität von CRM1 für RanGTP und NES-Substrat (Lindsay et al., 2001 [44], Engelmeyer et al., 2001 [45]). Des Weiteren fördert RanBP3 mit Hilfe von Ran die Bindung von CRM1 an RanGEF. Hierdurch wird CRM1 einer lokal erhöhten RanGTP-Konzentration ausgesetzt, welche wiederum die RanBP3-CRM1-RanGTP-NES-Komplexbildung begünstigt (Nemergut et al., 2002 [43]). Aktuelle Arbeiten deuten darauf hin, dass das Nucleoporin Nup98 ebenfalls in den CRM1-abhängigen Export involviert ist. Sie zeigen, dass Nup98 mit CRM1, CRM1-RanGTP, CRM1-RanGTP-NES-Substrat sowie mit RanBP3-CRM1-RanGTP-NESSubstrat Komplexe formen kann (Oka et al., 2010 [46]). Zusätzlich wird der CRM1abhängige Export eines Reporterproteins (GFP-GFP-NES) durch Mikroinjektion eines Antikörpers gegen Nup98 in den Zellkern verhindert. Diese Ergebnisse werfen die Frage auf, warum Hilfsfaktoren für den CRM1-abhängigen Export benötigt werden. Eine mögliche Erklärung hierfür könnte sein, dass CRM1 der limitierende Faktor im Protein-Export ist. Um diese Hypothese zu überprüfen, wurden HeLa-Zellen mit einem artifiziellen Reporterprotein aus einer NES (AS 47-116 des Rev-Proteins), zwei GFP und einem klassischen NLS-Signal (NES-GFP ${ }_{2}-\mathrm{CNLS}$ ) zusammen mit einem CRM1-HA-Konstrukt transient cotransfiziert und mittels Immunfluoreszenz analysiert (Abb. 2.1.A). Von den Kontrollzellen, die mit einer Kombination aus Reporterprotein und HA-Vektor transfiziert wurden, zeigten etwa 70\% der Zellen eine deutliche Kernlokalisation $(\mathrm{N}>\mathrm{C})$ des Reporterproteins (Abb. 2.1.A,B). Der Import überwiegt hier über den Export. Im Vergleich dazu hatte die Überexpression von CRM1-HA eine Reduktion der Zellen mit eindeutigem Kernsignal $(\mathrm{N}>\mathrm{C})$ von $70 \%$ auf ca. 30\% zur Folge (Abb. 2.1.B). Hier schien der Export über den Import zu dominieren. Um zu überprüfen, ob diese Veränderung der Lokalisation nach CRM1Überexpression tatsächlich dem CRM1-abhängigen Export und nicht einem 
inhibierten Import zuzuschreiben ist, wurden die Zellen mit Leptomycin B behandelt. LMB ist eine Substanz, die spezifisch an das Cystein 528 in der Substratbindestelle von CRM1 bindet, was die Interaktion des Exportcargos mit CRM1 und somit dessen Export aus dem Zellkern verhindert (Kudo et al., 1999 [36]). Wie in Abbildung 2.1 dargestellt, wiesen 85-95\% der LMB-behandelten Zellen eine Akkumulation des Reporterproteins im Zellkern auf. Dieses Ergebnis legt nahe, dass Kernhülle und Poren intakt waren und es sich bei dem Effekt nach CRM1-HA-CoTransfektion tatsächlich um eine Verstärkung des Exports handelte. Die Beobachtungen in diesem Abschnitt deuten darauf hin, dass die CRM1Konzentration im CRM1-abhängigen Export von Proteinen aus dem Zellkern tatsächlich limitierend ist und deshalb unterstützende Faktoren, wie RanBP3 und Nup98 benötigt, die den Export von Proteinen aus dem Zellkern begünstigen.

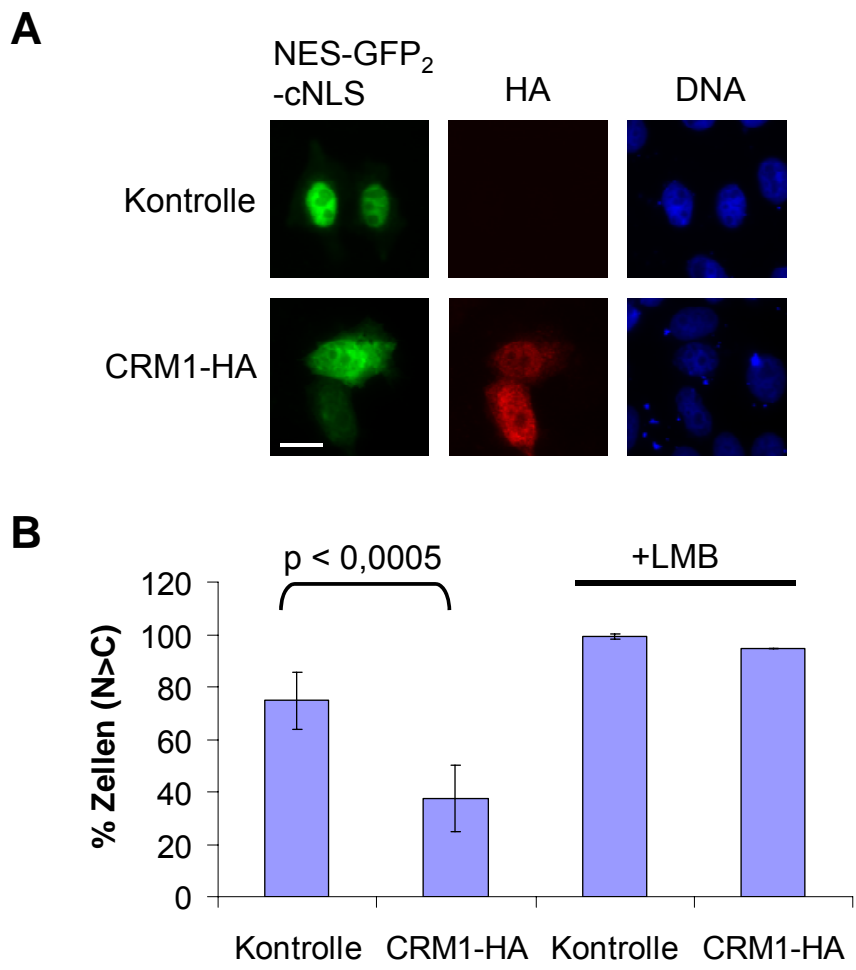

Abbildung 2.1. Überexpression von CRM1-HA beeinflusst die intrazelluläre Lokalisation des einfachen Reporterproteins NES(REV(47-116))-GFP ${ }_{2}$-CNLS. A) HeLaP4-Zellen wurden mit einem NES(REV(47-116))$\mathrm{GFP}_{2}$-CNLS-Konstrukt und einem CRM1-HA-Plasmid so wie dem leeren HA-Vektor als Kontrolle cotransfiziert. Die Analyse erfolgt nach $48 \mathrm{~h}$ durch Fluoreszenzmikroskopie (Balken, $10 \mu \mathrm{m}$ ). Grün ist das Reprterprotein, rot die HA-Proteine dargestellt. B) stellt die statistische Analyse der Fluoreszenzmikroskopie da. Hier wurde die Lokalisation von NES-GFP - -cNLS in cotransfizierten Zellen ausgezählt. Der Graph gibt in Prozent an, wie viele der analysierten Zellen mehr Reporterprotein im Zellkern als im Cytoplasma der Zelle $(\mathrm{N}>\mathrm{C}$ ) haben. Pro Transfektionsansatz wurden mehr als 100 Zellen analysiert. Zur Kontrolle wurden die Zellen für 2-3 h mit $5 \mathrm{nM} \mathrm{LMB}$ behandelt. Die Fehlerbalken geben die Standardabweichungen von 6 unabhängigen Versuchen bei nicht LMB-behandelten Zellen und 3 unabhängigen Versuchen bei LMB-behandelten Zellen an. Die statistische Signifikanz wurde mittels Student's T-Tests ermittelt. 


\subsection{Intrazelluläre Lokalisation von NLP1}

Das Protein NLP1, das in dieser Arbeit näher untersucht werden sollte, wurde im „Hefe Zwei Hybrid-System“ als Interaktionspartner von CRM1 identifiziert (Farjot et al., 1999, [96]). Wie auch RanBP3 und Nup98 enthält NLP1 Phenylalanin-GlycinRepeats (FG-Repeats) und wurde als im Kern lokalisiert beschrieben. In den nächsten Abschnitten soll nun die Frage beantwortet werden, ob und welche Funktion NLP1 im CRM1-abhängigen Export von Proteinen aus dem Zellkern inne hat.

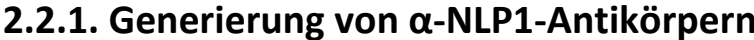

Um NLP1 in seiner Funktion genauer untersuchen zu können, sollten zunächst Antikörper hergestellt werden. Hierzu wurde der His-fusionierte N-Terminus von NLP1 (His-NLP1 1-204) als Antigen unter denaturierenden Bedingungen aufgereinigt (Abb. 2.2.A). Da das Protein nach der Dialyse gegen PBS nicht mehr löslich war, wurde das ausgefallene, denaturierte Protein zur Immunisierung zweier Kaninchen (3754, 3755) durch die Firma BioGenes verwendet. Nach der affinitätschromatographischen Aufreinigung der polyclonalen $\alpha$-NLP1-Antikörper aus den von BioGenes gelieferten Seren erfolgte die Charakterisierung der Antikörper. In Western Blot-Analysen erkennen beide Antikörper sowohl rekombinantes bakteriell hergestelltes MBP-NLP1 als auch endogenes NLP1 aus HeLa-Zelllysat (Abb. 2.2.B, Abb. S1A). Durch Vergleichen der Bandenstärken des rekombinanten MBP-NLP1 und des endogenen NLP1 ließ sich die Konzentration des endogenen NLP1 in HeLaZellen ermitteln. Beide Antikörper ließen auf eine Konzentration von ca 1-4 ng endogenem NLP1 in ca. 100.000 HeLa-Zellen schliessen, was einer zellulären Konzentration von ca. 50-200 nM NLP1 (ausgehend von einem Volumen von 4 pl/Zelle) entspricht.

Um die Spezifität der $\alpha$-NLP1 Antikörper in der Immunfluoreszenz zu testen, wurden HeLa- Zellen mit verschiedenen NLP1-Konstrukten (HA-NLP1, NLP1-HA, RFP-NLP1, NLP1-RFP) transient transfiziert und Immunfluoreszenzfärbungen gegen HA und 
NLP1 durchgeführt. Hierbei wurden unterschiedliche Färbemethoden, die sich zum Beispiel in der Art der Fixierung sowie Blockierungsmethoden usw. unterschieden, angewendet. Der 3755-Antikörper konnte überexprimiertes NLP1 detektieren (Abb. 2.2.C), während der 3754 Antikörper keinen Unterschied zwischen mit NLP1 transfizierten und untransfizierten Zellen erkannte (Abb. S1B).

A

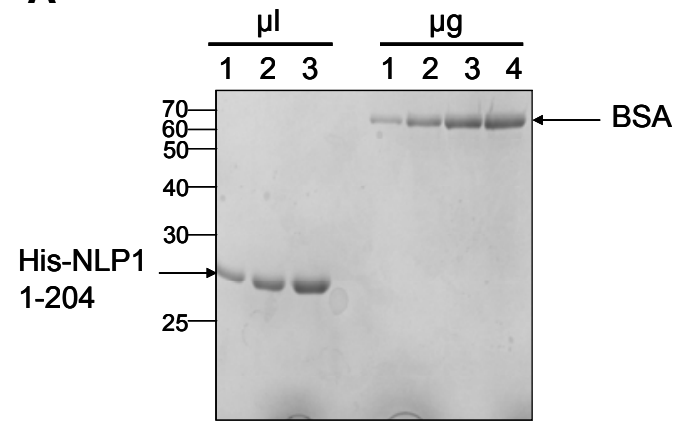

C

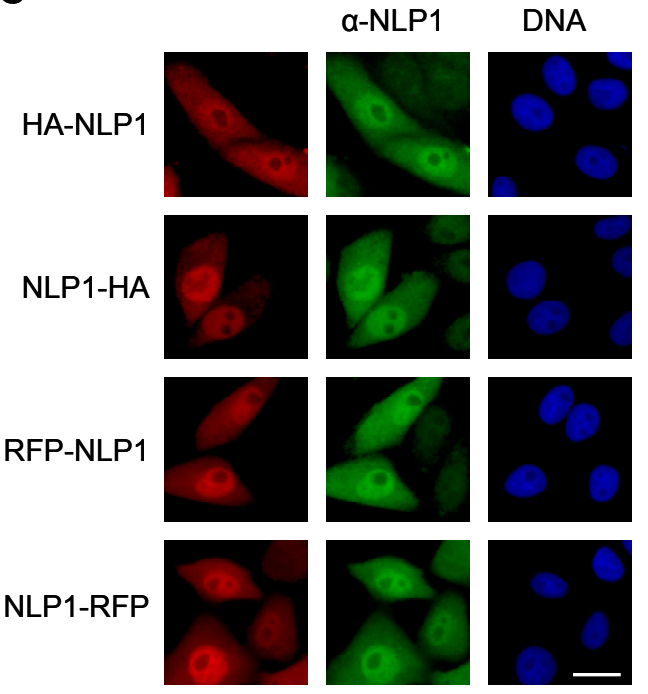

B

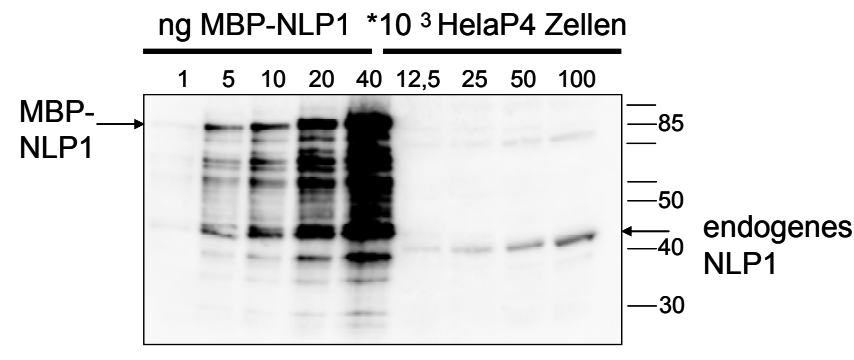

Abbildung 2.2. Charakterisierung von $\alpha$-NLP1-Antikörpern. A) Coomassie-gefärbtes SDS-Gel von His-NLP1 1-204. 1-3 $\mu$ l des aufgereinigenten His-NLP1 1-204 sowie 1-3 $\mu$ g BSA wurden per SDS-PAGE aufgetrennt und die Proteine mit Coomassie gefärbt. B) Western Blot-Detektion von rekombinantem MBP-NLP1 und endogenem NLP1. MBP-NLP1 und HeLa-Zellen wurden auf ein SDSGel aufgetragen und die Proteine elektrophoretisch aufgetrennt. Die Detektion erfolgte durch Immunoblot-Analyse mit $\alpha$-NLP1 3755-Antikörper. C) Immunofluoreszenz von überexprimiertem NLP1. HeLa-Zellen wurden mit Konstrukten für HA-NLP1, NLP1-HA, RFP-NLP1 sowie NLP1-RFP transfiziert und die Lokalisation von NLP1 (und HA) durch indirekte Immunufluoreszenz mit $\alpha$-NLP1 3755-Antikörpter (bzw. $\alpha$-HA-Antikörper) analysiert. Rot: $\alpha$-HA oder RFP; grün: $\alpha$-NLP1 (Balken, 10 $\mu \mathrm{m})$.

Um zu testen, wie spezifisch die Antikörper in der Immundetektion von endogenem NLP1 sind, wurden die Antikörper vor der Färbung mit rekombinantem MBP-NLP1 inkubiert. Hierdurch sollten die Antigen-Bindestellen blockiert werden und die spezifische Detektion von NLP1 somit verhindert werden. Bei beiden Antikörpern 
machte es keinen Unterschied, ob diese vorher mit ihrem Antigen präinkubiert wurden oder nicht (Daten nicht gezeigt). Obwohl beide Antikörper in Western BlotAnalysen sowohl rekombinantes als auch endogenes NLP1 aus HeLa-Zellen detektieren können, sind sie für Immunfluoreszenzanalysen von endogenem NLP1 nicht geeignet.

\subsubsection{Untersuchung der intrazellulären Lokalisation von NLP1}

1999 führten Farjot et al. [96] erste Untersuchungen zur Lokalisation von überexprimiertem NLP1 durch. Diese ergaben, dass NLP1 hauptsächlich im Zellkern lokalisiert ist. Später konnte in weiteren Studien gezeigt werden, dass Myc- oder GFP-fusioniertes NLP1 auch an der Kern-Hülle vorliegen kann (Kendirgi et al., 2005 [98]; Le Rouzic et al., 2002 [99]).

Um die Lokalisation von endogenem NLP1 genauer untersuchen zu können, wurde ein biochemischer Ansatz gewählt. In Abbildung 2.3.A wurde mittels KernCytoplasmatrennung die Lokalisation des endogenen NLP1 analysiert. Hierzu wurden HeLa-Zellen mittels Digitonin permeabilisiert und das Cytoplasma von den Kernen getrennt. Mittels Western Blot-Untersuchungen mit verschiedenen Antikörpern wurde untersucht, in welchen Fraktionen die detektierten Proteine vorhanden sind. Als Cytoplasma-Marker wurden Lactat-Dehydrogenase (LDH) und Tubulin gewählt. Beide lokalisierten ausschließlich in der cytoplasmatischen Fraktion. Als Marker für den Kern wurden Lamin A und C sowie verschiedene Kernporenproteine, die vom mAB414-Antikörper detektiert werden, ausgewählt. Sowohl Kernporenproteine als auch Lamine waren hauptsächlich in der Kernfraktion zu finden, aber etwa $10 \%$ von ihnen waren auch im Cytoplasma detektierbar. Hierbei könnte es sich allerdings um Proteine handeln, die aus sich gerade teilenden mitotischen Zellen, oder aus Kernen, die bei der Zentrifugation zerstört worden sind, stammen. Es könnte sich aber auch um neusythetisiertes Protein handeln, welches noch nicht in den Kern oder an die Kernpore tansportiert worden ist. Der Hauptteil an endogenem NLP1 wurde in der Kernfraktion (K) detektiert, während der Anteil in der cytoplasmatischen Franktion (C) weniger als $5 \%$ betrug. NLP1 ist in 
diesem Zellfraktionierungsexperiment folglich wie typische Kernporenproteine und die Lamine A und C lokalisiert.

Zur Überprüfung dieses Ergebnisses sollte die Lokalisation von überexprimiertem NLP1 mittels Immunfluoreszenz näher untersucht werden (HA-NLP1, NLP1-HA, RFPNLP1, NLP1-RFP (Abb. 2.2.C) und GFP-NLP1 (Abb. 2.3.B)). Abbildung 2.3.B zeigt die Lokalisation von transient transfiziertem GFP-NLP1 in HeLa-Zellen. In über 50\% der Zellen lokalisierte GFP-NLP1 hauptsächlich im Kern (oberes Bild). In Zellen mit geringer GFP-NLP1-Expression lokalisierte GFP-NLP1 an der Kernhülle und im Nucleoplasma (mittleres Bild), wobei in einigen Zellen eine Gleichverteilung von GFP-NLP zwischen Kern und Cytoplasma vorlag (unteres Bild). Alle getesteten NLP1Konstrukte verhielten sich ähnlich wie GFP-NLP1, was zeigt, dass die Lokalisation von überexprimiertem NLP1 weder durch das angehängte Fusionsprotein noch dessen Lage ( $\mathrm{N}$ - oder $\mathrm{C}$-terminal) beeinflusst wird.

A

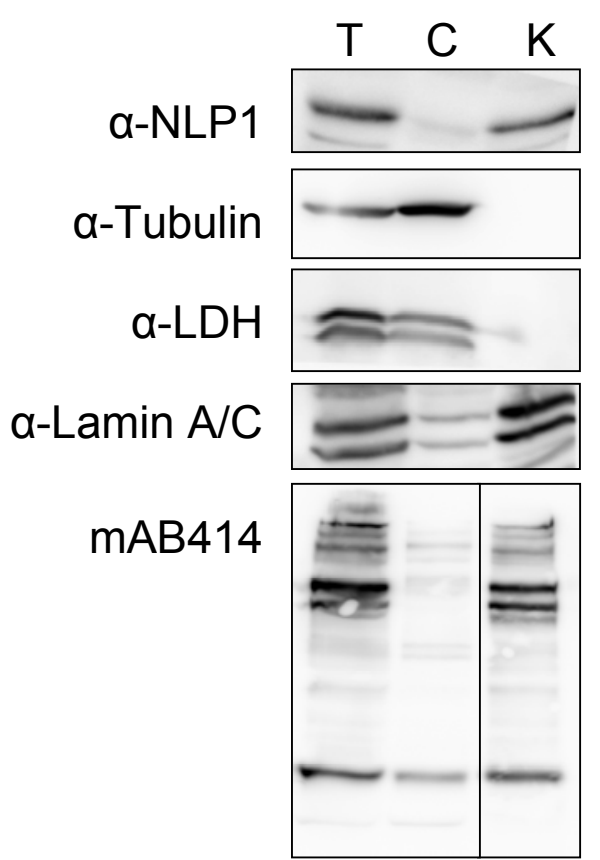

B

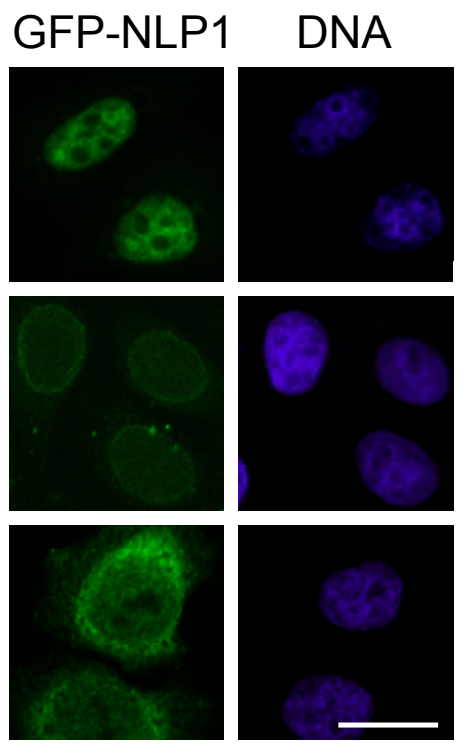

Abbildung 2.3. Lokalisation von NLP1. A) Endogenes NLP1 lokalisiert hauptsächlich im Kern. HeLaZellen wurden mit Digitonin permeabilisiet und das Cytoplasma von den Kernen durch Zentrifugation getrennt. Die Analyse erfolgte durch Western Blot. B) Lokalisation von GFP-NLP1. HeLa Zellen wurden transient mit GFP-NLP1 transfiziert. 48 Stunden nach Transfektion wurde die intrazelluläre Lokalisation des exprimiertem GFP-NLP1 durch konfokale Fluoreszenzmikroskopie analysiert. Obere Reihe: Kernlokalisation, mittlere Reihe: Lokalisation an der Kernhülle , untere Reihe: Gleichverteilung von GFP-NLP1 (Balken, $10 \mu \mathrm{m}$ ). 


\subsubsection{NLP1 unterliegt nicht CRM1-abhängigem Export und ist im Kern mobil}

Nachdem gezeigt werden konnte, dass sowohl endogenes als auch überexprimiertes NLP1 größtenteils im Kern lokalisiert ist, sollte dessen Mobilität in diesem Kompartiment näher untersucht werden. Die Mobilität von Proteinen kann durch verschiedene Faktoren wie zum Beispiel durch die eigene Beweglichkeit des Proteins, Interaktionspartner, aktiven Transport usw. beeinflusst werden. In Abbildung 2.4.A wurde mittels FRAP (正luorescense recovery after photobleaching) untersucht, ob GFP-NLP1 im Kern mobil ist. Zur Analyse der Mobilität von GFP-NLP1 wurden HeLa-Zellen mit einem Konstrukt für GFP-NLP1 transient transfiziert. Das GFP-Signal wurde durch Laserbestrahlung mit einer Wellenlänge von $488 \mathrm{~nm}$ einmalig in einem definierten Bereich im Zellkern ausgeblichen und dann die Rückkehr der Fluoreszenz in diesem Bereich über einen bestimmten Zeitraum gemessen. Wenn der Fluoreszenzwert, der vor dem Bleichen gemessen wurde, erreicht wird, kann man davon ausgehen, dass das Protein frei beweglich ist. Der Graph in Abbildung 2.4.A zeigt, dass nach ca. 30-40 Sekunden der Ausgangwert der Kernfluoreszenz von GFP-NLP1 wieder erreicht wurde. Es handelt sich bei GFP-NLP1 also um ein Protein, das im Zellkern komplett mobil ist.

Aufgrund der Tatsache, dass bei Fluoreszenzanalysen immer ein gewisser Teil des überexprimierten NLP1 im Cytoplasma lokalisiert und auch ein kleiner Teil des endogenen NLP1 bei der Kern-Cytoplasma-Trennung im Cytoplasma detektiert wurde, stellte sich nun die Frage, ob NLP1 zwischen Kern und Cytoplasma hin und her transportiert wird. Um diese Fragestellung zu beantworten, wurden FLIPAnalysen (f́luorescence loss in photobleaching) durchgeführt (Abb. 2.4.B). Hierzu wurden HeLa-Zellen entweder mit einem Plasmid für GFP-NLP1 oder für ein Reporterprotein (NES-GFP2-M9) transient transfiziert. 48 Stunden nach der Transfektion wurde ein definierter Bereich im Cytoplasma kontinuierlich mittels Argon488 Laser geblichen und dabei der Verlust der Kernfluoreszenz gemessen. Um zu überprüfen, ob es sich um CRM1-vermittelten Export handelt, wurden zusätzlich FLIP-Analysen mit transfizierten Zellen durchgeführt, die zuvor mit CRM1-Inhibitor Leptomycin B (LMB) behandelt wurden. 
Das Kontroll-Reporterprotein (NES-GFP2-M9) zeigte eine schnelle Abnahme der Kernfluoreszenz (Abb. 2.4.B, blaue Linie) die durch LMB-Behandlung inhibiert werden konnte (Abb. 2.4.B, grüne Linie). Der beobachtete Export des Reporterproteins ist folglich über CRM1 vermittelt worden. Im Fall von GFP-NLP1 ist die Abnahme der Kernfluoreszenz (Abb. 2.4.B, rote Linie) hingegen eher gering und wird durch die LMB-Behandlung nicht beeinflusst (Abb. 2.4.B, gelbe Linie).

Diese Ergebnisse deuten darauf hin, dass NLP1 mobil im Kern vorliegt (Abb. 2.4.A) und diesen langsam verlassen kann. Dieser Export scheint allerdings nicht CRM1vermittelt zu sein (Abb. 2.4.B).

A

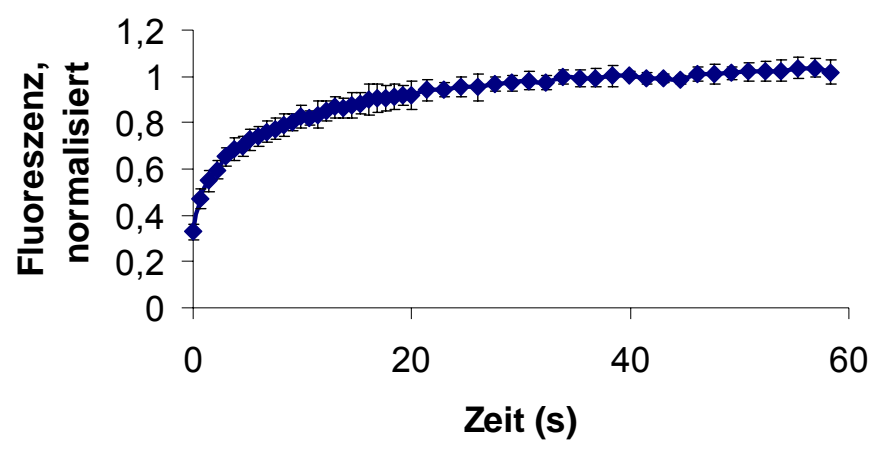

B

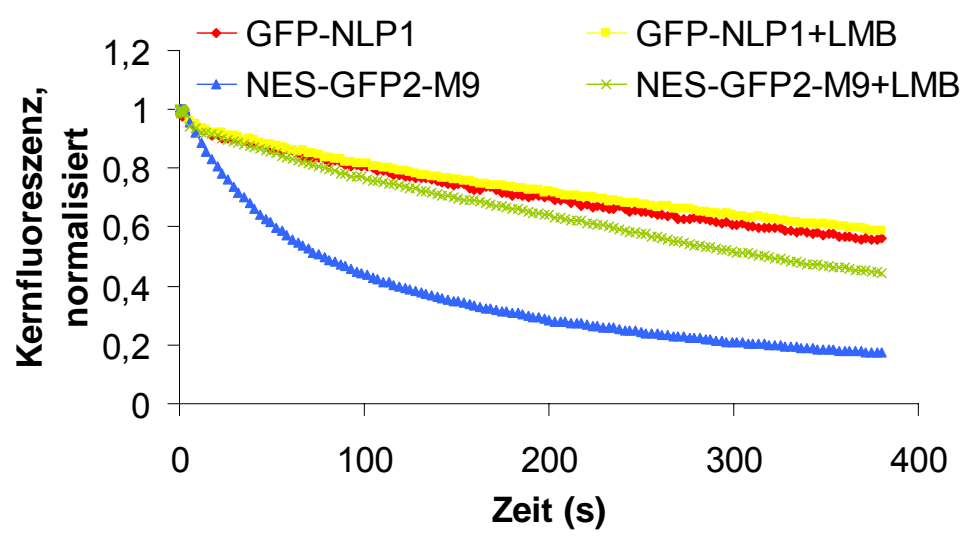

Abbildung 2.4. Mobilitätsstudien von GFP-NLP1. A) FRAP: GFP-NLP ist im Zellkern mobil HeLaZellen wurden transient mit GFP-NLP1 transfiziert. Das GFP-Signal wurde in einem definierten Bereich im Zellkern geblichen. Sowohl vor als auch nach dem Bleichen werden Bilder aufgenommen und die Fluoreszenz in der Bleichregion (ROI1), der Referenzzelle (ROI2) sowie im Hintergrund (ROI3) gemessen. Die Auswertung erfolgte mittels LAS-Software. Dabei wurden die Werte von ROI1 vor dem Bleichen als 1 gesetzt und alle nachfolgenden Werte darauf normalisiert. Der Graph repräsentiert das Ergebnis aus 10 Zellen und die Fehlerbalken geben die Standardabweichung an. B) FLIP: GFP-NLP1 wird nicht CRM1-abhängig exportiert. HeLa-Zellen wurden transient mit GFP-NLP1 oder NES(Rev68-90)-GFP2-M9 transfiziert. Die LMB-Behandlung erfolgte für 2-3 h mit 5 nM LMB. Die Zellen wurden in einem definierten Bereich im Cytoplasma geblichen, nach jedem Bleichen ein Foto gemacht und die Kernfluoreszenz bestimmt. Die Fluoreszenzen vor dem ersten Bleichen wurden als 1 definiert und alle folgenden Werte darauf normalisiert. Die Graphen zeigen jeweils das gemittelte Ergebnis aus 10 Zellen. 


\subsection{Biochemische Charakterisierung von NLP1}

\subsubsection{NLP1 kann Komplexe mit CRM1, RanGTP und einem Exportsubstrat bilden}

Nachdem die Interaktion von NLP1 mit dem Proteinexportfaktor CRM1 im „Hefe Zwei Hybrid-System“ entdeckt worden war (Farjot et al., 1999 [96]), sollte diese Interaktion im nächsten Abschnitt biochemisch überprüft und dann näher charakterisiert werden. Hierzu wurden Bindungsstudien mit rekombinantem MBPNLP1-Fusionsprotein durchgeführt. Dazu wurde MBP-NLP1 an Amylose-Matrix gebunden und mit CRM1, Snurportin1 oder NES-Peptid als Exportsubstrat und GTPbeladenem RanQ69L in verschiedenen Kombinationen inkubiert. RanQ69L ist eine GTPase-defiziente Mutante von Ran, die nicht mehr in der Lage ist die GTPHydrolyse zu katalysieren (Klebe et al., 1995 [31]). Einmal mit GTP beladen verbleibt sie in dieser Form, was zu einer ständigen Assoziation mit eventuell gebildeten Exportkomplexen führt. Abbildung 2.5.A zeigt, dass CRM1 nur in Anwesenheit von RanQ69LGTP mit NLP1 interagiert und dass diese Bindung durch Zugabe von GSTSnurportin1 oder NES-Peptid verstärkt wird. In Abwesenheit von RanQ69L findet diese Interaktion nicht statt. Um auszuschließen, dass MBP diese Bindungen vermittelt, wurden Kontrollen mit immobilisiertem MBP anstatt MBP-NLP1 durchgeführt. Der MBP-Anhang alleine konnte keine Komplexe mit CRM1, RanGTP und NES-Substrat eingehen (siehe Abb. S2A). Die Komplexbildung ist also auf NLP1 zurückzuführen.

Da in Abbildung 2.5.A eindeutig gezeigt wurde, dass NLP1 Komplexe mit CRM1, einem Export-Substrat und RanGTP eingehen kann, sollte nun untersucht werden, ob die Komplexbildung RanGTP abhängig ist, oder ob CRM1 und NLP1 auch in Anwesenheit von RanGDP interagieren können. Hierzu wurden Bindungsstudien durchgeführt, in denen GTP- bzw. GDP- beladenes GST-Ran (oder GST alleine zur Spezifitätskontrolle) an Gluthation-Agarose immobilisiert wurde und mit verschiedenen Kombinationen von MBP-NLP1, CRM1 oder Snurportin1 inkubiert wurde (Abb. 2.5.B). Es zeigte sich, dass weder NLP1 noch Snurportin1 alleine mit RanGTP interagierten. Die Bindung von CRM1 alleine an GST-RanGTP war sehr 
schwach und konnte nur mittels Western Blot-Analyse detektiert werden. Durch Zugabe von MBP-NLP1 oder Snurportin1 wurde die Bindung von CRM1 zu RanGTP verstärkt. Die effizienteste Bindung wurde erreicht, wenn sowohl NLP1 als auch Snurportin1 und CRM1 mit RanGTP inkubiert wurden und sich tetramere Komplexe ausbilden konnten. In den Ansätzen, in denen Ran mit GDP beladen war, konnten sich keine Komplexe formieren. Die Komplexbildung ist also RanGTP-abhängig.

A
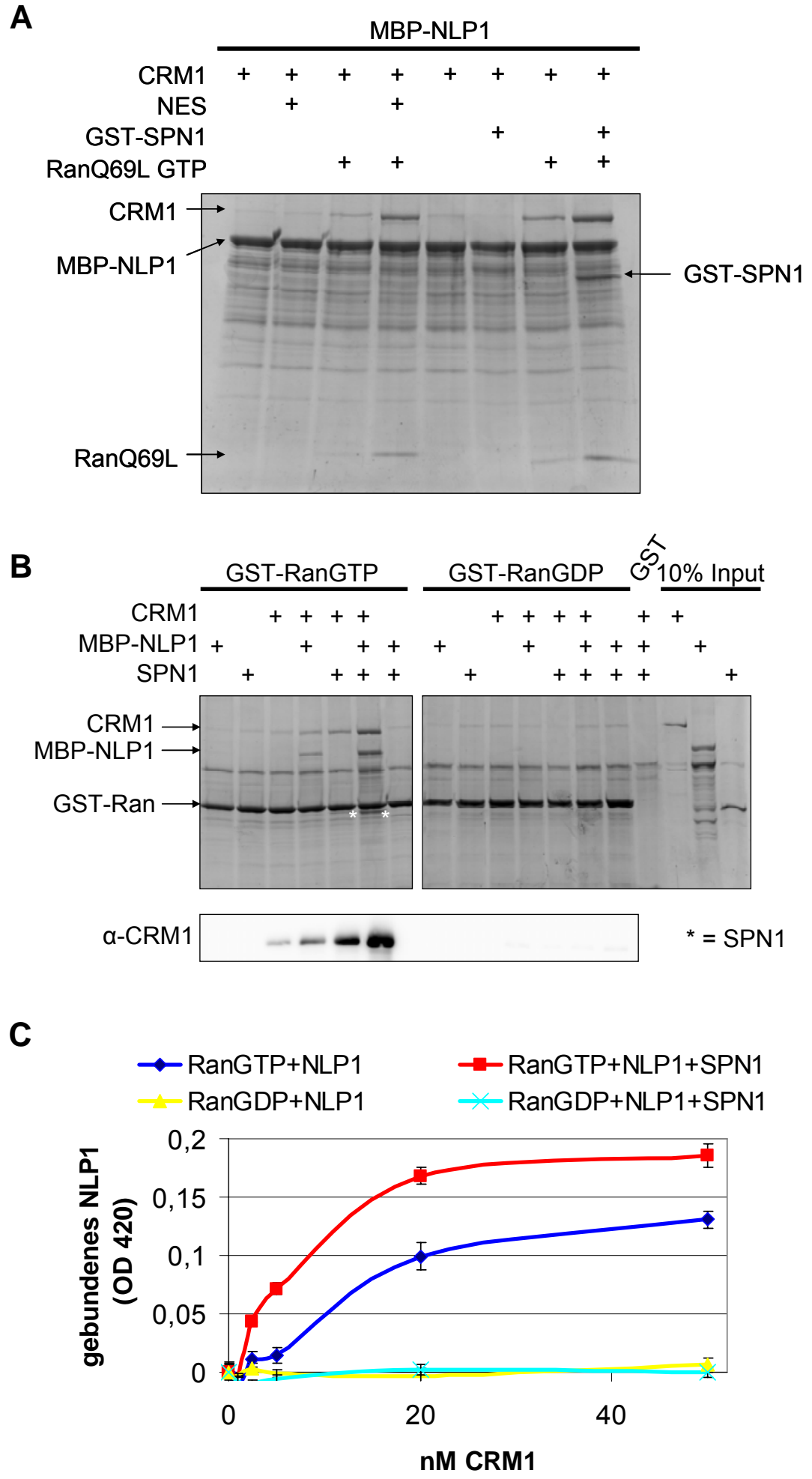


\begin{abstract}
Abbildung 2.5. MBP-NLP1 bildet trimere und tetramere Komplexe aus CRM1, RanGTP und Exportsubstrat. A) Bindungsstudien: $5 \mu \mathrm{g}$ CRM1, RanGTP, GST-Snurportin1 (GST-SPN1) oder NESPeptid wurden in verschiedenen Kombinationen mit immobilisiertem MBP-NLP1 inkubiert. In B) wurden Bindungsstudien mit je $5 \mu \mathrm{g}$ immobilisiertem GST-Ran beladen mit GTP oder GDP (oder immobilisiertem GST als Kontrolle), His CRM1 (CRM1), His-Snurportin1 (SPN1) und MBP-NLP1 in verschiedenen Kombinationen durchgeführt. In A) und B) wurden gebundene Proteine mit Proteinprobenpuffer eluiert und durch SDS-PAGE mit nachfolgender Coomassie-Färbung analysiert. Gebundenes CRM1 wurde in B) zusätzlich durch Westernblot-Analyse detektiert. C) zeigt das Ergebnis eines enzymgekoppelten Immunadsorptionstests (ELISA). Hierbei wurden zu 300 ng (120 $\mathrm{nM}$ ) immobilisiertem GST-Ran (beladen mit GTP oder GDP) jeweils $300 \mathrm{ng}$ (70 nM) MBP-NLP1 +/- 300 ng (120 nM) His-Snurportin1 und ansteigende Mengen von His-CRM1 hinzugegeben. Zur Analyse wurde das gebundene NLP1 durch den NLP1-Antikörper detektiert. Die Fehlerbalken geben die Standardabweichung von drei unabhängigen Ansätzen eines Experiments an.
\end{abstract}

Um den Affinitätsunterschied zwischen trimeren und tetrameren Komplexen genauer zu bestimmen, wurden ELISA-Analysen durchgeführt. Hierzu wurde GSTRan mit GTP (oder mit GDP zur Kontrolle) beladen und auf ELISA-Platten immobilisiert. Das immobilisierte Ran wurde mit einer konstanten Menge NLP1 und ansteigender Menge CRM1 in An- oder Abwesenheit von Snurportin1 inkubiert. Die Analyse erfolgte durch Detektion des gebundenen NLP1 mittels $\alpha$-NLP1-Antikörper. Während in den Kontrollansätzen mit GST-RanGDP keine Interaktion mit NLP1 stattfand (Abb. 2.5.C, gelbe und türkise Linie), konnte in dem RanGTP-Ansatz ohne Snurportin1 mit ansteigender CRM1-Konzentration gebundenenes NLP1 detektiert werden (Abb. 2.5.C, blaue Linie). Die Zugabe von Snurportin1 als Exportsubstrat erhöhte die Menge an gebundenem NLP1 um etwa 30\% (Abb. 2.5.C, rote Linie). Gerade in den Ansätzen mit geringen CRM1-Konzentrationen wird sichtbar, dass sich die Affinität von NLP1, CRM1 und Ran-GTP durch Zugabe von Snurportin1 erhöht, so dass sich auch bei sehr geringen CRM1-Konzentrationen tetramere Komplexe ausbilden können, während trimere Komplexe viel höhere CRM1Konzentrationen benötigen. Während zum Beispiel im Ansatz ohne Snurportin1 die Absortion bei Zugabe von 5 nM CRM1 bei 0,014 lag, war sie in dem Ansatz mit Snurportin1 schon bei 0,07, also 5-mal so hoch.

Es konnte also gezeigt werden, dass NLP1 Komplexe mit CRM1 und RanGTP in Anoder Abwesenheit eines NES-Substrates bilden kann. Zudem bewirkt die Anwesenheit eines Substrates eine deutlich effizientere Bildung des tetrameren Komplexes gegenüber dem trimeren ohne Substrat. 


\subsubsection{NLP1-Komplexe sind gegenüber RanGAP1-induzierter GTP-Hydrolyse insensitiv}

In den vorangegangenen Abschnitten wurde gezeigt, dass NLP1, CRM1 und RanGTP in An- bzw. Abwesenheit eines NES-Substrates Komplexe ausbilden können. In diesem Abschnitt sollte der trimere NLP1-Komplex mit Hilfe des RanGAP-Assays genauer untersucht werden. Dieser Assay basiert darauf, dass RanGTP durch Bindung in einem CRM1-Komplex gegenüber einer RanGAP-stimulierten GTPHydrolyse resistent wird.

Für den Versuch wurde rekombinantes CRM1 mit Ran[ $\left.\gamma^{32} \mathrm{P}\right] \mathrm{GTP}$ in Anwesenheit von MBP-NLP1, MBP-Nup214 oder MBP-Nup88 inkubiert und anschließend die durch Zugabe von RanGAP1 erhaltene GTP-Hydrolyse durch Messen des abgespaltenen radioaktiv-makierten Phosphats analysiert. Wie zuvor beschrieben, inhibierten schon sehr geringe Konzentrationen von Nup214 die RanGAP1 stimulierte GTPHydrolyse (grüne Linie), während die Zugabe von Nup88 keinen Effekt auf die Hydrolyseaktivität hatte (blaue Linie) (Hutten et al., 2006 [51]). Die Zugabe von NLP1 hatte die gleichen Auswirkungen wie die Zugabe von Nup214: die GTPHydrolyse wurde schon bei sehr geringen Konzentrationen an NLP1 inhibiert (rote Linie). Dieses Ergebnis bestätigt zunächst, dass CRM1-RanGTP-NLP1-Komplexe gebildet werden. Zudem zeigen sie, dass der NLP1-CRM1-RanGTP-Komplex RanGAP1-insensitiv ist.

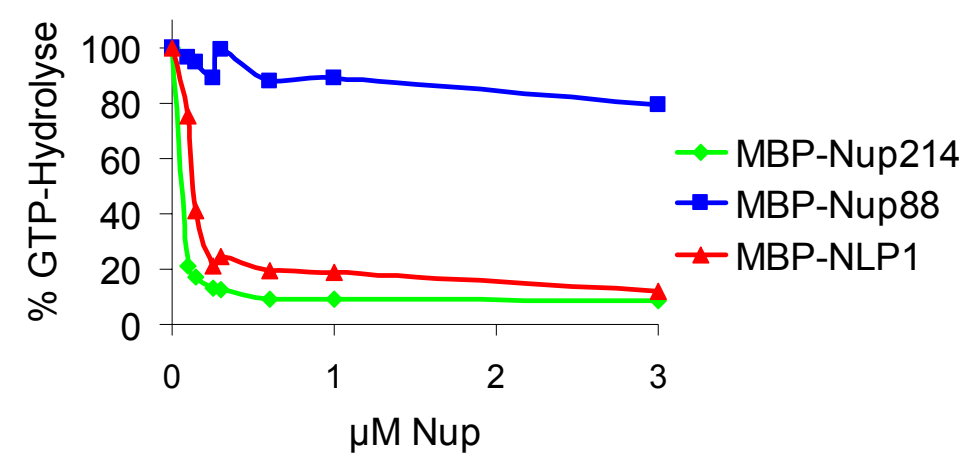

Abbildung 2.6. Der Komplex aus MBP-NLP1, His-CRM1 und RanGTP ist RanGAP1-insensitiv. Die RanGAP-Hydrolyse-Resistenz des trimeren NLP1-Komplexes wurde mittels RanGAP-Assay überprüft. Hierzu wurden rekombinantes CRM1, Ran[ $\left.\gamma^{32} \mathrm{P}\right] \mathrm{GTP}$ und ansteigende Mengen der angegebenen Nucleoporine (MBP-NLP1, MBP-Nup214 (AS 1859-2090), MBP-Nup-88 (AS 500-741)) zur Komplexbildung 20 min präinkubiert und anschließend für weitere 10 min mit RanGAP1 inkubiert. Die GTP-Hydrolyse wird in Prozent angegeben, wobei $100 \%$ GTP-Hydrolyse dem Ansatz entspricht, der kein Nucleoporin enthielt. 


\subsubsection{NLP1-Komplexe können durch RanBP1 dissoziiert werden}

Ein wichtiger Schritt im Export-Zyklus von Proteinen aus dem Zellkern ist das Ablösen des trimeren CRM1-RanGTP-Exportcargo-Komplexes von den Nucleoporinen auf der cytoplasmatischen Seite der Kernpore, das durch RanBP1 und/oder die Ran-bindenden Domänen von RanBP2 vermittelt wird (Kehlenbach et al., 1999 [50]). Im Rahmen dieser Arbeit wurde nun untersucht, ob die NLP1Komplexe ebenfalls RanBP1-sensitiv sind. Hierfür wurde immobilisiertes MBP-NLP1 mit CRM1 und RanGTP in An- oder Abwesenheit von NES-Peptid inkubiert, sodass sich die trimeren oder tetrameren NLP1-Komplexe ausbilden konnten. Anschließend wurden die Ansätze halbiert und eine Hälfte mit RanBP1 inkubiert. In den Ansätzen ohne RanBP1 bildeten sich trimere und tetramere NLP1-Komplexe, während die anschließende Inkubation mit RanBP1 zu einer Auflösung der Komplexe führte (Abb.2.7.). RanBP1 ist also in der Lage den Exportkomplex bestehend aus RanGTP, CRM1 und NES-Substrat von NLP1 abzulösen.

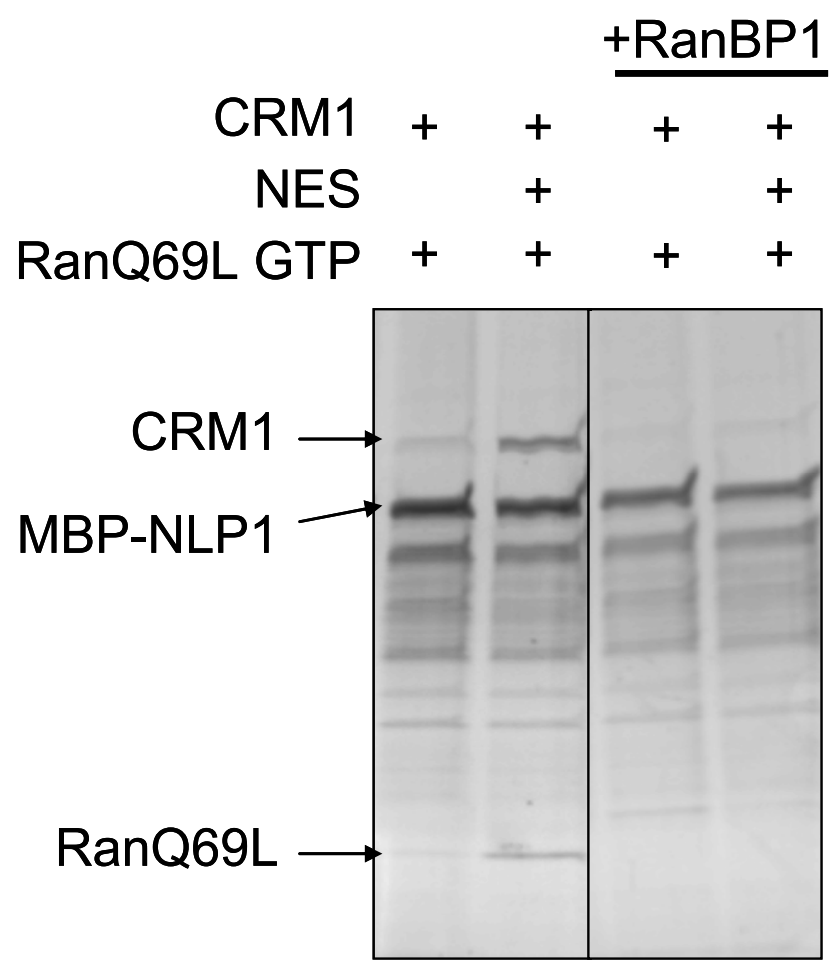

Abbildung 2.7. RanBP1 dissoziiert NLP1-Komplexe. Bindungsstudien wurden wie in Abb. 2.5.A beschrieben durchgeführt. (Das NES-Peptid (CVDEMTKKFGTLTIHDTEK) stammt aus NS2 protein of minute virus of mice (Askjaer et al., 1999 [106]). Nach 50 min Inkubation, in denen sich die NLP1Komplexe formieren konnten, wurden die Ansätze geteilt und zu einer Hälfte RanBP1 hinzugegeben. Nach einer weiteren Stunde wurden die gebundenen Proteine durch SDS-PAGE und CoomassieFärbung analysiert. 


\subsubsection{Identifizierung der CRM1-Bindestelle in NLP1}

Zur Identifizierung des Bereichs von NLP1, der die Komplexbildung mit CRM1 vermittelt, wurden verschiedene GST-oder MBP-fusionierte Deletionsmutanten von NLP1 erstellt (Abb. 2.8.A). Während für die langen NLP1-Fragmente ein MBPAnhang für die Löslichkeit der Proteine notwendig war, konnten kürzere Fragmente über einen GST-Anhang aufgereinigt werden. Die rekombinanten NLP1-Fragmente sind in Abbildung 2.8.B dargestellt. Zur Ermittlung der Bindungsregion wurden Bindungsstudien durchgeführt, in denen die GST- oder MBP-fusionierten NLP1Fragmente an der entsprechenden Matrix immobilisiert und mit CRM1 alleine, CRM1 und Snurportin1 oder CRM1 und RanGTP in An- oder Abwesenheit von Snurportin1 (oder NES, siehe Abb. S2.B) inkubiert wurden. Da es keinen Unterschied machte, ob als Exportsubstrat Snurportin1 oder NES-Peptid verwendet wurde, wird in Abbildung 2.8.C nur das Ergebnis der Bindungsstudie mit Snurportin1 als ExportCargo zusammenfassend dargestellt. Die vollständigen Gele, sowie die Bindungsstudien mit NES-Peptid sind im Anhang (Abb. S2A und B) beigefügt. Die Analyse ergab, dass die Zinkfinger-Domäne für die CRM1-NLP1-Komplexe nicht relevant ist, da die Bindung von CRM1 zum Fragment 24-423 genauso stark wie beim Wildtyp (1-423) war. Die Deletion der Coiled-Coil-Domäne (1-423 $\left.{ }_{165} \Delta_{204}\right)$ führte hingegen zu einer leichten Verringerung der Interaktion, war alleine (165-204 oder 130-230) jedoch nicht ausreichend um eine Komplexbildung zu vermitteln. Fügt man sie allerdings dem N-Terminus ohne Coiled-Coil (1-165) wieder hinzu, wird die vorher sehr schwache Komplexbildung wieder verstärkt (1-204). Interessanterweise können die Fragmente, die die meisten FG-Repeats enthalten (205-423, 165-423), gar keine oder nur sehr schwache CRM1-Komplexe bilden. Das $\mathrm{N}$-terminale Fragment (1-204), das nur zwei FG-Repeats enthält, zeigt eine stärkere Bindung zu CRM1, als der C-Terminus mit 10 FG-Repeats. In der Mutante NLP1 1423FGFGAAAA ${ }_{165} \Delta_{204}$ wurden die FG-Repeats im N-terminalen Teil von NLP1 (FGRepeat AS 14,15 und FG-Repeat AS 95,96) gegen Alanine ausgetauscht. Diese Mutante interagierte genauso stark mit CRM1 wie die Mutante $1-423_{165} \Delta_{204}$, in der die FG-Repeats noch vorhanden waren und ebenso stark, wie der N-Terminus (1- 
204), der zwar die FG-Repeats 14,15 und 95,96 noch enthält, aber dafür alle weiteren FG-Repeats vom C-Terminus entfernt sind.

Die Ergebnisse dieses Abschnitts legen die Vermutung nahe, dass die Bindung zu CRM1 nicht durch die FG-Repeats von NLP1 vermittelt wird, sondern eher vom Nterminalen Bereich. Hierbei scheint auch die Coiled-Coil-Region eine Rolle zu spielen.

A
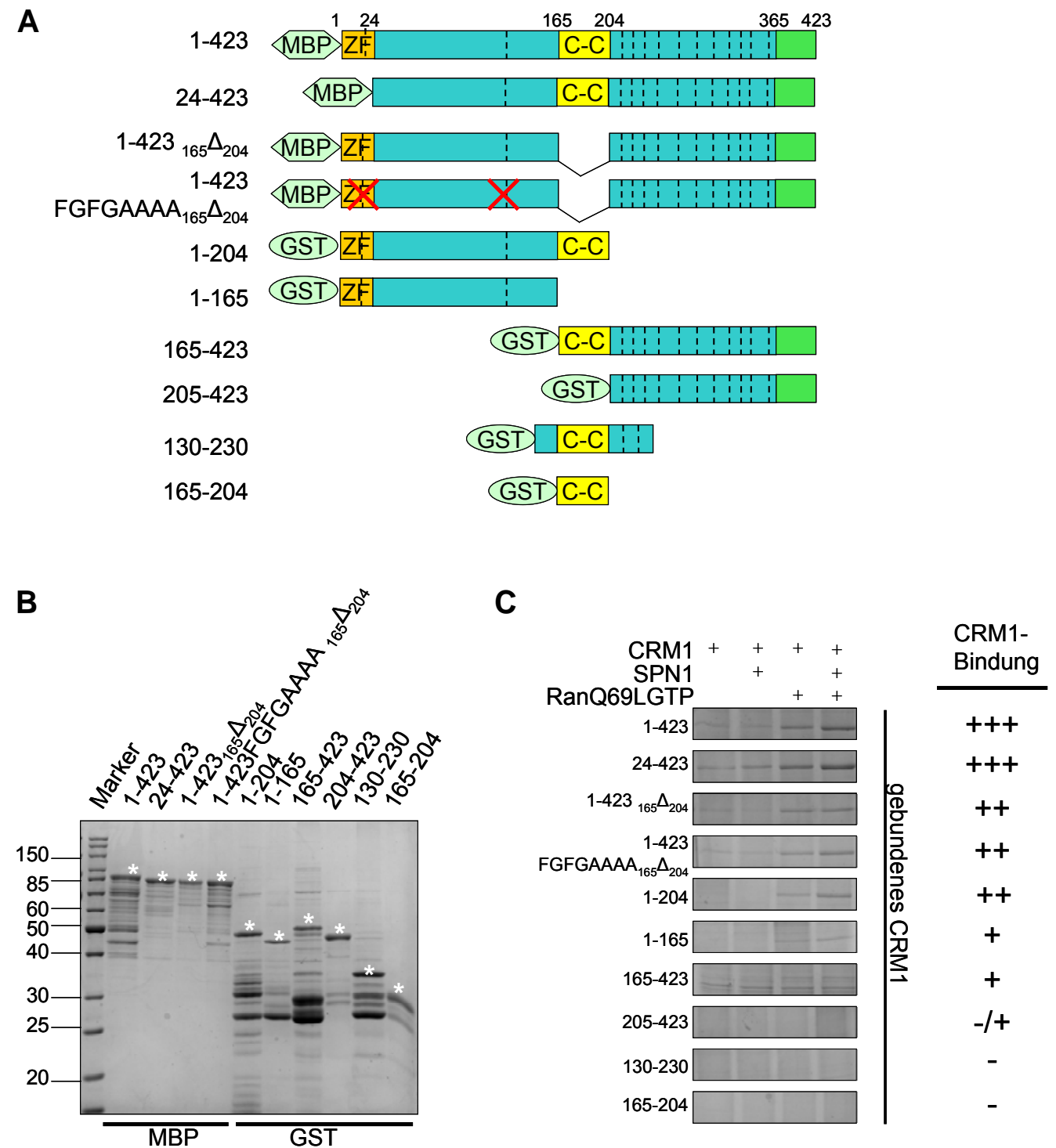

Abbildung 2.8. Identifizierung der CRM1-Binderegion in NLP1. A) Schematische Darstellung der rekombinant hergestellten GST- oder MBP-fusionierten NLP1-Fragmente. ZF = putativer Zinkfinger, C-C =putative Coiled-Coil-Domäne. Der grüne Bereich (Aminosäure 365-423) gibt den Bereich an, der für die Bindung an die Kernhülle verantwortlich sein soll (Kendirgi et al., 2005 [98]). Die gepunkteten Linien sollen Phenylalanin-Glycin-Repeats (FG-Repeats) darstellen. B) Coomassie-gefärbtes SDS-Gel der NLP1-Fragmente. Geladen wurde jeweils $1 \mu \mathrm{g}$ des angegebenen Proteins. Die mit einem weißen Stern gekennzeichnete Bande zeigt jeweils das angegebene NLP1-Fragment an. C) Bindungsstudien. $5 \mathrm{mg}$ der jeweiligen NLP1-Fragmente wurden an ihre entsprechende Matrix immobilisiert und in verschiedenen Kombinationen aus $5 \mu \mathrm{g}$ His-CRM1, $5 \mu \mathrm{g}$ His-Snurportin1 und circa $5 \mu \mathrm{g}$ RanQ69LGTP inkubiert. Die gebundenen Proteine wurden mit Proteinprobenpuffer eluiert und mittels SDS-PAGE und nachfolgender Coomassie-Färbung analysiert (+++ bedeutet sehr gute, ++ mittlere, + schwache, keine CRM1-Interaktion). 


\subsubsection{Das virale Protein HIV-Rev kann sowohl direkt als auch über CRM1 mit NLP1 interagieren}

Da NLP1 durch eineine breit angelegten „Hefe Zwei Hybrid-System“-Versuch mit HIV-Rev als "Köder" entdeckt wurde (Farjot et al., 1999 [96]), wurde neben Snurportin1 und NES-Peptid zusätzlich die Bindung des viralen Proteins HIV-1 Rev an NLP1 analysiert. Rev ist ein Adapterprotein für gespleißte oder ungespleißte RNA des $\mathrm{HI}$-Viruses, welches mit CRM1 interagieren und somit den Export viraler RNA aus dem Zellkern vermitteln kann (Fischer et al., 1994 und 1995 [38, 107]; Fornerod et al., 1997 [17]). Der Import von Rev kann durch verschiedene Importrezeptoren (Importin $\beta$, Transportin, Importin 5 und Importin 7) vermittelt werden (Arnold et al., 2006 [108],Henderson et al., 1997 [109]).

Um die Interaktion von Rev mit NLP1 genauer zu untersuchen, wurden erneut Bindungsstudien mit immobilisierten NLP1-Fragmenten und CRM1, RanGTP und Rev durchgeführt. Interessanterweise konnte Rev einerseits alleine mit MBP-NLP1 (1423) interagieren, andererseits aber auch die CRM1-Bindung zu NLP1 zusätzlich verstärken. Dies lässt vermuten, dass Rev direkt mit NLP1 und zusätzlich indirekt über CRM1 mit NLP1 interagieren kann (Abb. 2.9, oberes Bild). Da nach Entfernen der Zinkfinger-Domäne die direkte Interaktion zu Rev verloren geht, scheint dieser Bereich (AS 1-24) für die direkte Bindung von Rev an NLP1 verantwortlich zu sein (Abb. 2.9., oberes Bild). Da hier allerdings nicht ausgeschlossen werden kann, dass bei der Aufreinigung von NLP1 (oder der anderen Proteinkomponenten) ebenfalls RNA, die zum Beispiel an den Zinkfinger gebunden hat, mit aufgereinigt wurde, könnte die vermeintlich direkte Interaktion auch über RNA vermittelt worden sein. Um sicherzustellen, dass Rev nicht indirekt über RNA an NLP1 bindet, müssten bei einer Wiederholung dieses Versuchs alle Proteinkomponenten mit RNAse behandelt werden.

Da die Bindung von Rev an NLP1 über CRM1 vermittelt wird, sobald die Zinkfinger Domäne von NLP1 entfernt ist, ist es nicht verwunderlich, dass der N-Terminus (NLP1 1-204) und nicht der C-Terminus (NLP1 205-423) für diese Interaktion verantwortlich ist. 
Die Ergebnisse aus diesem Abschnitt zeigen, dass das Protein HIV-1 Rev einerseits mit der Zinkfinger-Domäne interagieren kann, sich aber andererseits auch wie ein „normales“ Exportsubstrat (zum Beispiel SPN1 und NES-Peptid, siehe Abschnitt 2.3.4.) verhält und über CRM1 mit dem N-Terminus von NLP1 interagiert.

A

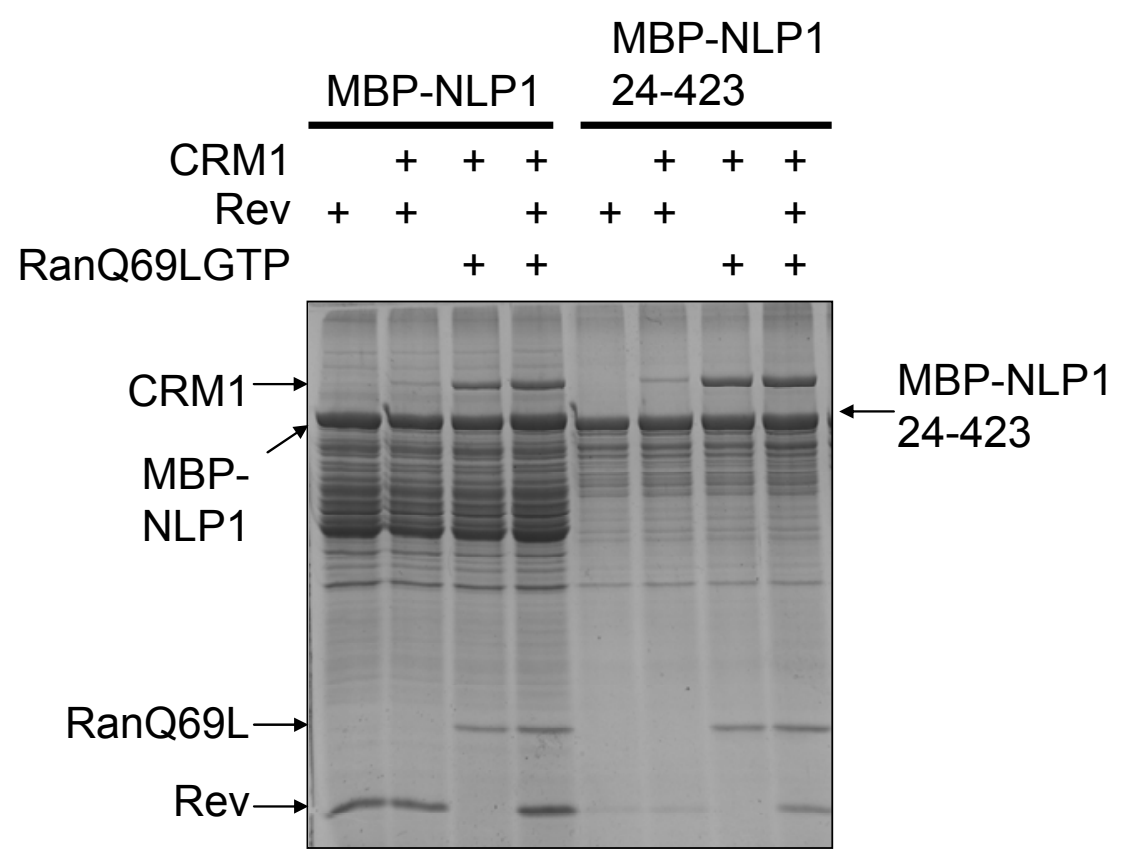

B

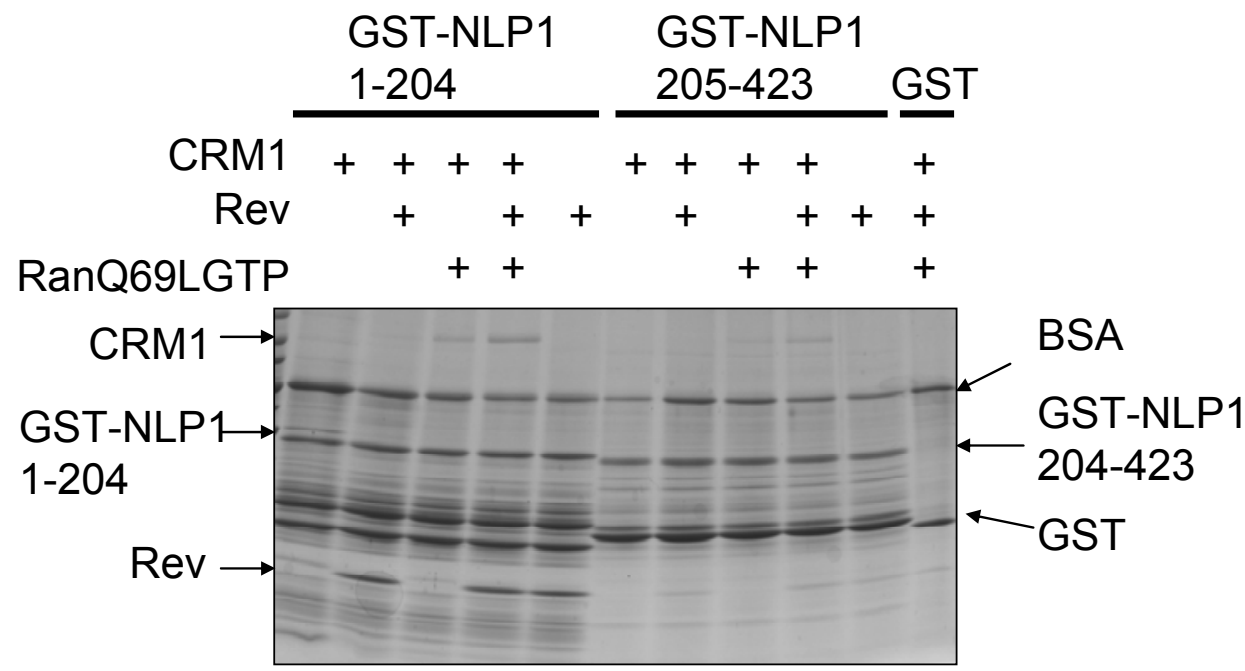

Abbildung 2.9. Rev interagiert sowohl direkt als auch über CRM1 mit NLP1. $5 \mu \mathrm{g}$ der jeweiligen NLP1-Fragmente sowie GST als Kontrolle wurde an die entsprechende Matrix (GST-Agarose, oder Amylose-Resin) gebunden und dann in verschiedenen Kombinationen mit His-CRM1, Rev und RanQ69LGTP inkubiert. Die gebundenen Proteine wurden mit Proteinprobenpuffer eluiert und durch SDS-PAGE und nachfolgende Coomassie-Färbu ng analysiert. 


\subsubsection{NLP1 kann in vitro nicht $O$-glykosyliert werden}

In vorangegangenen Studien wurden Indizien für eine O-Glykosylierung von NLP1 gefunden (Farjot et al., 1999 [96]). Überexprimiertes NLP1 aus einem HeLa-Zelllysat konnte mittels WGA-Sepharose präzipitiert werden. WGA (్heat Germ Agglutinin) ist ein Lektin, welches an O-glykosysierte Nucleoporine bindet und somit Kerntransport von Proteinen verhindert. Im Folgenden sollte nun überprüft werden, ob auch rekombinantes NLP1 aus Bakterien in vitro glykosyliert werden kann, um anschließend zu testen, ob die Glykosylierung von NLP1 Einfluss auf Interaktion mit dem CRM1-Komplex hat. Hierzu wurden MBP-NLP1 oder GST-p62 als Kontrolle mit O-GlcNAc-Transferase (OGT) und UDP-,N-Acetyl-Glucosamin inkubiert. Während bei dem Kontrollprotein GST-p62 Glykosylierung stattfand (Abb. 2.10.A roter Pfeil), konnte bei NLP1 keine Glykosylierung detektiert werden (Abb. 2.10.A). Um die generelle Glykosylierung aus HeLa-Zellen zu überprüfen, wurde endogenes NLP1 mit WGA-Sepharose aus HeLa-Zelllysat präzipitiert. Hierzu wurde das Zelllysat mit WGA-Sepharose oder GST-Agarose als Kontrolle inkubiert. Es zeigte sich, dass genauso viel endogenes NLP1 an die WGA-Sepharose wie an die Kontrollmatrix gebunden hat (Abbildung 2.10.B). Ein Kontrollversuch, in dem andere gebundene Nucleoporine mittels mAB414-Antikörper detektiert wurden, zeigte, dass Nucleoporine, nicht an GST-Agarose wohl aber an WGA-Sepharose binden (Daten nicht gezeigt). Somit muss davon ausgegangen werden, dass unter den hier angewandten Bedingungen kein endogenes O-glykosyliertes NLP1 präzipitiert werden kann.

Die in dieser Arbeit durchgeführten Experimente liefern keine Hinweise darauf, dass NLP1 glykosyliert in der Zelle vorliegt. 
A

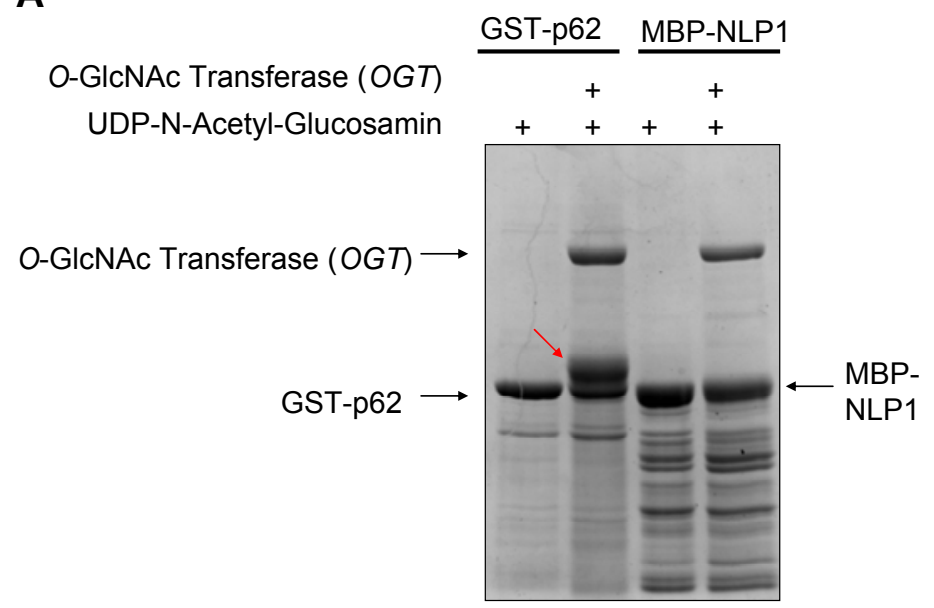

B

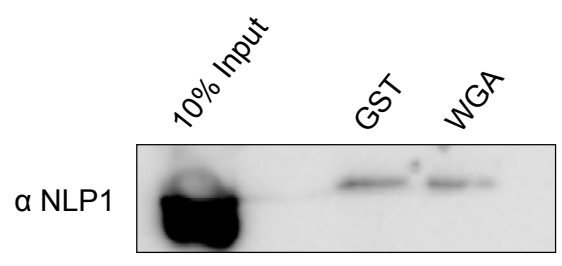

Abbildung 2.10. Glykosylierung von NLP1. A) zeigt das Ergebnis der in vitro-Glykosylierung von GSTp62 und MBP-NLP1. Die Analyse erfolgte durch SDS-PAGE mit nachfolgender Coomassie-Färbung. Der rote Pfeil zeigt auf $O$-glycosyliertes GST-p62. B) Das Zelllysat aus $7^{*} 10^{7} 293$ T Zellen wurde für 2 Stunden mit WGA-Sepharose oder GST-Agarose inkubiert. Die gebundenen Proteine wurden mit 4fach Proteinprobenpuffer eluiert. 50\% der eluierten Proteine wurden der Größe nach durch SDSGelelektrophorese aufgetrennt. Die Detektion von gebundenem NLP1 erfolgte durch Western BlotAnalyse mit $\alpha$-NLP1 3755-Antikörper.

\subsubsection{Nup214 konkurriert mit NLP1 um die Komplexbildung mit CRM1}

Nup214 ist ein an der cytoplasmatischen Seite der Kernpore lokalisiertes Nucleoporin (Kraemer et al., 1994 [48]). Sowohl in vitro als auch in vivo Studien geben klare Hinweise darauf, dass Nup214 eine wichtige Rolle im CRM1vermittelten Protein-Export zumindest einiger Proteine inne hat. Es wird vermutet, dass Nup214 die letzte Bindungsstation des trimeren CRM1-Komplexes ist, bevor dieser durch RanBP1 oder die Ran-Bindedomänen von RanBP2 von der Kernpore abgelöst wird (Kehlenbach et al., 1999 und 2001 [50, 110]; Hutten et al., 2006 [51], Bernad et al., 2004 [111]). Im Rahmen dieser Arbeit sollte nun näher untersucht werden, ob Nup214 mit NLP1 interagiert, ob Nup214 und NLP1 um die Bindung der CRM1-Komplexe konkurrieren oder ob sie gleichzeitig an die CRM1-Komplexe binden können. Hierzu wurden Bindungsstudien durchgeführt, in denen MBP-NLP1 (oder zur Kontrolle MBP alleine) immobilisiert und in verschiedenen Kombinationen mit CRM1, Snurportin, RanGTP und His-Nup214 (AS 1859-2090) inkubiert wurde. Abbildung 2.11.A zeigt, dass der hier verwendete C-Terminus von Nup214 alleine nicht mit NLP1 interagiert. Die Ansätze ohne Nup214, die CRM1 und RanGTP in An- 
oder Abwesenheit von Snurportin enthielten, bildeten Komplexe aus, während alle Ansätze die zusätzlich Nup214 enthielten, keine Komplexe formten. Dieses Ergebnis deutet darauf hin, dass die Affinität von Nup214 zu den CRM1-Komplexen höher ist als die Affinität von NLP1. Diese Vermutung wird durch nachfolgende Kompetitionsstudien bestätigt, in denen konstante Mengen aus MBP-NLP1, CRM1 und NES-Peptid und ansteigende Mengen von MBP-Nup214 (AS 1859-2090) zu immobilisiertem GST-RanGTP gegeben wurden (Abb. 2.11.B). Während die gebundene CRM1-Menge konstant blieb, nahm die gebundene NLP1-Menge mit ansteigender Nup214-Konzentration proportional ab. Dieses Phänomen konnte auch beobachtet werden, wenn Nup214 in ansteigenden Mengen zu einem bereits bestehenden tetrameren NLP1-Exportkomplex gegeben wurde (Daten nicht gezeigt). Nup214 hat also offensichtlich eine höhere Affinität als NLP1 zu den CRM1Exportkomplexen.

Die Ergebnisse dieses Abschnitts zeigen, dass NLP1 und Nup214 (AS 1859-2090) nicht miteinander interagieren und nicht gleichzeitig an den CRM1-Exportkomplex binden können. Desweiteren kann Nup214 NLP1 aus tetrameren Komplexen (NLP1CRM1-RanGTP-NES-Substrat) verdrängen. Dies könnte ein Hinweis darauf sein, dass der C-Termius von Nup214 und NLP1 die gleiche Bindestelle des CRM1Exportkomplexes verwenden. 
A

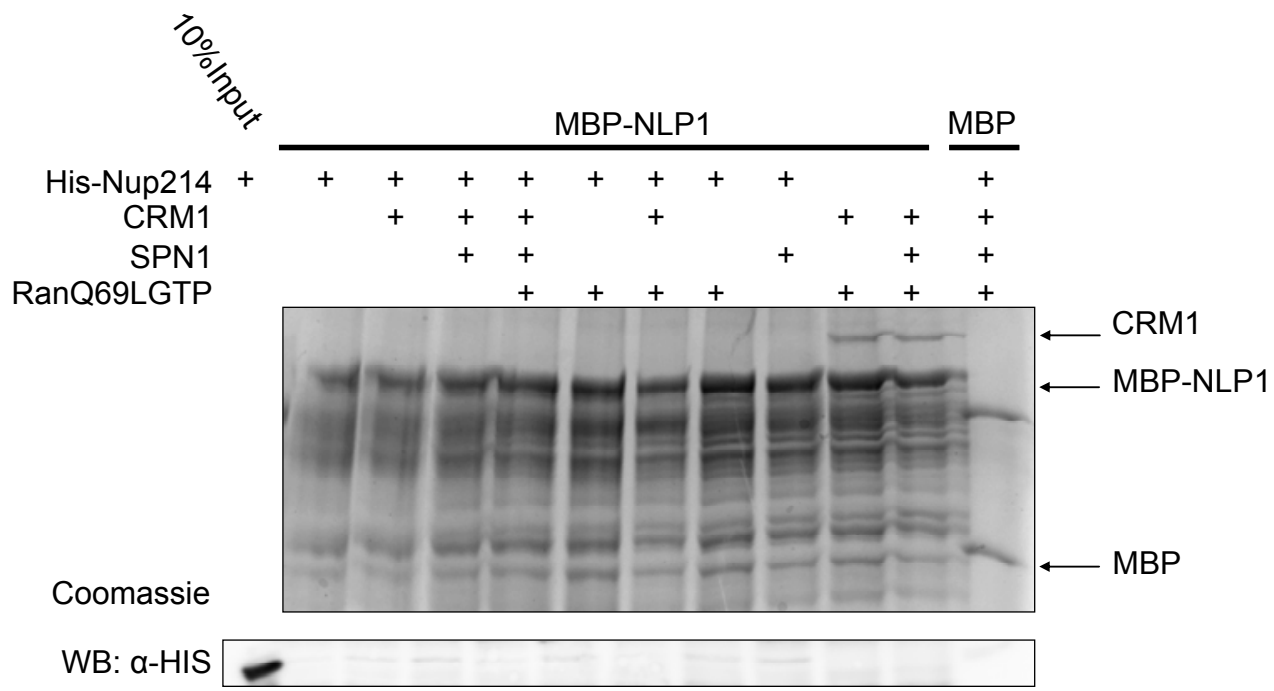

B

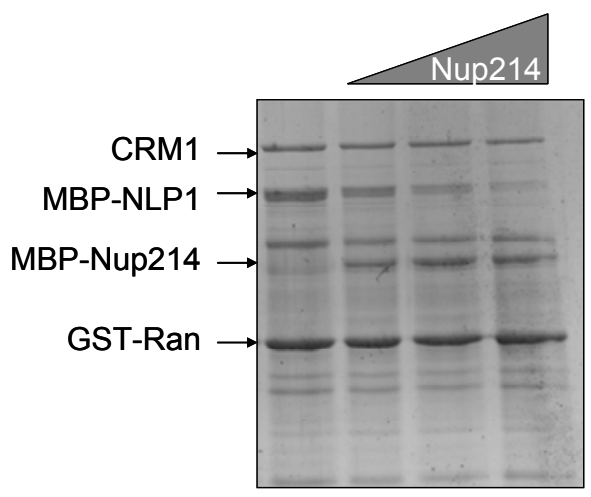

Abbildung 2.11. Nup214 und NLP1 kompetieren um die Bindung an CRM1. A) zeigt eine Bindungsstudie in der pro Ansatz $5 \mu \mathrm{g}$ MBP-NLP1 immobilisiert wurde und mit je $5 \mu \mathrm{g}$ His-CRM1, RanQ69LGTP, His-Snurportin1 (SPN1) sowie dem C-Terminus von Nup214 (His-Nup214 (AS 18592090)) in verschiedenen Kombinationen inkubiert wurde. In B) wurde GST-Ran mit GTP beladen und an GST-Agarose immobilisiert. In jeden Ansatz wurden konstante Mengen MBP-NLP1, His-CRM1, NES-Peptid und ansteigende Mengen des MBP-Nup214 C-Terminus (0, 2.5, 5, $10 \mu \mathrm{g}$ ) miteinander inkubiert. Die Analyse der gebundenen Proteine in A) und B) erfolgte durch SDS-PAGE und anschließende Coomassie-Färbung. Die Bindung von His-Nup214 in A) wurde durch Western BlotAnalyse mit einem $\alpha$-HIS-Antikörper detektiert. 


\subsubsection{Der mRNA-Exportfaktor TAP interagiert direkt mit NLP1 und konkurriert nicht mit CRM1}

Nachdem NLP1 in „Hefe Zwei Hybrid Systemen“ (Katahira et al., 1999 [103]) und verschiedenen Bindungsstudien als direkter Interaktionspartner des mRNAExportfaktor TAP beschrieben worden war (Bachi et al., 2000 [112]; Wiegand et al, 2001 [113]; Katahira et al., 2002 [114]), sollte der Effekt von TAP auf die Interaktion zwischen NLP1 und CRM1 untersucht werden. Hierzu wurden Bindungsstudien mit immobilisiertem GST-TAP (Abb. 2.12.A) oder immobilisiertem MBP-NLP1 (Abb. 2.12.B) durchgeführt. In Abbildung 2.122A ist ersichtlich, dass die Zugabe von CRM1 und GTP in An- oder Abwesenheit von NES-Peptid die Bindung von MBP-NLP1 zu TAP weder verstärkt noch vermindert (vergleiche Spur 1 mit Spur 4 und 5). Auch durch Zugabe eines 5-fachen Überschusses des trimeren CRM1-RanGTP-NES-PeptidKomplexes wird die Interaktion von NLP1 zu TAP nicht beeinflusst (vergleiche Spur 1 mit Spur 7). Ein Folgeexperiment stützt dieses Ergebnis (Abb. 2.12.B). Anstatt GSTTAP wurde MBP-NLP1 immobilisiert und mit TAP und verschiedenen Kombinationen CRM1, RanGTP und NES-Peptid inkubiert. Hier zeigte sich ebenfalls, dass die Bindung von TAP an NLP1 durch Zugabe von CRM1 und RanGTP nicht beeinflusst wird (vergleiche Spur 1 mit Spur 4, 5 und 7). Da es sich bei TAP um ein RNAbindendes Protein handelt, ist auch bei diesem Versuch nicht auszuschließen, dass die Bindung von TAP an NLP1 indirekt über RNA stattfindet, die zum Beispiel bei der Proteinaufreinigung mitisoliert wurde. Um diese Möglichkeit auszuschließen, müsste man bei einer Wiederholung des Versuchs alle Proteinkomponenten mit RNasen behandeln.

Die Ergebnisse dieses Abschnitts weisen darauf hin, dass der mRNA-Exportfaktor TAP und der Proteinexportkomplex bestehend aus CRM1, RanGTP und NES-Substrat gleichzeitig an NLP1 binden können. 
A
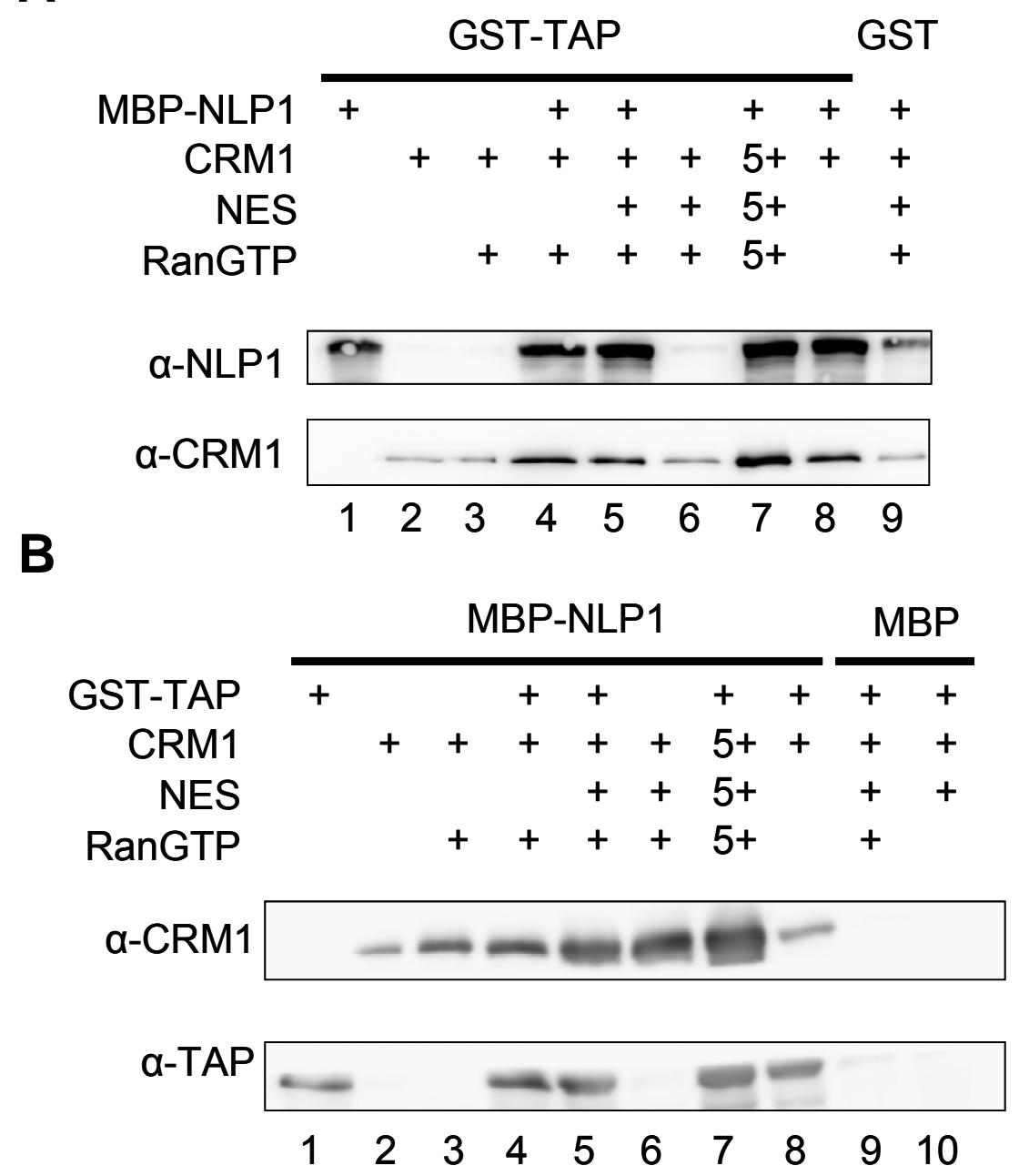

Abbildung 2.12. TAP und CRM1 können gleichzeitig an NLP1 binden. A) und B) zeigen Bindungstudien, in denen A) pro Ansatz $5 \mu \mathrm{g}$ GST-TAP (oder GST zur Kontrolle), oder B) $5 \mu \mathrm{g}$ MBPNLP1 (oder MBP zur Kontrolle), in verschiedenen Kombinationen mit MBP-NLP1, His-CRM1, RanGTP und NES-Peptid inkubiert wurden. Die gebundenen Proteine wurden mit Proteinprobenpuffer eluiert und per Western Blot-Analyse detektiert. 


\subsection{Funktionelle Charakterisierung von NLP1}

\subsection{1. Überexpression von RFP-NLP1 inhibiert den poly(A)-mRNA-Export in HeLa Zellen}

NLP1 interagiert mit den mRNA-Export-Faktoren TAP (Katahira et al., 1999 [103]) und Gle1 (Strahm et al., 1999 [97]). Ein Hinweis darauf, dass NLP1 selbst eine wichtige Rolle im mRNA-Export spielen könnte, lieferten Experimente, in denen NLP1 depletiert wurde. Die Depletion verursachte eine Inhibition des mRNA-Exports der HSP70 mRNA (Kendirgi et al., 2005 [98]). Um zu überprüfen, ob NLP1 auch beim generellen Export von mRNA eine Rolle spielt, wurden HeLa-Zellen entweder mit RFP-NLP1-Konstrukten transfiziert oder endogenes NLP1 wurde durch siRNABehandlung depletiert. Anschließend wurde die Lokalisation der mRNA mittels FISH

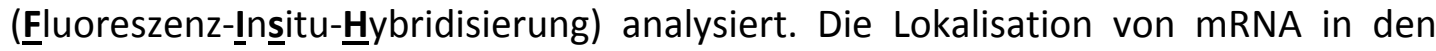
RFP-exprimierenden Kontrollzellen lässt sich als cytoplasmatisch mit Spots im Zellkern beschreiben (Abb. 2.13.A). In Zellen, die RFP-NLP1 stark überexprimieren (siehe Abb. 2.13.A, Pfeile), befindet sich die mRNA hauptsächlich im Zellkern. In Zellen, in denen die RFP-NLP1-Expression schwächer ist, ändert sich die mRNALokalisation nicht (siehe Abb. 2.13.A, Sternchen). Abbildung 2.13.B zeigt die anschließende Quantifizierung. Pro Ansatz wurde die Lokalisation von mindestens hundert Zellen analysiert und in zwei Kategorien eingeteilt: Zellen, die mehr mRNA im Zellkern als im Cytoplasma haben $((\mathrm{K}>\mathrm{C})$; Abb. 2.13.A, Pfeil) und Zellen, bei denen die mRNA „normal“ lokalisiert (Abb. 2.13.A, Sternchen). Nur 20\% der mit RFP transfizierten Kontrollzellen zeigten mehr mRNA im Kern als im Cytoplasma. Durch starke Überexpression von RFP-NLP1 steigt die Anzahl der Zellen mit K>C auf über 50\%. Die Überexpression von RFP-NLP1 inhibiert also den poly(A)mRNA-Export.

Die Depletion von NLP1 hatte hingegen keinen Einfluss auf die Lokalisation des gesamten mRNA-Pools (Daten nicht gezeigt). Da Western Blot-Analysen gezeigt haben, dass die effektivste Depletion nur etwa 90\% betrug, kann hier nicht ausgeschlossen werden, dass die verbleibenden 10\% NLP1 ausreichend für die Erfüllung eventueller Funktionen im mRNA-Transport sind. 
A

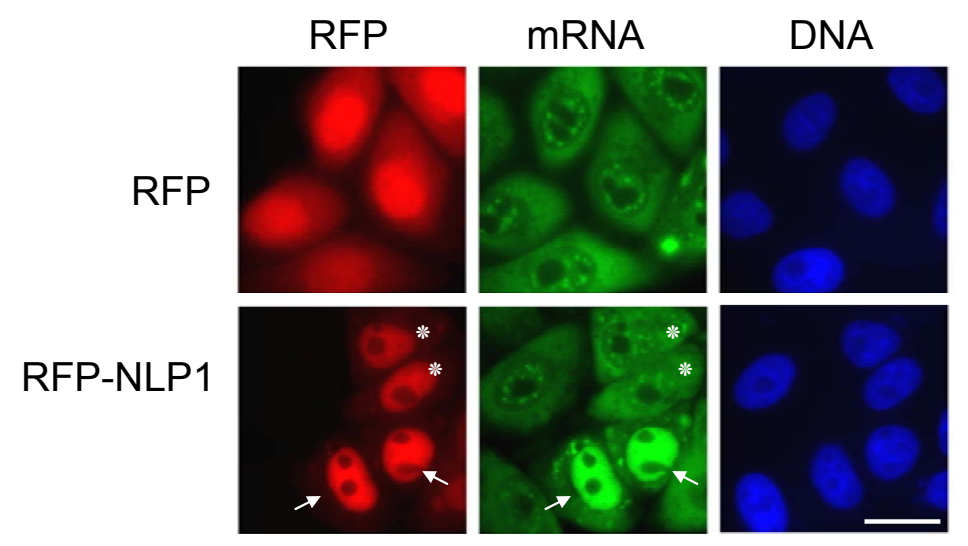

B

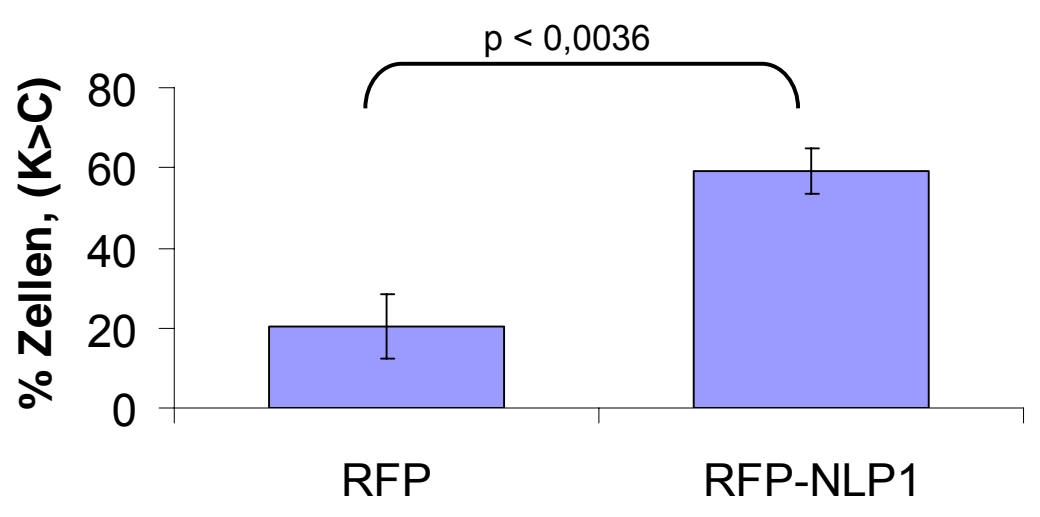

Abbildung 2.13. Starke Überexpression von RFP-NLP1 inhibiert den Export von poly(A)-mRNA in HeLa-Zellen A)HeLa-Zellen wurden entweder mit RFP oder mit RFP-NLP1 transfiziert. 48h nach der Transfektion wurde die Lokalisation der mRNA durch Fluoreszenz in situ ㅂybridisierung (FISH) mit einer Sonde gegen poly(A) sichtbar gemacht. Die mit dem Stern gekennzeichneten Zellen zeigen eher schwache RFP-NLP1-Überexpression während die mit dem Pfeil gekennzeichneten Zellen eine starke RFP-NLP1 Überexpression aufweisen (Balken, 10 $\mathrm{m}$ ). Bei der Quantifikation in B) werden nur Zellen berücksichtigt, die eine starke Überexpression von RFP bzw RFP-NLP1 zeigten. Die Lokalisation der mRNA wurde in zwei Kategorien eingeteilt: Zellen, bei denen die mRNA hauptsächlich im Kern lokalisiert $(K>C)$ oder Zellen bei denen die mRNA anders lokalisiert. Die Fehlerbalken zeigen die Standard-Abweichung dreier unabhängiger Experimente ( $n \geq 100$ Zellen). 


\subsubsection{NLP1 fördert den Export von GFP-Snurportin1}

Nachdem die biochemische Analyse von NLP1 gezeigt hatte, dass NLP1 CRM1abhängige Export-Komplexe mit Exportsubstraten (NES-Peptid und Snurportin1) bilden kann, sollte nun herausgefunden werden, welche Rolle NLP1 im Export von Proteinen in vivo spielt.

Hierzu wurde zunächst der Einfluss von NLP1 auf die Lokalisation von Snurportin1 näher untersucht. GFP-Snurportin1 wurde dazu mit RFP-NLP1 in HeLa-Zellen überexprimiert (Abb. 2.14.A, B, C) und die Lokalisation von GFP-Snurportin1 analysiert. In den mit RFP transifizierten Kontroll- sowie in den RFP-NLP1exprimierenden Zellen war GFP-Snurportin1 hauptsächlich im Cytoplasma lokalisiert (Abb. 2.14.A und B, obere Bildreihe). Auch GFP-Snurportin1 alleine zeigte eine hauptächlich cytoplasmatische Lokalisation (Daten nicht gezeigt). Um zu kontrollieren, ob diese Lokalisation auf einen starken Export oder auf einen inhibierten Import von GFP-Snurportin1 zurückzuführen ist, wurden die Zellen mit $10 \mathrm{nM}$ LeptomycinB (LMB) inkubiert. Nach LMB-Behandlung war das Reporterprotein unter allen Bedingungen im Kern lokalisiert (Daten nicht gezeigt). Die cytoplasmatische Lokalisation von NLP1 wurde also durch einen starken Export von GFP-Snurportin1 hervorgerufen. Mit der einfachen Co-Transfektion von GFPSnurportin1 und RFP-NLP1 ließ sich also keine Aussage über den Einfluss von NLP1 auf den Export von Snurportin1 machen, da das Gleichgewicht aufgrund des sehr effizienten Exports von vornherein auf Seiten cytoplasmatischer Lokalisation lag. Aus diesem Grund sollte der Export von Snurportin1 so stark eingeschränkt werden, dass die Lokalisation sich eher zu einer Gleichverteilung hin verschob. Hierzu wurden die Zellen kurz mit einer geringen LMB-Konzentration inkubiert, um die endogene CRM1-Konzentration für den Snurportin1-Export limitierend zu machen und so den Export von Snurportin1 einzuschränken. Während die Kontrollzellen unter diesen Bedingungen eine Gleichverteilung von GFP-Snurportin1 zeigten, lokalisierte das Reporterprotein in RFP-NLP1 co-transfizierten Zellen weiterhin hauptsächlich im Cytoplasma (Abb. 2.14.A und B, untere Bildreihe). Das Ergebnis dieses Experiments weist darauf hin, dass durch die Überexpression von NLP1 der 
inhibitorische Effekt, der durch die CRM1-Limitierung entsteht, zumindest zum Teil aufgehoben werden kann.

A
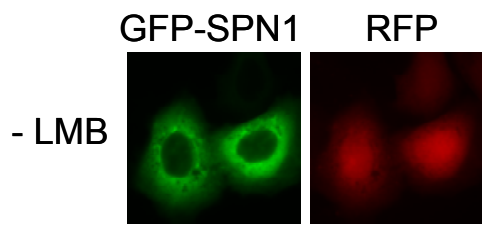

$+\mathrm{LMB}$
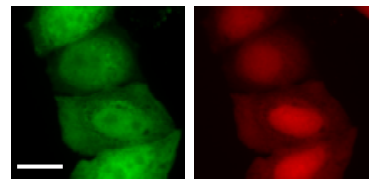

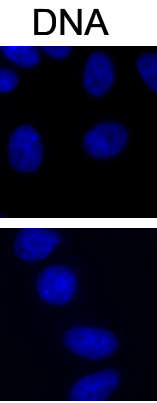

B

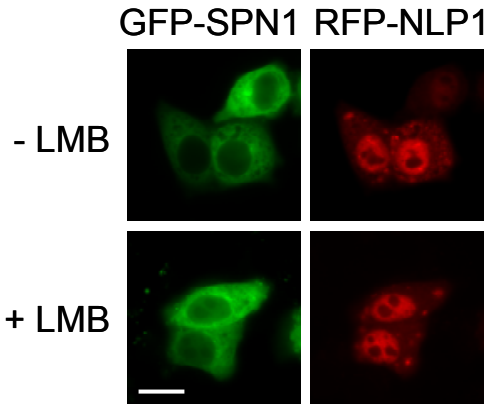

DNA

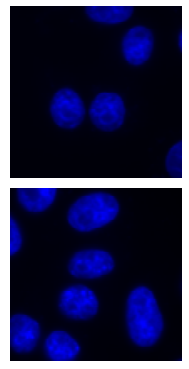

C

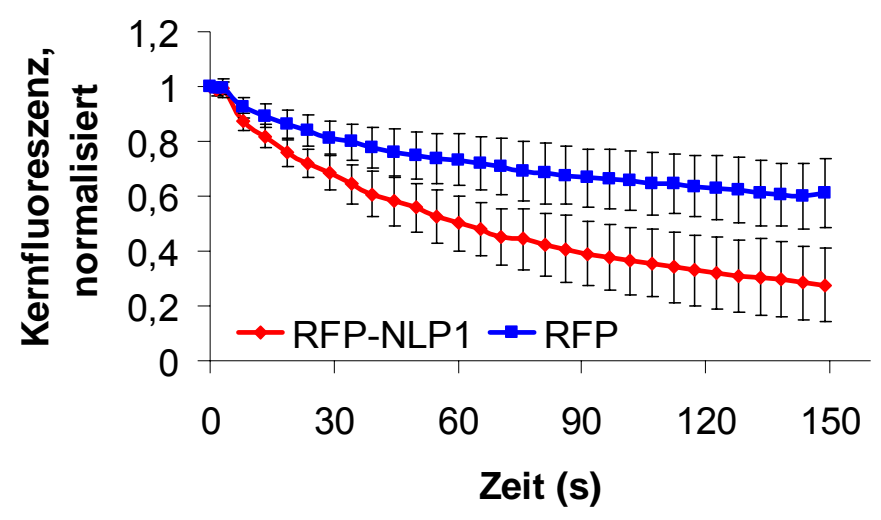

Abb. 2.14. Überexpression von RFP-NLP1 fördert den Export von GFP-Snurportin1. A) und B) HeLaZellen wurden mit GFP-Snurportin1 und RFP oder RFP-NLP1 cotransfiziert. Nach 48 Stunden wurde der Export von GFP-Snurportin1 durch LMB Zugabe $(2.5 \mathrm{M}, 30 \mathrm{~min})$ verlangsamt. Die Analyse erfolgte über Fluoreszenzmikroskopie. Grün: GFP-Snurportin1 (GFP-SPN1); rot: RFP oder RFP-NLP1 (Balken, $10 \mu \mathrm{m}$ ). C) zeigt eine FLIP-Analyse des Exports von GFP-Snurportin1, cotransfiziert mit RFP (blaue Linie) oder mit RFP-NLP1 (rote Linie). Die Fluoreszenzen vor dem ersten Bleichen wurden als 1 definiert und alle folgenden Werte darauf normalisiert. Die Fehlerbalken repräsentieren die Standardabweichung von je 15 verschiedenen Zellen.

Um sicher zu gehen, dass es sich bei diesem Effekt tatsächlich um eine Stimulierung des Exports und nicht etwa um Inhibition des Imports handelt, wurden kinetische Untersuchungen durchgeführt (Abb. 2.14.C). Hierzu wurden Zellen mit GFPSnurportin und RFP oder RFP-NLP1 co-transfiziert, dann der CRM1-abhängige Export durch LMB limitiert und der Export von GFP-Snurportin1 mittels FLIP untersucht. Die kinetischen Analysen zeigen, dass der Export von GFP-Snurportin1 in mit RFPNLP1 co-transfizierten Zellen deutlich effizienter gegenüber den Kontrollzellen ablief. Während die Kernfluoreszenz in den Kontrollzellen nach $148 \mathrm{~s}$ noch bei 0.6 lag, hatten die RFP-NLP1-exprimierenden Zellen zu diesem Zeitpunkt nur noch eine Kernfluoreszenz von 0.3. Wenn man den Verlust der Kernfluoreszenz innerhalb der 
ersten 30 Sekunden näher betrachtet, wird deutlich, dass die Kurve bei RFP-NLP1 überexprimierten Zellen viel schneller abfällt als in den Kontrollzellen.

Diese Ergebnisse weisen darauf hin, dass NLP1 den Export von GFP-Snurportin1 fördert, auch wenn dies unter normalen Bedingungen nicht sichtbar ist, da Snurportin1 im „steady state“ im Cytoplasma lokalisiert ist.

\subsubsection{Der Export von NC2ß-GFP 2 ist durch CRM1 limitiert und wird durch NLP1 gefördert}

Im vorherigen Abschnitt 2.4.2. konnte gezeigt werden, dass der CRM1-abhängige Export von Snurportin1 unter Bedingungen, in denen die CRM1-Konzentration in der Zelle durch LMB limitiert wurde, durch Überexpression von NLP1 verstärkt wird. Es stellt sich hier die Frage, ob es in Zellen Zielproteine gibt, für deren Export die natürliche CRM1-Konzentration limitierend ist. Zur Beantwortung dieser Fragestellung sollte ein Reporterprotein untersucht werden, das CRM1-abhängig aus dem Zellkern exportiert wird, aber eine eher niedrige Affinität zu CRM1 und somit zur Ausbildung eines Export-Komplexes aufweist. Als ein solches

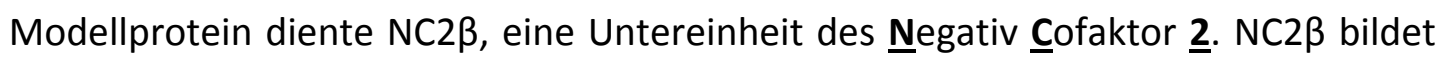
mit NC2 $\alpha$ ein Heterodimer, das mit dem an Promotoren gebundenen IATA-BoxBinding-Protein (TBP) assoziieren und somit die Initiation der Transkription durch die RNA-Polymerase 2 beeinflussen kann (Goppelt et al., 1996 [115]; Mermelstein et al., 1996, [116], Kamada et al., 2001, [117]; Inostroza et al., 1992,[118]; Meisterernst et al., 1991, [119] Chang et al., 2001 [120]; Castano et al., 2000,[121]; Willy et al., 2000,[122]; Geisberg, 2001 [123]; Lemaire et al., 2000, [124]). Das notwendige Kernexportsignal für den CRM1-abhängigen Export ist nur in der $\beta$ Untereinheit zu finden (Kahle et al., 2009 [125]). Anhand von Bindungsstudien mit rekombinanten Proteinen konnte die direkte Interaktion von NC2 $\beta$ mit CRM1 in Anwesenheit von RanGTP nachwiesen werden. Allerdings war diese Bindung als eher schwach einzustufen. 
Um herauszufinden, ob die CRM1-Konzentration in der Zelle für den Export von $\mathrm{NC2} \beta$ tatsächlich limiterend ist, wurden NC2ß-GFP 2 und HA-CRM1-Konstrukte cotransfiziert. Nach 48 Stunden zeigte sich ein deutlicher Effekt bei den CRM1-cotransfizierten Zellen (Abbildung 2.15. A und B): Während circa 70\% der Kontrollzellen mehr NC2 $\beta$ im Kern als im Rest der Zelle hatten $(K>C)$, zeigten nach Co-Transfektion mit CRM1-HA nur noch circa 15\% der Zellen diese Verteilung. Der Rest der Zellen wies eher eine cytoplasmatische oder eine Gleichverteilung von NC2ß-GFP 2 auf. Um zu überprüfen, ob dieser Effekt wirklich auf die erhöhte Menge von CRM1 in den Zellen und nicht etwa auf eine defekte Kernmembran oder beschädigte Kernporen zurückzuführen ist, wurden die Zellen mit LMB behandelt. Sowohl bei den Kontroll- als auch bei den mit CRM1-exprimierenden Zellen zeigte sich eine deutliche Inhibition des Exports von NC2 $\beta$ durch LMB. Bei mindestens $90 \%$ der untersuchten Zellen lokalisierte NC2 $\beta$ im Zellkern. Es kann also davon ausgegangen werden, dass der durch Überexpression von CRM1 hervorgerufene Effekt tatsächlich in CRM1-vermitteltem Export begründet liegt und somit die natürliche CRM1-Konzentration für den Export von NC2 $\beta$ in HeLa-Zellen limitierend ist.

A

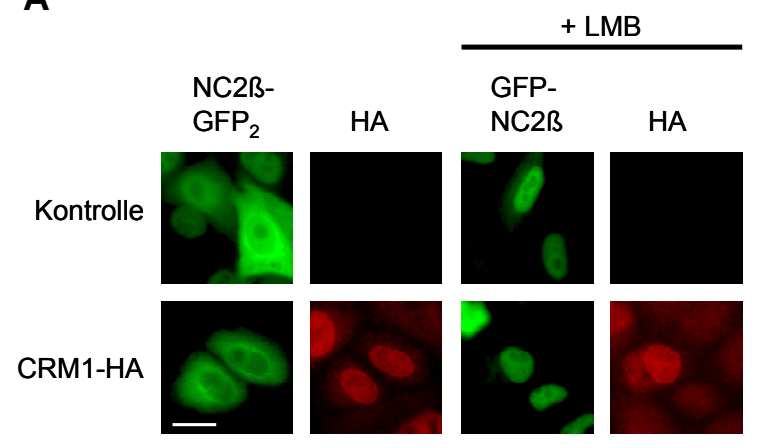

B

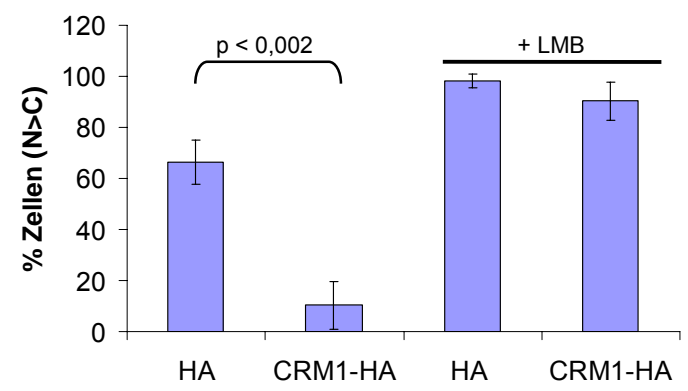

Abbildung 2.15 (A, B) Der Kernexport von NC2ß-GFP 2 wird durch Co-Transfektion von CRM1 verstärkt. A) HeLa-Zellen wurden mit einem NC2ß-GFP 2 -Konstrukt und CRM1-HA dem leeren HAVektor zur Kontrolle, cotransfiziert. Nach $48 \mathrm{~h}$ erfolgte die Analyse durch Fluoreszenzmikroskopie (Balken, $10 \mu \mathrm{m}$ ). In B) wurde die Lokalisation von NC2ß-GFP 2 in cotransfizierten Zellen durch Auszählen analysiert. Der Graph gibt in Prozent an, wieviele der analysierten Zellen eine eindeutige Kernlokalisation $(\mathrm{N}>\mathrm{C}$ ) von NC2ß-GFP 2 zeigen. Pro Transfektionsansatz wurden mehr als 100 Zellen analysiert. Zur Kontrolle wurden die Zellen für 2,5 h mit $5 \mathrm{nM}$ LMB behandelt. Die Fehlerbalken geben die Standardabweichungen von drei unabhängigen Experimenten an. Die p-Werte wurde mit Hilfe des Student's T-Tests ermittelt.

Um den Einfluss von NLP1 auf den Export von NC2 $\beta$ zu analysieren, wurde NC2ß$\mathrm{GFP}_{2}$ mit unterschiedlichen NLP1-Konstrukten (NLP1-HA, RFP-NLP1 und NLP1-RFP) 
co-transfiziert und die Lokalisation von NC2ß-GFP 2 durch Auszählen (Abb. S4A, Abb. 2.15.C und D) untersucht und kinetische Studien FLIP (Abb. 2.15.E) durchgeführt. Die Überexpression aller drei NLP1-Konstrukte hatte einen positiven Einfluss auf den CRM1-abhängigen Export von NC2 $\beta$. Während in den meisten Kontrollzellen (70\%), die mit RFP oder HA co-transfiziert wurden, NC2 $\beta$ eher im Kern zu finden war, hatte die Co-Transfektion mit den NLP1-Konstrukten einen ähnlich deutlichen Effekt wie die Überexpression von CRM1 in Abbildung 2.15.A und B: Überexpression von NLP1-HA reduzierte die Anzahl der Zellen mit N>K von 70 auf circa 35\% (Abb. S4A). Dieser Effekt konnte durch die Co-Transfektion von NLP1-RFP oder RFP-NLP1 noch deutlich verstärkt werden. Hier sank die Anzahl der Zellen mit N>K sogar auf 15-20\% (Abbildung 2.15.C und D). In allen Fällen konnte durch Inhibition des CRM1vermittelten Exports durch LMB gezeigt werden, dass sowohl Kernmembran, als auch Kernporen intakt waren. Nach LMB-Behandlung lokalisierte NC2 $\beta$ sowohl in NLP1-HA als auch in RFP-NLP1, NLP1-RFP und in den Kontrollzellen in circa $90 \%$ der Fälle eindeutig im Kern.

Die NLP1-abhängige Stimulation des Exports lässt sich nicht nur bei NC2 $\beta$ sondern auch bei dem in Abschnitt 1 verwendeten artifiziellen Reporterkonstrukt NES-GFP2cNLS beobachten (Abb. S4B). Auch hier zeigte sich nach Überexpression von NLP1$\mathrm{HA}$ eine signifikante Verminderung der Zellen mit N>C um 30\%.

Die Überexpression von NLP1-Konstrukten beeinflusst folglich sowohl die Lokalisation von NC2ß-GFP 2 als auch die Lokalisation eines artifiziellen Import/Export-Substrats. Um sicher zu gehen, dass es sich hierbei tatsächlich um verstärkten Export der Substrate handelt, wurden kinetische Studien mittels FLIP durchgeführt. In Abbildung 2.15.E wurde durch FLIP-Analysen der Export von NC2ß$\mathrm{GFP}_{2}$ nach Überexpression von RFP oder RFP-NLP1 genauer analysiert. Während Zellen, die mit RFP co-transfiziert wurden, nach $148 \mathrm{~s}$ noch eine Kernfluoreszenz von 0.65 zeigten, wurde bei RFP-NLP1 exprimierenden Zellen nur eine Kernfluoreszenz von 0.4 gemessen. Wenn man sich den Verlauf beider Kurven in den ersten 50 Sekunden anschaut, kann man feststellen dass die rote Kurve (RFPNLP1) viel steiler als die blaue Kurve (RFP) abfällt. 
Die Ergebnisse der vorgestellten Untersuchungen lassen darauf schließen, dass die zelluläre CRM1-Konzentration für den Export von NC2 $\beta$ limitierend ist und dass die Überexpression von CRM1 oder NLP1 den Export von NC2 $\beta$ verstärken kann.

C

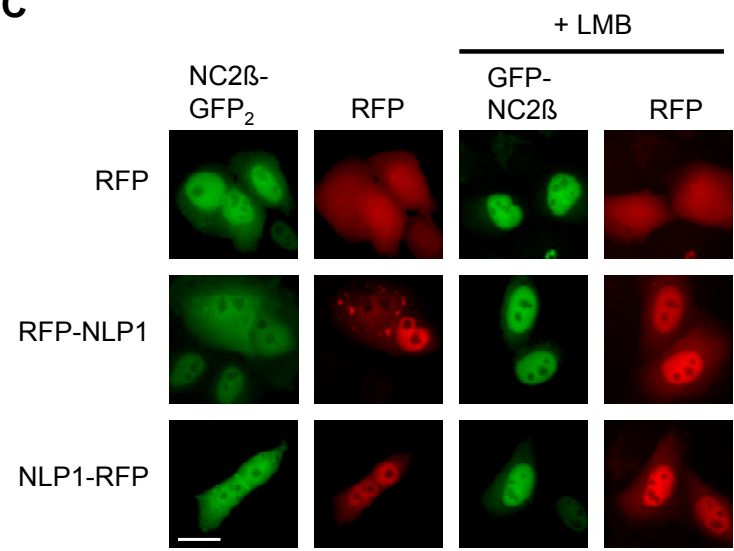

D

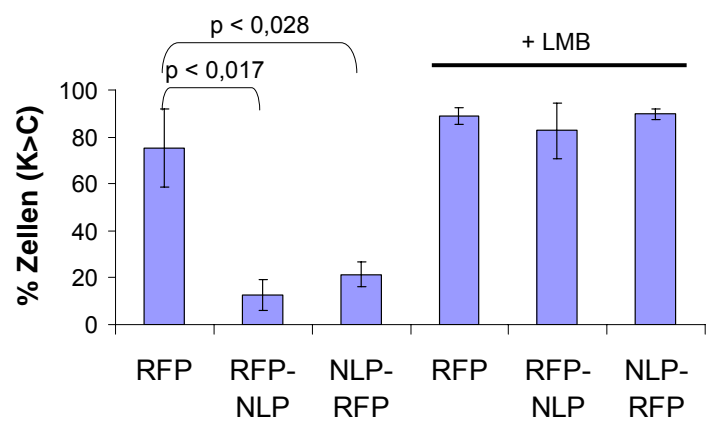

E

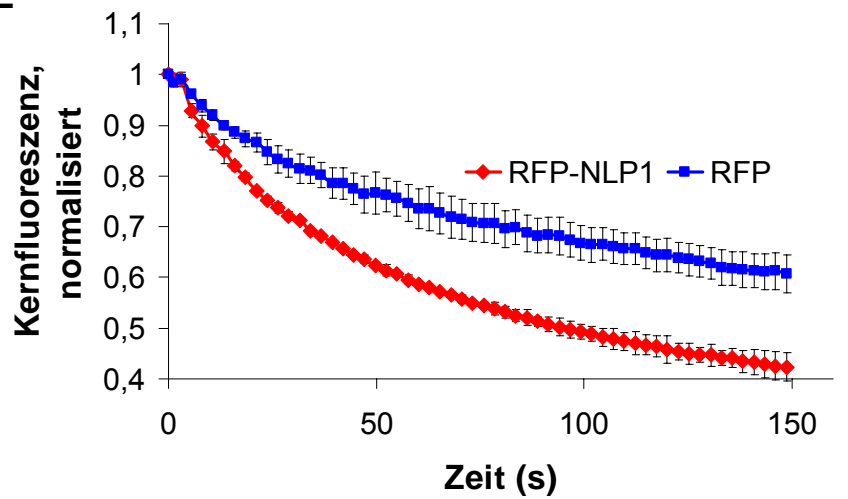

Abbildung 2.15. (C, D, E) Der Kernexport von NC2ß-GFP ${ }_{2}$ wird durch Co-Transfektion von NLP1 verstärkt. HeLa-Zellen wurden mit NC2ß-GFP ${ }_{2}$ und entweder RFP (Kontrolle), NLP1-RFP oder RFPNLP1 cotransfiziert. Die Analyse erfolgte durch Fluoreszenzmikroskopie C) und Auszählen D) (Balken, $10 \mu \mathrm{m})$. In D) wurde die Lokalisation von NC2B-GFP in cotransfizierten Zellen analysiert. Der Graph gibt in Prozent an, wie viele der analysierten Zellen eine eindeutige Kernlokalisation $(\mathrm{N}>\mathrm{C})$ von $\mathrm{NC2}$ $\mathrm{GFP}_{2}$ zeigen. Pro Transfektionsansatz wurden mehr als 100 Zellen analysiert. Zur Kontrolle wurden die Zellen für 2,5 h mit $5 \mathrm{nM}$ LMB behandelt. Die Fehlerbalken geben die Standardabweichungen von drei unabhängigen Experimenten an. Die p-Werte wurden durch den Student's T-Tests ermittelt. E) zeigt eine FLIP-Analyse von NC2ß-GFP ${ }_{2}$ cotransfiziert mit RFP (blaue Linie) oder RFP-NLP1 (rote Linie). Die Fluoreszenzen vor dem ersten Bleichen wurden als 1 definiert und alle folgenden Werte darauf normalisiert. Die Fehlerbalken repräsentieren die Standardabweichung von zwei unabhängigen Experimenten, wobei in einem Experiment pro Bedingung je 10-15 Zellen analysiert wurden. 


\subsubsection{NLP1 erhöht den Export von GFP-NFAT in vitro}

Abschnitt 2.2.3. dieser Arbeit zeigte mittels FLIP und FRAP-Analysen deutlich, dass NLP1 ein mobiles Protein ist, dass den Kern auch verlassen kann. In diesem Teil der Arbeit soll nun in vitro untersucht werden, ob eine Stimulation des Exports eines Reporterproteins durch Zugabe von rekombinantem NLP1 zu Digitoninpermeabilierten Zellen erreicht werden kann.

Ein gutes Modellprotein zur Untersuchung der Mechanismen von Kern-Export und Import ist das Protein nuclear factor of activated t-Cells (NFAT). NFAT ist ein Transkriptionsfaktor, der zwischen Kern und Cytoplasma hin- und her transportiert wird. Während der Import über den klassischen $\alpha / \beta$-Importweg stattfindet (Beals et al., 1997 [126, 127]), wird der Export durch CRM1 vermittelt (Kehlenbach et al.,1998 [128]). Import und Export von NFAT hängen von seinem Phosphorylierungsstatus ab. Unter normalen Bedingungen liegt NFAT phosphoryliert im Cytoplasma vor. Durch Zugabe von Ionomycin wird in Zellen eine Calciumausschüttung hervorgerufen, wodurch es zur Induktion der Dephosphorylierung von NFAT und zum Import in den Zellkern kommt. Wird Ionomycin wieder aus dem Medium entfernt, wird das Protein wieder phosphoryliert und NFAT wird aus dem Zellkern exportiert (Shibasaki et al, 1996 [129]). Durch Zugabe oder Entfernung von Ionomycin sind Import und Export von NFAT also induzierbar, wodurch es in vitro ein gutes System für Untersuchungen zum Einfluss bestimmter Proteine auf den Kerntransport bietet.

Um den Einfluss von NLP1 auf den Export von NFAT zu untersuchen, wurde eine mit GFP-NFAT stabil-transfizierte HeLa-Zelllinie genutzt (Kehlenbach et al., 1998 [128]). Zunächst wurde der Import von GFP-NFAT in den Zellkern induziert, dann die Zellmembran mit Digitonin permeabilisiert und anschließend lösliche cytosolische Faktoren durch Waschen entfernt. Für die Exportreaktion wurde dann eine definierte Zusammensetzung rekombinanter Proteine zu den permeabilisierten Zellen gegeben. Zur Analyse erfolgte die Messung der nach Exportreaktion im Zellkern verbliebenen Restfluoreszenz per Durchflusscytometrie.

In Abbildung 2.16.A wurden die Kerne mit unterschiedlichen Mischungen aus rekombinantem CRM1, MBP-NLP1, Ran und einem ATP-regenerierendem System 
für 0, 12 oder 20 Minuten inkubiert. Wurden den Kernen weder Exportfaktoren noch Energie in Form des ATP-regeneriendem Systems zugegeben, so fand kein Export von GFP-NFAT statt (siehe Abb. 2.16.A blaue Linie), die Kernfluoreszenz blieb nahezu bei $100 \%$ (blaue Linie). Durch Inkubation mit dem ATP-regenerierendem System, CRM1 und Ran fiel die Kernfluoreszenz innerhalb von 20 Minuten von 100 auf $60 \%$ ab (gelbe Linie). Dieser Exporteffekt kann durch Zugabe von NLP1 noch um weitere $20 \%$ auf $40 \%$ Restkernfluoreszenz gesteigert werden (rote Linie). Um die Spezifität des beobachteten Effektes zu bestätigen und auszuschließen dass er auf Beschädigungen der Kerne beruht, wurden die Zellkerne mit CRM1, Ran und NLP1 aber ohne ATP-regenerierendes System inkubiert. Auch nach 20 Minuten Exportreaktion fiel die Kernfluoreszenz in diesem Ansatz nicht ab (Abb. 2.16.A, grüne Linie).

Um auszuschließen, dass der NLP1-Effekt durch den MBP-Anhang vermittelt wurde, wurde der Versuch aus Abbildung 2.16.A wiederholt und ein Ansatz mit MBP anstatt MBP-NLP1 inkubiert (Abbildung 2.16.B, grüne Linie). Das MBP-Protein alleine konnte den CRM1-abhängigen Export nicht (gelbe Linie), das Fusionsprotein MBPNLP1 konnte diesen hingegen doch verstärken (rote Linie). Somit ist davon auszugehen, dass es sich hierbei um einen durch NLP1 hervorgerufenen Effekt handelt.

Eine weitere Spezifitätskontrolle ist in Abbildung 2.16.B dargestellt. Hier wurden die Kerne vor und während der Exportreaktion mit WGA präinkubiert. Ohne Präinkubation fand ein normaler, durch CRM1 und Ran vermittelter Export von GFPNFAT statt (gelber Balken), der durch Zugabe von NLP1 verstärkt werden konnte (roter Balken). Die Präinkubation mit WGA als Inhibitor des Kerrntransports, führte zu einer absoluten Inhibition des Exports von GFP-NFAT (grüner Balken). Sowohl die ATP-Kontrolle aus 2.16.A, als auch die WGA-Kontrolle aus 2.16.B zeigten eindeutig, dass Kernporen und Kernhülle intakt waren.

Rekombinantes NLP1 kann also den Export von GFP-NFAT in permeabilisierten Zellen fördern. 
A

$\rightarrow$ Puffer
$\rightarrow$ ATP+Ran+CRM1+NLP1

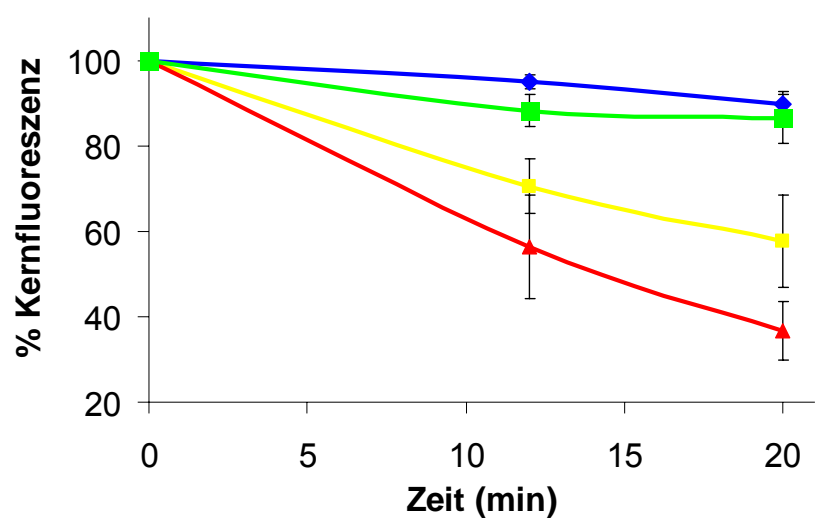

B

$\rightarrow$ Puffer
$\rightarrow$ Ran+CRM1+MBP-NLP1 - Ran+CRM1
$\rightarrow$ Ran+CRM1+MBP

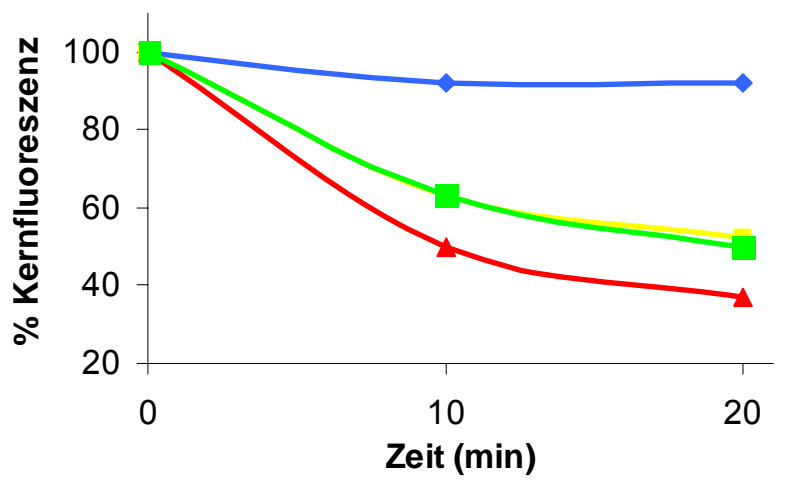

C

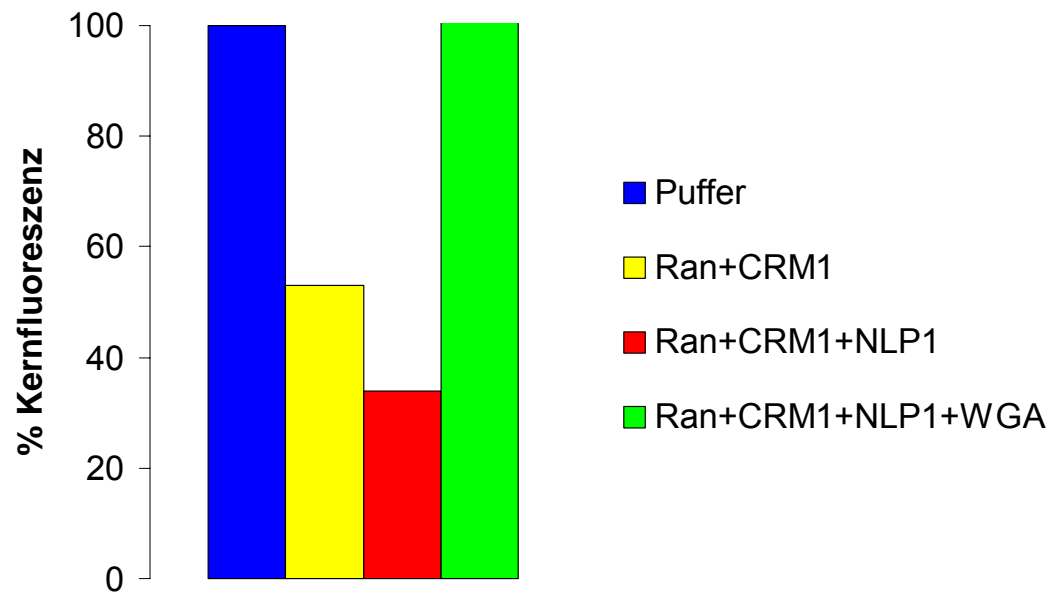

Abbildung 2.16. in vitro Exportassay von GFP-NFAT. Der Import von GFP-NFAT wurde für 30 Minuten mit lonomycin induziert, dann die Zellen mit Digitonin permeabilisiert und mit rekombinantem His-CRM1, Ran, MBP-NLP1 oder MBP in An-, oder Abwesenheit eines ATPregenerierenden Systems (ATP) bei $30^{\circ} \mathrm{C}$ inkubiert und nach 0,10 (12 in A) oder 20 min Proben entnommen $(\mathbf{A}+\mathbf{B})$. In $\mathbf{C})$ wurde ein Teil der Zellen mit $2 \mathrm{mg} / \mathrm{ml}$ WGA präinkubiert und auch während der Exportreaktion beinhaltete dieser Ansatz $2 \mathrm{mg} / \mathrm{ml}$ WGA (grüner Balken). Die Exportreaktion fand hier für $25 \mathrm{~min}$ bei $30^{\circ} \mathrm{C}$ statt. Die Analyse in A), B) und C) fand mittels Durchflusscytometrie statt. Die Fehlerbalken in A) geben die Standardabweichungen aus drei unabhängigen Experimenten an. 


\subsubsection{Die Depletion von NLP1 inhibiert den Export von NC2 $\beta$}

Nachdem der Export-fördernde Effekt von NC2 $\beta$ durch Co-Transfektion von NLP1 gezeigt konnte, sollte nun überprüft werden, welchen Einfluss die Depletion von NLP1 hat. Zuerst wurde getestet, unter welchen Bedingungen die beste Reduktion von NLP1 erreicht werden kann. Hierzu wurden HeLa-Zellen mit siRNA gegen NLP1 oder dem Transfektionsreagenz alleine (Mock) transfiziert und per Western BlotAnalyse die Menge an NLP1 zu verschiedenen Zeitpunkten analysiert. Es erwies sich, dass die effizienteste Depletion von NLP1 nach 48 Stunden siRNA-Transfektion erreicht werden konnte (Daten nicht gezeigt).

Als nächstes wurde der Einfluss der NLP1-Depletion auf verschiedene Proteine, die teilweise im Kerntransport beteiligt sind, getestet. Wie man in Abbildung $2.17 \mathrm{~A}$ und B sieht, wird sowohl die Konzentration der hier überprüften Proteine (Ran, Lamin A/C, CRM1, RanGAP1, Nup214, RanBP1 und RanBP3) (Abb. 17A) als auch die Lokalisation (von Ran, CRM1, RanBP2 und Nup214) (Abb. 17B) nicht durch NLP1Depletion verändert. Bei der Analyse stellte allerdings die Unterscheidung zwischen NLP1-depletierten und mit siRNA untransfizierten Zellen ein Problem dar, da kein Antikörper zu Detektion von endogenem NLP1 in der Immunfluoreszenz zur Verfügung stand. Die erfolgreiche Depletion von NLP1 konnte somit nur per Western-Blot-Analyse eines parallel durchgeführten Transfektionsansatzes überprüft werden.

Nach 12 Stunden siRNA-Transfektion wurde NC2ß-GFP 2 transfiziert und 40 Stunden später wurde die Lokalisation von NC2ß-GFP 2 mikroskopisch analysiert. Auszählungen zeigten, dass die Depletion von NLP1 keinen Einfluss auf „Steady state-Lokalisation" von NC2ß-GFP 2 hatte. Sowohl in Mock- als auch siRNAbehandelten Zellen war in $60 \%$ aller Fälle NC2ß-GFP 2 hauptsächlich im Kern lokalisiert ist(Abb. S5).

Im Gegensatz zu den mikroskopischen Auszählungen konnte in FLIP-Analysen jedoch gezeigt werden, dass NLP1-Depletion einen zwar geringen, aber signifikanten Einfluss auf das Exportverhalten von NC2 $\beta$ hatte (Abb.2.17.C). Während die Kernfluoreszenz der Kontroll-Zellen (Mock) nach ca. 98 s bei 0.6 lag (rote Linie), war sie bei NLP1-depletierten Zellen noch bei 0.7 (blaue Linie). Der 
Kernexport von NC2ß-GFP 2 wird also durch die Depletion von NLP1 verlangsamt. Da nicht ausgeschlossen werden kann, dass auch unvollständig oder gar nicht depletierte Zellen mit NLP1 in der Auswertung enthalten waren, könnte vermutet werden, dass der tatsächliche Effekt noch stärker ist, als hier gezeigt werden konnte.

A

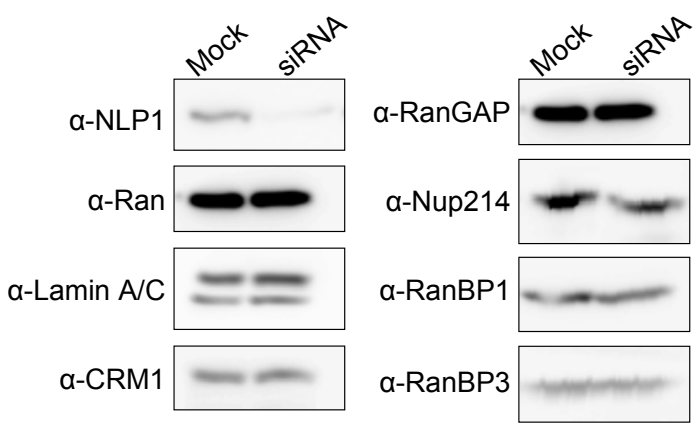

B
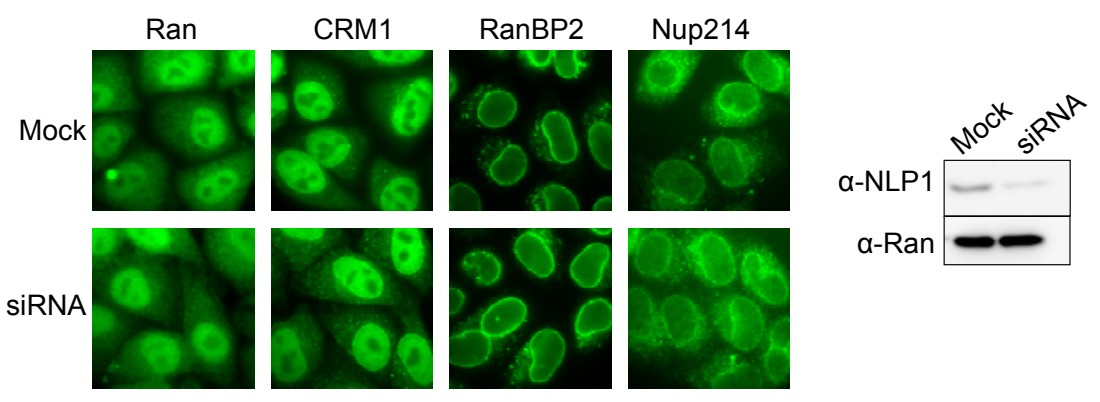

C

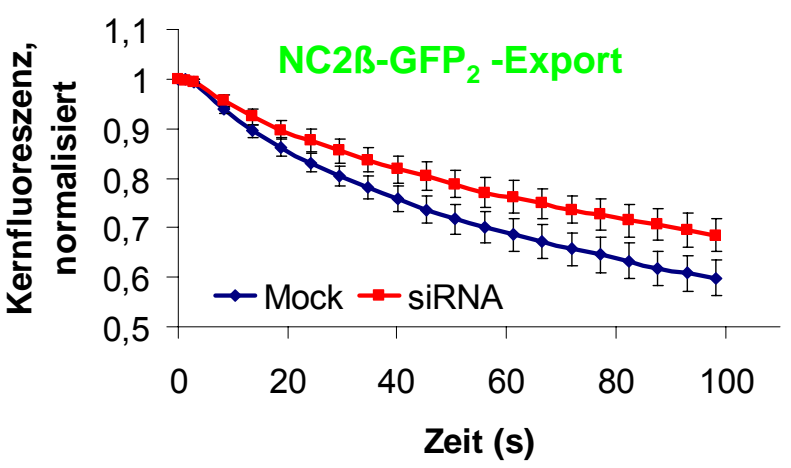

Abbildung 2.17. Spezifische Reduktion von NLP1 mittels RNAi verlangsamt den NC2ß-GFP-Export. A) HeLa-Zellen wurden mit einer spezifischen siRNA gegen NLP1 für 48 Stunden behandelt. Mock und siRNA behandeltes Zelllysat wurde mittels spezifischer Antikörper gegen NLP1, Ran. Lamin, CRM1, RanBP2, Nup214, RanBP1 und RanBP3 miteinander verglichen. B) Mock und siRNA-behandelte Zellen wurden in der Immunfluoreszenz parallel mit Antikörpern gegen Ran, CRM1, RanBP2 und Nup214 miteinander verglichen. Die Depletion von NLP1 wurde im Western Blot überprüft. C) Nach 24 siRNABehandlung werden die Zellen mit NC2ß-GFP ${ }_{2}$ transfiziert. 24h nach der Transfektion wurden FLIPAnalysen durchgeführt. Die Fehlerbalken repräsentieren die Standardabweichung von vier unabhängigen Experimenten, wobei in einem Experiment pro Bedingung 8-10 Zellen analysiert wurden. 


\subsubsection{Die Depletion von NLP1 inhibiert den Export von GFP-NFAT}

Zur Überprüfung des Einflusses der Depletion von NLP1 auf Import und Export von GFP-NFAT wurde eine etablierte, mit GFP-NFAT stabil transfizierte HeLa-Zelllinie verwendet (Hutten et al., 2006 [51]). Nach 48 Stunden siRNA-Behandlung wurde der Import von GFP-NFAT sowohl in Mock- als auch in siRNA-behandelten Zellen durch Zugabe von Ionomycin zum Medium induziert. Nach 20 Minuten wurde das lonomycin weggewaschen und die Zellen entweder direkt $(0 \mathrm{~h})$ oder nach einer Stunde (1 h) fixiert (Abbildung 2.18.A). Da zum Zeitpunkt $0 \mathrm{~h}$ GFP-NFAT sowohl in den Mock- als auch in den siRNA-behandelten Zellen komplett im Zellkern war, kann davon ausgegangen werden, dass die Depletion von NLP1 wahrscheinlich keinen Einfluss auf den Import von NFAT hat. Der Export von GFP-NFAT war allerdings signifikant beeinflusst. Hier konnte eindeutig festggestellt werden, dass nach NLP1Depletion ca. 30 \% mehr Zellen mit einer N>C-Verteilung von GFP-NFAT vorkamen, als in den Mock-behandelten Zellen (Abb. 2.18.B).

Um den Effekt des verminderten Exports bei NLP1-Depletion genauer zu untersuchen, wurden Export-Kinetiken mittels „Life-Cell-Imaging“ gemessen (Abb. 2.18.C). Hierzu wurden HeLa-Zellen zuerst für 24 Stunden Mock- oder mit NLP1siRNA behandelt und dann transient mit GFP-NFAT transfiziert (24 h). Um den Export zu untersuchen, musste GFP-NFAT zuerst durch Zugabe von Ionomycin in den Zellkern importiert werden. Durch Auswaschen des lonomycins und anschließende Inkubation der Zellen bei $37^{\circ} \mathrm{C}$ erfolgte der Export von GFP-NFAT. Zur Analyse wurde alle 30 Sekunden ein Bild gemacht und das Verhältnis zwischen Kernfluoreszenz zur Gesamtfluoreszenz der Zelle bestimmt. Nach ca. 300 s wird deutlich, dass in Mock-Zellen das Verhältnis zwischen Kernfluoreszenz und Gesamtfluoreszenz schneller abnahm als bei siRNA-behandelten Zellen.

Zusammenfassend zeigten die Experimente in Abschnitt 2.4.5. und 2.4.6. eindeutig, dass die Depletion von NLP1 eine Reduktion des Exports sowohl von NC2 $\beta-G F P_{2}$ als auch GFP-NFAT verursacht. 
A

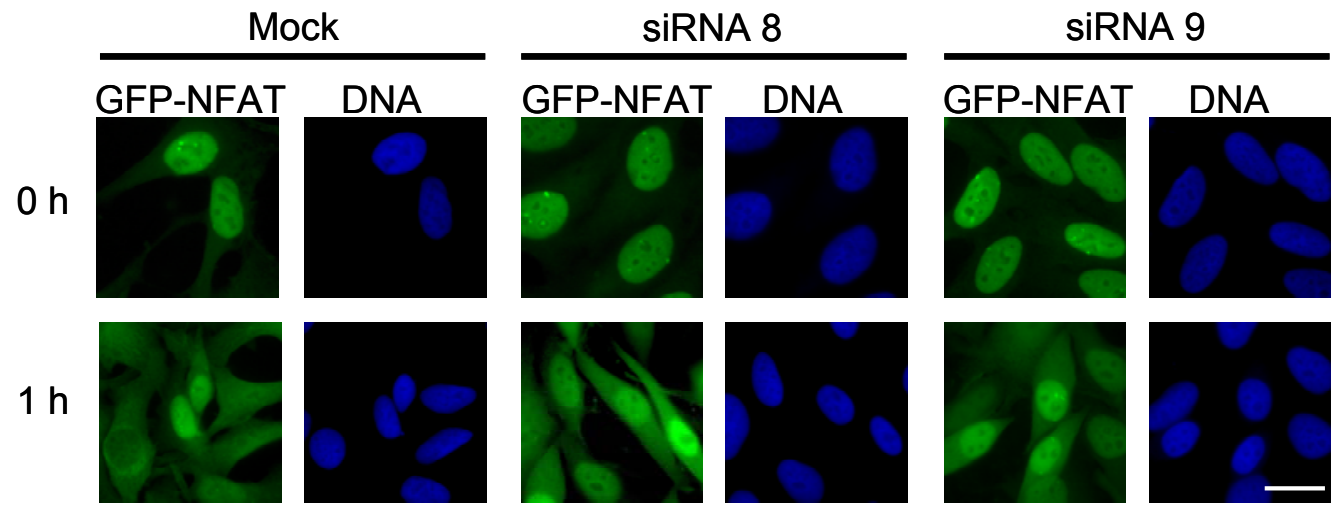

B

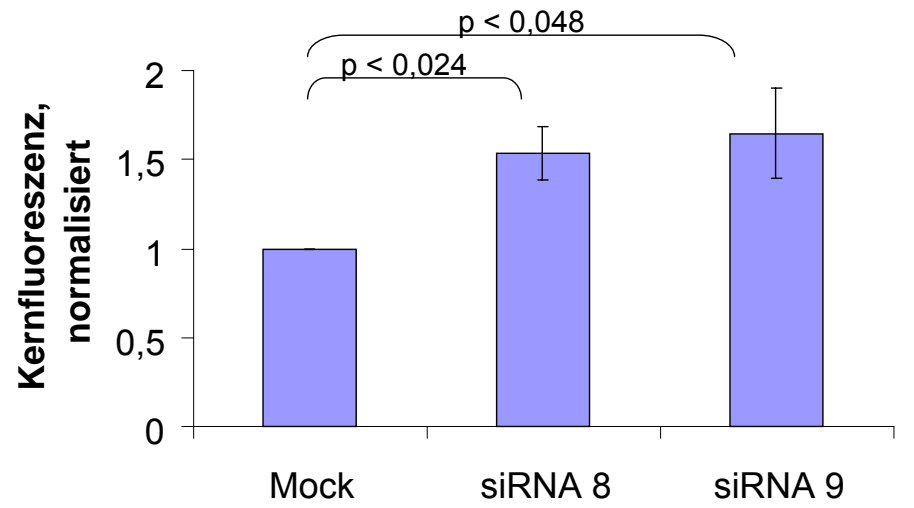

C

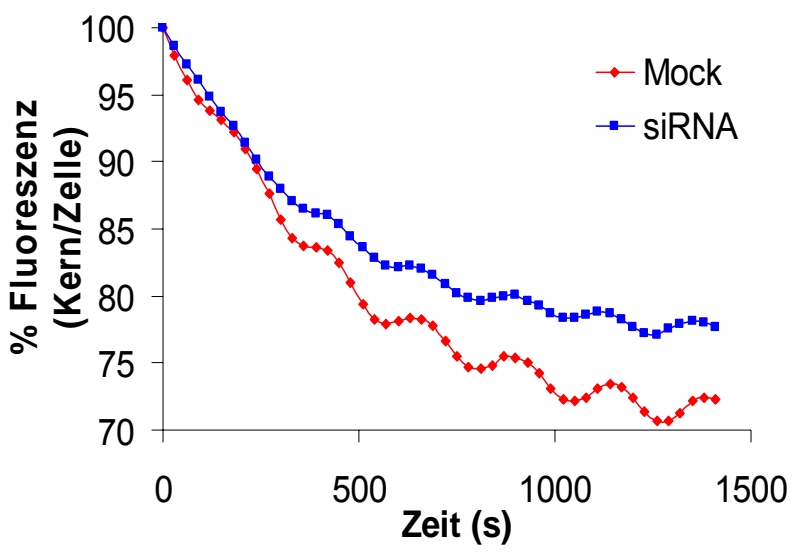

Abb. 2.18 Depletion von NLP1 inhibiert den Export von GFP-NFAT Mock- oder siRNA behandelte HeLaNFAT-Zellen wurden einem Import/Export-Zyklus unterzogen. Nach einer Stunde Export wurden die Zellen durch Fluoreszenzmikroskopie A) und Auszählen B) analysiert. Bei der Auszählung B) wurde die Lokalisation von GFP-NFAT ermittelt. Der Graph gibt an, wie viele der analysierten Zellen eine eindeutige Kernlokalisation $(\mathrm{N}>\mathrm{C}$ ) von GFP-NFAT zeigen. Da die Mock-Werte in unterschiedlichen Experimenten stark variierten, wurden sie auf 1 normalisiert um eine bessere Vergleichbarkeit zu erreichen. Pro Ansatz wurden mehr als 100 Zellen analysiert. Die Fehlerbalken geben die Standardabweichungen von drei unabhängigen Experimenten an. Die statistische Signifikanz wurde mit Hilfe des Student's T-Tests ermittelt. C) Mock- oder NLP1-depletierte Zellen wurden mit GFP-NFAT transient transfiziert. Nachdem GFP-NFAT durch lonomycin-Behandlung in den Kern importiert worden war, wurde der Export durch Wegwaschen des lonomycins induziert und der Kernexport über 1440 s gemessen. Der Graph gibt das Fluorezenzverhältins Kern/Zelle in Prozent an. Er zeigt ein Mittel aus drei unabhängigen Versuchen. 


\section{DISKUSSION}

\subsection{Die zelluläre CRM1-Konzentration ist für den Protein-Export limitierend}

Die meisten aus dem Kern zu transportierenden Proteine werden mit Hilfe des Hauptexportfaktors für Proteine CRM1 aus dem Zellkern exportiert. Viele Exportsubstrate weisen eine eher geringe Affinität zu CRM1 auf (Kutay et al., 2005 [41]). In der Literatur sind bisher zwei Proteine beschrieben, die als Proteinexportunterstützende Faktoren wirken (Nup98 (Oka et al., 2010 [46]) und RanBP3 (Lindsay et al., 2001 [44]; Englmeier et al., 2001 [45]; Nemergut et al.,2002 [43]). Ein Ziel dieser Arbeit war es herauszufinden, warum unterstützende Faktoren für den CRM1-vermittelten Proteinexport in der Zelle vorhanden sind.

Eine Vermutung für die Notwendigkeit von Proteinexport-unterstützenden Faktoren in der Zelle war, dass die endogene CRM1-Konzentration für den Export von Proteinen limitierend ist. Um diese Hypothese zu überprüfen, wurden zwei verschiedene Reporterproteine (NES-GFP $2-\mathrm{NLS}$ und NC2ß-GFP ${ }_{2}$ ) mit CRM1-HA cotransfiziert (Abb. 2.1.A und B und Abb. 2.15.A und B). In der Tat zeigte sich, dass die Überexpression von CRM1 die Lokalisation beider Reporterproteine signifikant beeinflusste. Sie führte bei beiden Proteinen zu einer Verlagerung der Lokalisation ins Cytoplasma. Dieses Ergebnis zeigt eindeutig, dass die Erhöhung der CRM1Konzentration den Export der Reporterproteine beschleunigt und somit die endogene CRM1-Konzentration limitierend für den Export ist. Hier stellt sich nun die Frage, welchen Vorteil die Zelle aus einer Limitierung der Konzentration ihres Hauptproteinexporfaktors ziehen könnte.

Unsere Hypothese ist, dass die Zelle so den Export von Proteinen, die unterschiedlich effizient mit CRM1 interagieren, kontrollieren kann: Exportsubstrate mit niedriger Affinität stehen mit denen hoher Affinität in Konkurrenz. Während hochaffine Exportsubstrate effizient an CRM1 binden können und folglich auch schnell aus dem Zellkern exportiert werden, würden niedrigaffine Proteine länger 
im Kern verweilen oder gar nicht exportiert werden, da die meisten CRM1-Moleküle mit stark bindenden Substraten besetzt sind.

Dass auch Proteine mit niedriger Affinität effizient aus dem Zellkern exportiert werden können, zeigt uns das in dieser Arbeit verwendete Beispiel NC2 $\beta$. Obwohl es eine eher niedrige Affinität zum CRM1-RanGTP besitzt (Kahle et al., 2009 [125]) und die CRM1-Konzentration limitierend ist, wird es dennoch effizient aus dem Kern exportiert (Abb. 2.15.).

Um die Exportrate von niedrigaffinen Proteinen zu verstärken, hätte die Zelle mehrere Möglichkeiten. Eine davon ist, die CRM1-Konzentration zu erhöhen, sodass auch niedrigaffine Substrate die Chance hätten, mit CRM1 zu interagieren und exportiert $\mathrm{zu}$ werden. Untersuchungen $\mathrm{zu}$ sich ändernden CRM1Proteinkonzentrationen wurden bis zum heutigen Zeitpunkt jedoch nicht durchgeführt.

Eine andere Möglichkeit der Zelle zur Verbesserung der Exporteffizienz von schwach bindenden Substraten wäre, das Exportsubstrat an sich so zu modifizieren (zum Beispiel durch Phosphorylierung, Acetylierung, Methylierung usw.), dass sich dessen Affinität zu CRM1 erhöht. Ein prominentes Beispiel hierfür ist das Tumorsupressorprotein p53, welches zwischen Kern und Cytoplasma hin- und hertransportiert wird (Liang et al., 2001 [130]). Für den CRM1-abhängigen Export ist die Phosphorylierung des Tyrosins 55 notwendig (Cai et al., 2008 [131]). Mutationen des Tyrosins zu Alanin oder Inhibition der Phosphorylierung durch spezifische Kinase-Inhibitoren, führen zur starken Reduktion der CRM1-Interaktion und somit zur Exportinhibition von p53. Neben der Phosphorylierung ist eine Monoubiquitinierung für den Export von p53 notwendig, die zur „Demaskierung“ der NES führt und somit zusätzlich die Interaktion zwischen CRM1 und p53 fördert (Geyer et al., 2000 [132]; Li et al., 2003 [133]). Die Interaktion zwischen MDM2 und p53 ist ebenfalls von der Phosphorylierung des Tyrosins 55 abhängig (Cai et al., 2008 [131]). Ein weiteres Beispiel stellt Cyclin D1 dar. Überexpression von CRM1 führt bei Cyclin D1 zu einer Verschiebung der Lokalisation ins Cytoplasma, CRM1 ist also für den Export von Cyclin D1 limitierend (Alt et al., 2000 [134]). Durch die Kinase GSK-3 $\beta$ kann ein bestimmtes Tyrosin (T 286) phosphoryliert werden (Diehl et al., 1998 [135]). Dadurch wird die Affinität zwischen CRM1 und Cyclin D1 stark 
erhöht (Alt et al., 2000 [134]). Mutiert man dieses Tyrosin zu Alanin oder inhibiert man spezifisch die Kinase, so ist die Affinität von Cyclin D1 zu CRM1 stark reduziert und es wird nicht mehr effizient aus dem Zellkern exportiert (Alt et al., 2000 [134]). Auch die Überexpression von CRM1 kann den Export der nicht phosphorylierbaren Mutante von Cyclin D1 nicht verstärken.

Denkbar sind auch direkte Modifikationen von CRM1 oder anderer Faktoren, die am Proteinexport beteiligt sind, die dann Einfluss auf die Bindekapazität verschiedener Substrate hätten. Tatsächlich wurden bei CRM1 in einem Screen für acetylierte Proteine drei acetyliert vorliegende Lysine (K 446, K 455 und K 693) gefunden, die sich auch noch in der Nähe der hydrophoben, NES-bindenden Spalte (AS 511-574) von CRM1 befinden (Choudhary et al., 2009 [136]). Ob und welchen Einfluss diese Modifikationen auf den Export spezifischer Proteine haben, wurde allerdings nicht weiter untersucht.

Eine wesentliche Hilfestellung bei der Interaktion mit CRM1 erhalten niedrigaffine Proteine von verschiedenen Faktoren, die die Bindung von niedrigaffinen Proteinen an CRM1 (und somit deren Exporteffizienz) fördern. RanBP3 ist so ein Faktor: Bindungsstudien haben gezeigt, dass die Affinität von Snurportin1 zu CRM1 höher als die eines GST-NES-Proteins (NES aus Rev) ist (Paraskeva et al., 1999 [42]). In Kompetitionsstudien verdrängt Snurportin1 deshalb das GST-NES-Protein aus dem Exportkomplex. Durch Zugabe von RanBP3 konnte dieses Ergebnis umgekehrt werden (Englmeier et al., 2001 [45]). RanBP3 fördert also die Bindung des schwächer interagierenden GST-NES zu CRM1, welches sich so gegen das Exportsubstrat mit höherer CRM1-Affinität (Snurportin1) durchsetzen kann. Neben RanBP3 gibt es verschiedene andere Faktoren, wie zum Beispiel Nup98, die in den CRM1-abhängigen Export von Proteinen involviert sind. Inhibition von Nup98 durch Mikroinjektion eines Antikörpers führte zum Beispiel zur Inhibition des Exports eines einfachen Reporterproteins. In dieser Arbeit konnte erstmalig gezeigt werden, dass auch NLP1 in die Reihe der Proteinexport-fördernden Faktoren eingeordnet werden kann. 
Zusammenfassend kann man sagen, dass CRM1 für den Export der in dieser Arbeit überexprimierten Substrate limitierend ist und dass diese Limitierung der Zelle viele Möglichkeiten bieten könnte, den Proteinexport effizient zu regulieren.

\subsection{Die Lokalisation von NLP1}

Um die Funktion von NLP1 im Protein- und mRNA-Export genauer analysieren zu können, wurden zunächst Lokalisationsstudien durchgeführt. Es zeigte sich in Fraktionierungsstudien, dass NLP1 hauptsächlich im Kern und ein kleiner Teil auch im Cytoplasma zu detektieren ist (Abb. 2.3.). Mikroskopische Analysen von überexprimiertem NLP1 unterstützten dieses Ergebnis (Abb. 2.3.). Zusätzlich konnte ein Teil des überexprimierten NLP1s an der Kernhülle gezeigt werden. Andere Arbeitsgruppen zeigten ähnliche Ergebnisse, sie konnten die Lokalisation von überexprimiertem NLP1 im Kern (Farjot et al., 1999 [96]) und nach Digitoninbehandlung der Zellen an der Kernhülle (Rouzic et al., 2002 [99]) beobachten. Biochemische Untersuchungen untermauerten diese Befunde. Sie identifizierten NLP1 als Kernporenprotein mit 16 Kopien pro Pore (Cronshaw et al., 2002 [61]). Wenn man davon ausgeht, dass eine proliferierende Zelle circa 20005000 Poren pro Zellkern hat (Cordes et al.,1995 [56]), ergibt sich eine Gesamtanzahl von 32.000 bis 80.000 NLP1-Proteine an der Kernhülle. Vergleichende Untersuchungen von rekombinanten MBP-NLP1 und endogenem NLP1 in HeLaZellen im Abschnitt 2.2.1. dieser Arbeit zeigten, dass die NLP1-Konzentration in der Zelle bei circa 50-200 nM liegt, was einer tatsächlichen Anzahl von ca. 30.000 bis 120.000 NLP1-Molekülen pro Zelle entspricht. Ein Großteil der endogenen NLP1Moleküle liegt also wahrscheinlich mit der Kernpore assoziiert vor. Ob endogenes NLP1 nur an der Kernhülle, oder auch im Nucleoplasma oder Cytoplasma zu finden ist, ließ sich nur mittels eines in der Immunfluoreszenz funktionierenden Antikörpers beantworten. Trotz der Anwendung von vier verschiedenen Antikörpern aus verschiedenen Spezies (zwei aus Kaninchen und zwei aus Meerschwein) und verschiedenster Protokolle für die Immunfluoreszenz konnte 
endogenes NLP1 in der Zelle nicht detektiert werden. Auf Grund dieser Tatsache, sollte das Verhalten von überexprimiertem NLP1 in der Zelle näher untersucht werden. Da überexprimiertes NLP1 zum größten Teil im Kern zu finden ist, wurde dessen Mobilität in diesem Kompartiment mittels FLIP und FRAP gemessen. Die Analysen ergaben, dass sich das im Kern befindende NLP1 frei im Kern bewegen kann (Abb. 2.4.A). FLIP-Analysen zeigten zusätzlich, dass NLP1 langsam aus dem Kern exportiert werden kann (Abb. 2.4.B). Da LMB-Behandlung keinen Einfluss auf das Exportverhalten von NLP1 hatte, ist davon auszugehen, dass NLP1 nicht über den CRM1-abhängigen Export aus dem Kern exportiert wird.

Wie dynamisch die Interaktion zwischen NLP1 und Kernpore ist und ob alle endogenen NLP1-Moleküle ständig mit der Pore assoziiert vorliegen, ist noch unklar. Mittels FRAP-Analysen von überexprimiertem GFP-NLP1 könnte die Dynamik von NLP1 an der Kernhülle untersucht werden. Hierzu müsste ein definierter Bereich der Kernmembran gebleicht und dann überprüft werden, ob die Kernfluoreszenz in kurzer Zeit wieder in den gebleichten Bereich zurückkehrt. Würde sie gar nicht oder nur langsam zurückkehren, so ließe das eine eher immobile Fraktion von NLP1 an der Pore vermuten. Hätte die Kernfluoreszenz allerdings schnell wieder ihre Ursprungsintensität erreicht, so könnte man davon ausgehen, dass NLP1 auch an der Pore sehr mobil ist und es hier zum regen Austausch von NLP1-Molekülen kommt.

Ausgehend davon, dass überexprimiertes NLP1 sich wie endogenes NLP1 verhält, ist NLP1 nicht nur an der Kernhülle zu finden, sondern auch im Kern und zum geringen Teil im Cytoplasma. Es ist im Kern frei beweglich und kann langsam CRM1unabhängig aus dem Kern exportiert werden.

Um Klarheit über die Lokalisation von endogenem NLP1 zu bekommen, sollen in Zunkunft neue Antikörper gegen unterschiedliche Regionen von NLP1 hergestellt generiert und mit diesen Elektronenmikroskopische Analysen durchgeführt werden. 


\subsection{Die Rolle von NLP1 im poly(A)mRNA-Export}

Verschiedene Untersuchungen zeigten, dass NLP1 mit Faktoren, die im RNA-Export beteiligt sind (TAP, Gle1), interagiert (Katahira et al., 1999 [103]; Wiegand et al., 2002 [113]; Kendirgi et al., [98] 2005). Interessanterweise konnte in Kompetitionsstudien dieser Arbeit gezeigt werden, dass der mRNA-Exportfaktor TAP und der Proteinexportkomplex bestehend aus CRM1, RanGTP und einem Exportsubstrat, gleichzeitig an NLP1 binden können, ohne um die Bindung an NLP1 zu konkurrieren (Abschnitt 2.3.8.). Da NLP1 eine essentielle Aufgabe im Export der mRNA von HSP 70 unter Hitzeschockbedingungen $\left(42^{\circ} \mathrm{C}\right)$ zugesprochen wurde (Kendirgi et al., [98]), dessen Rolle im generellen Export von mRNA aber noch unklar war, wurde diese im Abschnitt 2.4.1. dieser Arbeit in NLP1-Überexpressions- oder Depletions-Studien genauer analysiert. Es stellte sich heraus, dass die Depletion von NLP1 mittels siRNA keinen Effekt auf die Lokalisation von poly(A)mRNA hatte. Da die Depletionseffizienz von NLP1 auf Proteinebene im besten Fall ca. 90\% betrug, muss hier auch in Betracht gezogen werden, dass die übriggebliebenen $10 \%$ ausreichend für die Ausführung eventueller Funktionen im mRNA-Export waren.

Starke Überexpression von NLP1 führte zur Inhibition des mRNA-Exports. Eine Vermutung ist, dass durch die große Anzahl an überexprimierten NLP1-Molekülen wichtige Faktoren für mRNA-Export (zum Beispiel TAP oder Gle1) im Kern gebunden werden, welche daraufhin nicht mehr für den mRNA-Export zur Verfügung stehen und es somit zur Inhibition des Exports kommt.

Wie bereits erwähnt, zeigten frühere Untersuchungen, dass NLP1 notwendig für den Export der mRNA des Hitzeschockproteins HSP 70 ist (Kendirgi et al., 2005 [98]). Auf Grund dessen, dass keine tragende Rolle für NLP1 im Export von mRNA festgestellt werden konnte, liegt die Vermutung nahe, dass NLP1 entweder nur für den Export spezifischer mRNAs essentiell ist oder nur unter bestimmten Bedingungen, wie zum Beispiel unter Hitzestress, wie es bei Kendirgis Untersuchungen der Fall war, für den mRNA-Export notwendig wird. Letzteres scheint für das NLP1 Homolog aus Hefe, Rip1p/Nup42, zuzutreffen. Untersuchungen zeigten hier, dass in Rip1p/Nup42-depletierten Hefezellen, der Export von 
poly $(\mathrm{A}) \mathrm{mRNA}$ bei $42^{\circ} \mathrm{C}$, nicht aber bei $25^{\circ} \mathrm{C}$ stark inhibiert ist (Vainberg et al., 2000 [102]).

Da die Depletion von NLP1 keinen und nur sehr starke Überexpression von NLP1 einen Effekt auf die poly(A)mRNA Lokalisation zeigte, kann davon ausgegangen werden, dass NLP1 unter „Normalbedingungen“ keine tragende Rolle beim generellen Export von mRNAs hat. Der Fokus dieser Arbeit wurde daher auf die Erforschung der Rolle von NLP1 im Proteinexport gerichtet.

\subsection{Biochemische Charakterisierung von NLP1}

Verschiedene Bindungsstudien dieser Arbeit zeigten, dass NLP1 sowohl im Komplex mit RanGTP und CRM1 als auch im Komplex mit CRM1, RanGTP und einem NESSubstrat vorliegen kann. Dabei ist eindeutig, dass die zusätzliche Bindung eines NESSubstrates die Affinität von NLP1, CRM1 und RanGTP zueinander erhöht und dass die Zugabe von NLP1 die Affinität von CRM1 zu RanGTP und zum NES-Substrat verstärkt (Abschnitt 2.3.1.).

Interessanterweise war nicht nicht der FG-repeat-reiche C-Terminus von NLP1 sondern die nur 2 FG-repeats beinhaltende N-terminale Hälfte für die Interaktion mit CRM1 verantwortlich (Abb. 2.8.). In verschiedenen Hefe-zwei-Hybridanalysen wurde entgegen diesem Resultat postuliert, dass der C-Terminus von NLP1 mit CRM1 interagiert (Strahm et al., 1999 [97]; Rouzic et al., 2002 [137]). Diese Diskrepanz kann einerseits daher zustande kommen, dass unsere Versuche mit rekombinanten Proteinen aus Bakterien durchgeführt wurden und ihnen deshalb zum Beispiel spezifische, für Interaktion mit CRM1 notwendige Modifikationen wie O-Glykosylierungen oder Phosphorylierungen usw. fehlten. Andererseits fanden die vorher beschriebenen Interaktionstudien in einem Zellsystem (Saccharomyces Cervisiae) statt, das neben den zu untersuchenden Proteinen den kompletten Proteinsatz einer Zelle enthält. Folglich kann eine indirekte Interaktion dort nicht ausgeschlossen werden. 
Da NLP1 als O-glykosyliert beschrieben wurde (Farjot et al., 1999 [96]), sollte der Einfluss der Glykosylierung auf das Bindeverhalten von NLP1 überprüft und rekombinantes NLP1 in vitro O-glykosyliert werden. Obwohl die Positivkontrolle p62, eins der am besten charakterisierten O-glykosylierten Nukeoporine (Holt et al., 1987 [138]), eine deutliche Glykosylierung zeigte, konnte bei NLP1 keine Glykosylierung unter den hier gewählten Bedingungen festgestellt werden. Ein essentieller Unterschied zu dem Experiment von Farjot et al. ist, dass bei unserem Ansatz rekombinante Proteine aus Bakterien verwendet wurden, während ihr Ansatz in vitro-translatiertes NLP1 aus Retikulozytenlysat enthielt. Es könnte daher sein, dass dem rekombinanten NLP1 aus Bakterien Modifikationen fehlten, die zur Glykosylierung benötigt werden oder dass die Bakterien, aus denen NLP1 isoliert wurde, das Protein so modifiziert haben, dass eine Glykosylierung ausgeschlossen ist. Um die generelle Glykosylierung von endogenem NLP1 aus HeLa-Zellen zu überprüfen, sollte aus einem HeLa-Zelllysat endogenes NLP1 mittels WGASepharose präzipitiert werden. Allerdings konnte endogenes NLP1 ebenfalls nicht mit WGA-Sepharose präzipitiert werden. Die Ergebnisse dieser Arbeit lassen also eher vermuten, dass NLP1 nicht glykosyliert in der Zelle vorliegt.

Zusammenfassend kann gesagt werden, dass NLP1 trimere und tetramere Komplexe mit CRM1 und RanGTP in An- oder Abwesenheit eines NES-Substrates eingehen kann. Interessanterweise ist für diese Komplexbildung nicht wie erwartet der C-Terminus, der die meisten FG-Repeats enthält, sondern eher die N-terminale Hälfte von NLP1 notwendig, die nur zwei FG-Repeats beinhaltet. Da strukturelle Untersuchungen des Transportfaktors Importin $\beta$ mit unterschiedlichen FG-RepeatPeptiden gezeigt haben, dass die Bindung von Nucleoporinen und Transportrezeptoren durch Interaktion der FG-Repeats mit hydrophoben Bereichen zwischen den HEAT-Repeats der Transportrezeptoren zustande kommt (Bayliss et al., 2000 und $2002[63,69])$, wäre es sehr aufschlussreich die Interaktion zwischen CRM1 und einer FG-Repeat-defizienten Mutante des NLP1-N-Terminus näher zu untersuchen. 


\subsection{NLP1 fördert den Export verschiedener Exportsubstrate}

Die Überexpression von NLP1 führte bei verschiedenen Substraten (NES-GFP ${ }_{2}$-CNLS und NC2ß-GFP 2 ) in FLIP- und konventionellen mikroskopischen Analysen dieser Arbeit zu einem erhöhten Export aus dem Zellkern. Die Depletion von NLP1 führte hingegen zu etwas vermindertem, aber dennoch funktionierendem Export. Dies lässt darauf schließen, dass NLP1 als ein Co-Faktor für den CRM1-abhängigen Export fungiert, welcher zwar den Export verschiedener Substrate fördern kann, für diesen aber nicht essentiell ist. Eine Möglichkeit ist, dass NLP1 den Export von Proteinen, die eine geringe Affinität zu CRM1 haben, fördert. Solche Proteine stehen mit für CRM1 hochaffinen Exportsubstraten in Konkurrenz, was ein Grund dafür ist, dass für niedrigaffine Exportsubstrate die CRM1-Konzentration in der Zelle limitierend ist (siehe Abschnitt 2.1.). Sowohl für das einfache Reporterprotein NES-GFP ${ }_{2}$-CNLS als auch für NC2ß-GFP 2 ließ sich dieser Sachverhalt bestätigen, denn der Effekt nach Überexpression von NLP1 war ähnlich dem Effekt nach CRM1-Überexpression: beide Proteine wurden effizienter aus dem Zellkern exportiert. Wie aber kommt dieser Effekt zustande? Die Bindungsstudien dieser Arbeit lassen vermuten, dass ein Grund für die erhöhte Exportrate die erhöhte Bindungsaffinität von CRM1, Substrat und RanGTP sein könnte. Die Ergebnisse in Kapitel 2.3.1. zeigten eindeutig, dass NLP1 die Interaktion zwischen CRM1 und RanGTP fördert und zusätzlich die Affinität von CRM1 zum Export-Substrat erhöht. Die Vermutung, dass NLP1 den Export von speziell niedrigaffinen Substraten fördert, setzt allerdings voraus, dass niedrigaffine Exportsubstrate gegenüber hochaffinen Exportsubstraten in den tetrameren Komplexen (bestehend aus NLP1, CRM1, RanGTP und Exportsubstrat) bevorzugt werden (Abb. 3.1.A). Tatsächlich gibt es einen Co-Faktor im CRM1-abhängigen Export, der genau dieses Verhalten zeigt: RanBP3 fördert die Bindung vom schwächeren NES-Substrat (BSA-NES) an CRM1, auch wenn ebenfalls ein Substrat mit höherer Affinität (Snurportin1) für CRM1 vorhanden ist (Engelmeier et al., 2001 [45]). Computergestützte Strukturanalysen von einem CRM1-RanGTP-Snurportin1RanBP3-Komplex haben gezeigt, dass die Bindung von RanBP3 an CRM1 eine der drei Bindungen von Snurportin1 an CRM1, sterisch, in einem Bereich der ungefähr $30 \AA ̊$ von der hydrophoben NES-Bindungsgrube entfernt ist, schwächt (Langer et al., 
2011 [139]). Die NES-Bindungsgrube von CRM1 bleibt davon allerdings unbeeinflusst. Ob NLP1 sich ähnlich verhält und folglich durch Bindung von NLP1 an CRM1 die Bindung von spezifischen Exportsubstraten durch räumliche Behinderung ausgeschlossen oder vermindert ist, steht noch offen. Kompetitionsstudien mit CRM1, RanGTP und verschieden affinen Exportsubstraten in An- und Abwesenheit von NLP1 würden Aufschluss darüber geben.

Eine zusätzliche Möglichkeit, wie NLP1 die Affinität spezifischer Substrate zu CRM1 erhöhen könnte, wäre, dass bestimmte Substrate zuerst direkt an NLP1 binden könnten, was daraufhin die Interaktion mit CRM1 und RanGTP begünstigen würde (Abb. 3.1.B). Für diese Hypothese spricht das Ergebnis dieser Arbeit, dass das Protein HIV-1 Rev sowohl alleine als auch über CRM1 mit NLP1 interagieren kann. Für die direkte Interaktion von Rev und NLP1 ist die N-terminale Zinkfinger-Domäne (AS 1-24) verantwortlich, die aber für die CRM1-RanGTP-Komplexbildung erlässlich ist.

Neben der Erhöhung der Bindungsaffinität zwischen CRM1 und NES-Substrat ist ebenfalls vorstellbar, dass durch NLP1 die Mobilität von Exportkomplexen im Kern zur Pore hin beeinflusst wird (Abb. 3.1.C). Eine Spekulation ist, dass NLP1 zum Beispiel Transkriptionsfaktoren als NES-Substrat direkt an ihrer DNA-Bindestelle „abholt“. Durch die Interaktion mit NLP1 (alleine oder im tetrameren Komplex mit CRM1 und RanGTP) könnte zum Beispiel die Affinität der Transkriptionsfaktoren für DNA erniedrigt werden. Durch Interaktion mit NLP1 würde sich somit die Mobilität des Transkriptionsfaktors erhöhen. Dass NLP1 im Kern relativ mobil ist, zeigen die Ergebnisse der FRAP Experimente in Kapitel 2.2.3. Um herauszufinden, ob die Transportgeschwindigkeit von Exportsubstraten im Kern tatsächlich durch NLP1 beeinflusst wird, könnte durch FRAP-Analysen die Mobilität von Exportsubstraten alleine und von Exportsubstraten, die mit NLP1 cotransfiziert wurden, überprüft werden. Würde die oben beschriebene Theorie stimmen, so würde die CoTransfektion von NLP1 die Mobilität des Reporterproteins im Zellkern steigern.

Eine weitere Theorie zur erhöhten Exportgeschwindigkeit von Substraten ist, dass deren Durchtritt durch die Pore durch NLP1 erleichtert werden könnte (Abb. 3.1.D). Da der CRM1-Exportkomplex am N-Terminus von NLP1 bindet, könnten die FGRepeats des C-Terminus mit den FG-Repeats der Pore interagieren und so den 
Transport durch die Pore erleichtern. Um diesen Sachverhalt zu überprüfen, könnte man Co-Transfektionen und anschließende FLIP-Experimente mit Reporterproteinen und NLP1-Konstrukten, die nicht mehr in der Lage sind mit der Kernpore zu interagieren, aber dennoch Exportkomplexe ausbilden können, durchführen. Würde die Überexpression der NLP1-Mutanten keinen verstärkenden Exporteffekt auf die Reporterproteine haben, so wäre dies ein Hinweis darauf, dass die durch NLP1-CoTransfektion verursachte erhöhte Exportrate nicht nur auf Erhöhung der Affinität zwischen CRM1, RanGTP und Exportsubstrat, sondern auch auf die Erhöhung der Durchtrittgeschwindigkeit durch die Pore zurückzuführen ist.

\subsubsection{Dissoziation der NLP1-Komplexe}

Nachdem die CRM1-Exportkomplexe die Pore durchquert haben, können sie mit Hilfe von RanGAP1 und RanBP1 (oder den Ran-bindenden Domänen von Nup358) von der Pore abgelöst und durch GTP-Hydrolyse dissoziiert werden (Kehlenbach et al., 1999 [50]), was die Freilassung des Exportsubstrates ins Cytoplasma zur Folge hat.

Sollte NLP1 nicht nur die Komplexbildung zwischen CRM1, RanGTP und Substrat unterstützen, sondern auch den Transport durch die Pore vermitteln, so müssten die NLP1-Komplexe einige Vorraussetzungen erfüllen. Unter anderem sollte sich der tetramere Komplex bestehend aus CRM1, RanGTP und Substrat durch RanBP1 (oder den Ran-bindenden Domänen von Nup358) von NLP1 ablösen lassen, sodass dieser mit Hilfe von RanGAP1 induzierter GTP-Hydrolyse dissoziiert werden kann (Abb. 3.1.F). Tatsächlich zeigte sich, dass trimere und tetramere NLP1-Exportkomplexe gegenüber RanGAP1 vermittelter GTP-Hydrolyse insensitiv sind (Kapitel 2.3.2. und Daten nicht gezeigt). Die Ablösung der CRM1-Komplexe von NLP1 durch RanBP1 wäre also notwendig, um das Exportsubstrat ins Cytoplasma zu entlassen. Kapitel 2.3.3. dieser Arbeit zeigt eindeutig, dass RanBP1 sowohl CRM1-RanGTP als auch CRM1-RanGTP-NES-Substrat-Komplexe von NLP1 ablösen kann, welche somit der RanGAP1 vermittelten Hydrolyse ausgesetzt wären. 
Eine weitere Möglichkeit wäre, dass die CRM1-Exportkomplexe nicht direkt von NLP1 ins Cytoplasma entlassen, sondern zuerst an ein Nucleoporin auf der cytoplasmatischen Seite der Pore weitergegeben werden (Abb. 3.3.D), um danach erst dissoziiert zu werden. Tatsächlich zeigten Kompetitionstudien mit NLP1 und Nup214, welches auf der cytoplasmatsichen Seite der Pore lokalisiert und wie NLP1 trimere und tetramere Komplexe mit CRM1 und RanGTP in An- oder Abwesenheit eines Exportsubstrates bilden kann, dass Nup214 mit NLP1 um die Bindung an CRM1 Komplexe konkurriert und aufgrund seiner höheren Affinität NLP1 aus dem tetrameren Komplex verdrängt. Ein Hinweis darauf, dass dieses Szenario auch in vivo so stattfindet könnte, ist, dass der Export des Reporterproteins GFP-NFAT, sowohl durch NLP1- als auch durch Nup214-Depletion inhibiert ist (Abschnitt 2.4.5. und 2.4.6. und Hutten et al., 2006 [51]). Aufschluss darüber, ob NLP1 den CRM1Exportkomplex tatsächlich an Nup214 übergibt, würden Lokalisationsstudien von GFP-NFAT in Nup214 depletierten Zellen geben die gleichzeitig mit NLP1 überexprimiert sind. Wenn die Überexpression non NLP1 in den Nup214depletierten Zellen keine Verstärkung des GFP-NFAT-Exports hervorrufen würde, die Überexpression von NLP1 in nicht depletierten Zellen hingegen schon, wäre dies ein klarer Hinweis darauf, dass eine Übergabe des Exportkomplexes von NLP1 an Nup214 stattfindet. Ein Vorteil der Übergabe an Nup214 wäre, dass der Exportkomplex auf der cytoplasmatischen Seite der Pore platziert wäre und somit gut für die durch die Ran-bindenden Domänen von Nup358 vermittelte GTPHydrolyse positioniert wäre.

Abschließend ist in Abbildung 3.1. ein Modell dargestellt, das alle möglichen Funktionen von NLP1 im CRM1-abhängigen Export von Proteinen noch einmal zusammenfasst. 

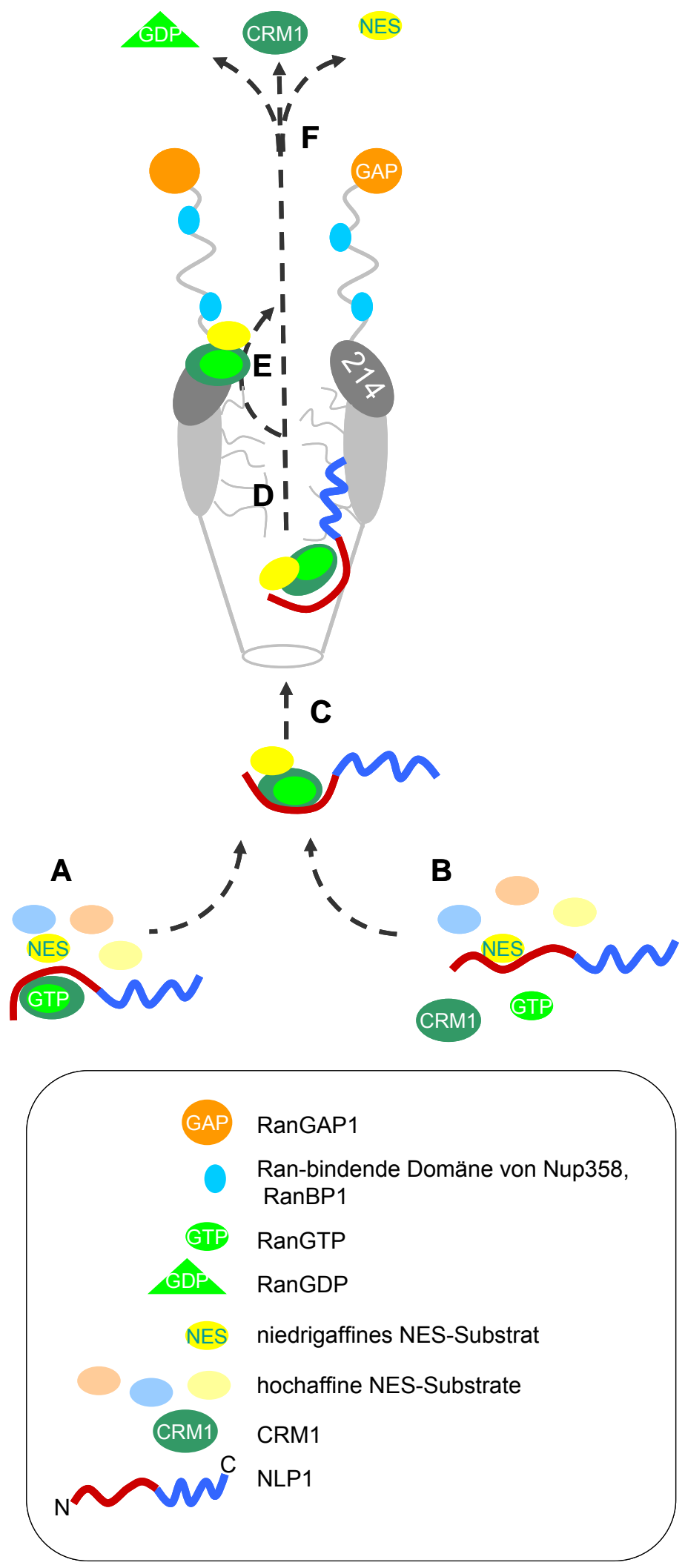

Abbildung 3.1. Modell: NLP1 fördert den Export von Proteinen aus dem Zellkern Hellgrau ist die Kernpore dargestellt. A) NLP1 fördert die Bindung von spezifischen niedrigaffinen NES-Substraten, indem es die Komplexbildung begünstigt. B) Das Exportsubstrat interagiert zuerst mit NLP1, welches daraufhin die Interaktion mit CRM1 und RanGTP fördert. C) NLP1 transportiert den Exportkomplex durch das Nucleoplasma zur Kernpore und vermittelt dessen Durchtritt durch die Pore. Der Exportkomplex wird daraufhin entweder direkt mit Hilfe von RanGAP und RanBP1 oder den Ranbindenden Domänen von Nup358 dissoziiert, sodass das Exportsubstrat ins Cytoplasma entlassen wird (F), oder er wird zunächst an Nup214 abgegeben (E) und dann dissoziiert. 


\subsection{Ausblick}

Generell konnte in dieser Arbeit gezeigt werden, dass NLP1 den Export von Substraten, für die die CRM1-Konzentration in der Zelle limitierend ist, durch Erhöhung der Affinität zu CRM1 fördert. Hierfür ist nicht der C-terminale Teil, der die meisten FG-Repeats von NLP1 enthält, verantwortlich, sondern eher der Nterminale Bereich, der allerdings noch zwei FG-Repeats enthält. Hier wäre es sehr interessant Interaktionssstudien mit einer Mutante von NLP1 durchzuführen, die keine FG-Repeats mehr enthält. Sie würden Aufschluss darüber geben, ob NLP1 für die Interaktion mit CRM1 FG-Repeats benötigt oder nicht. Weiterhin wäre es sehr aufschlussreich Strukturanalysen der tetrameren Komplexe bestehend aus NLP1, CRM1, RanGTP und NES-Substrat durchzuführen, um die Bindungen näher zu analysieren. Sie würden Informationen darüber liefern, ob Exportsubstrate in dem Komplex nur über CRM1 mit NLP1, oder eventuell direkt mit NLP1 interagieren. Wenn Letzteres der Fall wäre, könnte NLP1 eine Art Adapterfunktion zwischen Exportsubstrat und CRM1 zugesprochen werden.

Die Frage, ob NLP1 den Export aller Proteine gleichermaßen fördert, oder ob nur der Transport spezifischer Exportproteine, wie zum Beispiel für CRM1 niedrigaffine Proteine, unterstützt wird, bleibt ebenfalls offen. Um diese Frage beantworten zu können, müsste der Einfluss von NLP1 auf viele unterschiedliche zu exportierende Proteine untersucht werden. Auch hierbei würden Strukturanalysen von tetrameren Exportkomplexen mit verschiedenen Substraten hilfreich sein und Hinweise auf mögliche Bindungskriterien eventuell bevorzugter NES-Substrate geben. Kompetitionsstudien mit verschiedenen Substraten sowohl in vitro als auch in vivo würden ebenfalls bei der Aufklärung dieser Fragestellung helfen. 


\section{Material}

\subsection{Chemikalien und Reagenzien}

Alle in dieser Arbeit verwendeten Chemikalien wurden, wenn nicht anders angegeben, über die Firmen AppliChem, CARL ROTH GmbH, Sigma-Aldrich, Merck und Serva bezogen.

Spezifische Chemikalien und Reagenzien sind untenstehend aufgelistet:

\begin{tabular}{|c|c|}
\hline Reagenz & Herkunft \\
\hline Acrylamid (30\%) & Amersham \\
\hline Aprotinin & Biomol \\
\hline ATP & Sigma \\
\hline BSA, Fraktion V & PAA \\
\hline $\mathrm{CO}_{2}$ unabhängiges Medium & Gibco \\
\hline Creatinphosphat & Calbiochem \\
\hline Creatinphosphokinase & Calbiochem \\
\hline Digitonin & Calbiochem \\
\hline Dithiothreitol (DTT) & AppliChem \\
\hline DNA-Marker & Fermentas \\
\hline dNTPs & Fermentas \\
\hline ECL & Pierce \\
\hline FCS & Gibco \\
\hline Glutamin & Gibco \\
\hline GDP und GTP & Sigma \\
\hline$\left[\gamma^{32} \mathrm{P}\right] \mathrm{GTP}$ & Amersham \\
\hline Histogel-Mounting Medium & Linaris \\
\hline Hoechst 33258 & Sigma \\
\hline IPTG & Fermentas \\
\hline Leptomycin B & Alexis Biochemicals \\
\hline Leupeptin & Biomol \\
\hline
\end{tabular}




\begin{tabular}{l|l} 
Oligofectamin & Invitrogen \\
OptiMEM & Gibco \\
PAN ScriptDNA Polymerase & PAN Biotech \\
Penicillin & PAA \\
Pepstatin & Biomol \\
Phusion Polymerase & New England Biolabs \\
Poly-L-Lysin & Sigma-Aldrich \\
Protein-Marker SeeBlue2 & Invitrogen \\
Restriktionsenzyme & Fermentas, New England Biolabs \\
Sequenziermix, -puffer & Applied Biosystems \\
siRNA-Oligonucleotide & Ambion \\
Streptomycin & PAA \\
TMB Substrate Reagent Set & Millipore \\
T4-DNA-Ligase & Fermentas \\
T4-Polynucleotidkinase & Fermentas \\
TrypanBlau & Fluka \\
Trypsin/EDTA & Gibco/PAA \\
WGA & Sigma \\
\hline
\end{tabular}

\subsection{Kits}

\begin{tabular}{l|l} 
Name & Herkunft \\
\hline NucleoBond ${ }^{\circledR}$ PC100. PC500 & Macherey \& Nagel \\
NucleoSpin ${ }^{\circledR}$ Extractll & Macherey \& Nagel \\
QuickChange ${ }^{\circledR}$ Site-Directed Mutagenesis & Statagene \\
Kit &
\end{tabular}




\subsection{Verbrauchsmaterialien}

\begin{tabular}{l|l} 
Material & Herkunft \\
\hline Amylose-Resin & New England Biolabs \\
Cyanbromid aktivierte Sepharose 4B & Sigma-Aldrich \\
Deckgläschen (Durchmesser 10 und 12 & Marienfeld \\
mm) & \\
MaxiSorp ${ }^{\text {TM} S u r f a c e ~}$ & Nunc \\
Filterpapier & Whatman \\
GST-Agarose & GE Healthcare \\
Ni-NTA-Agarose & Qiagen \\
Objektträger & Marienfeld \\
PD10-Säulen & Amersham \\
PROTAN-Nitrocellulose & Schleicher \& Schuell \\
Reagenzgefäße & Sarstedt, Eppendorf \\
Zellkultur-Materialien & Sarstedt, TPP
\end{tabular}

\subsection{Allgemeine Puffer und Medien}

Alle Puffer und Medien wurden grundsätzlich mit demineralisiertem Wasser angesetzt. Medien wurden durch Autoklavieren sterilisiert. pH-Werte wurden mit Natronlauge oder Salzsäure titriert.

\begin{tabular}{l|l} 
Bezeichnung & Inhalt \\
\hline Colloidale Coomassie-Färbelösung & $\begin{array}{l}0.1 \%(\mathrm{v} / \mathrm{v}) \text { Brilliant Blue G-250, 2\% (w/v) ortho- } \\
\text { Phosphosäure, 10\% (w/v) Ammoniumsulfat } \\
40 \%(\mathrm{v} / \mathrm{v}) \text { Ethanol, 10\% (v/v) Essigsäure }\end{array}$ \\
Colloidale-Coomassie- Fixierlösung & $\begin{array}{l}10 \%(\mathrm{v} / \mathrm{v}) \text { Essigsäure, 0.025\% (w/v) Coomassie } \\
\text { Brilliant Blue G-250 } \\
\text { Coomassie-Färbelösung }\end{array}$ \\
Coomassie-Fixierlösung &
\end{tabular}


DMEM high (Gibco)

10x DNA-Probenpuffer

2x HBS

Hybridisierungspuffer (FISH)

10x Laemmli-Laufpuffer

LB-Medium

LB-Agar-Platten

P1

P2

P3

PBS

PBS-Tween

Ponceau S-Lösung

4x Proteinprobenpuffer

SOC-Medium

$10 \times$ SSC

Stopplösung-RanGAP-Assay

50X TAE

1x TE

Western Blot-Putter (WB-Puffer)

Transportpuffer high Glucose (4500 mg/ml), 10\% (v/v) FCS, 2 $\mathrm{mM}$ Glutamin, $100 \mathrm{U} / \mathrm{ml}$ Penicillin, $100 \mu \mathrm{g} / \mathrm{ml}$ Streptomycin

$50 \% \quad(\mathrm{v} / \mathrm{v}) \quad$ Glycerin, $0.1 \% \quad(\mathrm{w} / \mathrm{v})$ Bromphenolblau, $0.1 \%(\mathrm{w} / \mathrm{v})$ Xylencyanol

$50 \mathrm{mM}$ HEPES (pH 6.96), $250 \mathrm{mM} \mathrm{NaCl}, 1.5$ $\mathrm{mM} \mathrm{Na}_{2} \mathrm{HPO}_{4}$

2xSSC, $1 \mathrm{mg} / \mathrm{ml}$ t-RNA, $0.02 \%$ BSA, 2 mM RVC, $25 \%$ Formamid, $5 \%(\mathrm{w} / \mathrm{v})$ Dextransulfat, 20 $\mu \mathrm{g} / \mathrm{ml}(\mathrm{N})_{50}$

250 mM Tris, 1.92 M Glycin, $0.1 \%$ (w/v) SDS

1\% Bacto-Trypton, $0.5 \%(\mathrm{w} / \mathrm{v})$ Hefe-Extrakt, $1 \%(\mathrm{w} / \mathrm{v}) \mathrm{NaCl}(\mathrm{pH} 7)$

LB-Medium + 1,5\% (w/v) Agar

$50 \mathrm{mM}$ Tris- $\mathrm{HCl}(\mathrm{pH}$ 8), $10 \mathrm{mM}$ EDTA, 100 $\mu \mathrm{g} / \mathrm{ml}$ RNase $\mathrm{A}$

$200 \mathrm{mM} \mathrm{NAOH}, 1 \%(\mathrm{v} / \mathrm{v})$ SDS

$3 \mathrm{M} \mathrm{KOAc}(\mathrm{pH} 5.3)$

$140 \mathrm{mM} \mathrm{NaCl}, 2.5 \mathrm{mM} \mathrm{KCl}, 10 \mathrm{mM} \mathrm{Na}{ }_{2} \mathrm{HPO}_{4}$, $\mathrm{KH}_{2} \mathrm{PO}_{4}(\mathrm{pH} 7.5)$

$140 \mathrm{mM} \mathrm{NaCl}, 2,5 \mathrm{mM} \mathrm{KCl}, 10 \mathrm{mM} \mathrm{Na}_{2} \mathrm{HPO}_{4}$, $\mathrm{KH}_{2} \mathrm{PO}_{4}(\mathrm{pH} 7.5)+0.1 \%(\mathrm{v} / \mathrm{v})$ Tween 20

$0.5 \%(\mathrm{w} / \mathrm{v})$ Ponceau S, 1\% (v/v) Essigsäure

4\% (w/v) SDS, $125 \mathrm{mM}$ Tris pH 6.8, 10\% (v/v) Glycerin, $0.02 \%(\mathrm{w} / \mathrm{v})$ Bromphenolblau, 10\% (v/v) $\beta$-Mercaptoethanol

2\% Trypton, 5\% Hefe-Extrakt, $50 \mathrm{mM} \mathrm{NaCl}, 2.5$ $\mathrm{mM} \mathrm{KCl}, 10 \mathrm{mM} \mathrm{MgCl}_{2}, 10 \mathrm{mM} \mathrm{MgSO}_{4}$

$3 \mathrm{M} \mathrm{NaCl}, 0.3 \mathrm{M}$ Natriumcitrat, $\mathrm{pH} 7.0$

7\% (w/v) Aktivkohle, 10\% (v/v) Ethanol, 100 $\mathrm{mM} \mathrm{HCl}, 10 \mathrm{mM} \mathrm{Na}_{2} \mathrm{H}_{2} \mathrm{PO}_{4}$

$2 \mathrm{M}$ Tris, 0.05 M EDTA pH 8, 5.8\% Essigsäure

$10 \mathrm{mM}$ Tris pH 7.5, 1 mM EDTA

192 mM Glycin, 25 mM Tris, 0.05\% (v/v) SDS, $20 \%(\mathrm{v} / \mathrm{v})$ Methanol

$20 \mathrm{mM}$ Hepes pH 7.3, $110 \mathrm{mM}$ KOAc, $2 \mathrm{mM}$ $\mathrm{Mg}(\mathrm{OAc})_{2}, 1 \mathrm{mM}$ EDTA 


\subsection{Puffer für Proteinaufreinigungen}

\begin{tabular}{|c|c|}
\hline Bezeichnung & Inhalt \\
\hline Carbonatpuffer & $0.2 \mathrm{M} \mathrm{NaHCO}_{3}, \mathrm{pH} 9,8$ \\
\hline GST-Ran-Puffer & PBS, $1 \mu \mathrm{g} / \mathrm{ml}$ AP/LP, 2 mM DTT \\
\hline CRM1-His-Aufreinigung & $\begin{array}{l}50 \mathrm{mM} \text { HEPES pH 7.5, } 500 \mathrm{mM} \mathrm{NaCl}, 2 \\
\mathrm{mM} \mathrm{MgCl} 2,1 \mu \mathrm{g} / \mathrm{ml} \mathrm{AP} / \mathrm{LP}, 2 \mathrm{mM} \text { DTT }\end{array}$ \\
\hline His-NLP-Aufschlusspuffer & $\begin{array}{l}50 \mathrm{mM} \text { Tris pH 8.0, } 2 \% \text { Triton, } 1 \mu \mathrm{g} / \mathrm{ml} \\
\text { AP/LP, } 1 \mathrm{mM} \text { DTT }\end{array}$ \\
\hline His-NLP-Resuspensionspuffer & $\begin{array}{l}50 \mathrm{mM} \text { Tris pH 8.0, } 4 \mathrm{M} \text { Urea, } 1 \text { } \mathrm{gg} / \mathrm{ml} \\
\text { AP/LP, } 1 \mathrm{mM} \text { DTT }\end{array}$ \\
\hline His-NLP-Lösungspuffer & $\begin{array}{l}50 \mathrm{mM} \text { Tris pH 8.0, } 8 \mathrm{M} \text { Urea, } 1 \mu \mathrm{g} / \mathrm{ml} \\
\text { AP/LP, } 1 \mathrm{mM} \text { DTT }\end{array}$ \\
\hline His-Snurportin-Puffer & $\begin{array}{l}\text { PBS, } 2 \text { mM EDTA, 1\% Triton, } 2 \text { mM DTT, } 1 \\
\mu \mathrm{g} / \mathrm{ml} \text { AP/LP }\end{array}$ \\
\hline NC2 $\beta$-Puffer & $\begin{array}{l}50 \mathrm{mM} \text { Tris pH 7.4, } 400 \mathrm{mM} \mathrm{NaCl}, 1 \mu \mathrm{g} \\
\text { AP/LP, } 2 \text { mM DTT }\end{array}$ \\
\hline NLP1-Aufschlusspuffer & $\begin{array}{l}\text { PBS, } 2 \text { mM EDTA, 1\% Triton, } 5 \text { mM DTT, } 1 \\
\mu \mathrm{g} / \mathrm{ml} \text { AP/LP }\end{array}$ \\
\hline NLP1 Verdünnungspuffer & $\begin{array}{l}\text { PBS, } 10 \mathrm{mM} \mathrm{MgCL} 2,5 \mathrm{mM} \text { DTT, } 1 \mu \mathrm{g} / \mathrm{ml} \\
\text { AP/LP }\end{array}$ \\
\hline NLP1-Waschpuffer & $\begin{array}{l}10 \mathrm{mM} \text { HEPES pH 8.0, 0.2\% Triton, } 5 \% \\
\text { Glycerin, } 150 \mathrm{mM} \mathrm{NaCl}, 1 \mathrm{mM} \text { DTT, } 1 \\
\mu \mathrm{g} / \mathrm{ml} \mathrm{AP/LP}\end{array}$ \\
\hline MBP-Nup214-Puffer & $\begin{array}{l}20 \mathrm{mM} \text { Tris pH 7.5, } 200 \mathrm{mM} \mathrm{NaCl}, 1 \mathrm{mM} \\
\text { EDTA, } 1 \mathrm{\mu g} / \mathrm{ml} \text { AP/LP, } 1 \mathrm{mM} \mathrm{PMSF}\end{array}$ \\
\hline TGN-Puffer & $\begin{array}{l}20 \mathrm{mM} \text { TrisHCl pH 8.0, } 10 \% \text { Glycerol, } 150 \\
\mathrm{mM} \mathrm{NaCl}, 1 \mu \mathrm{g} / \mathrm{ml} \text { AP/LP, } 2 \text { mM DTT }\end{array}$ \\
\hline
\end{tabular}




\subsection{Stamm-Lösungen}

\begin{tabular}{l|l} 
Bezeichnung & Inhalt \\
\hline Ampicillin & $100 \mathrm{mg} / \mathrm{ml}$ \\
Aprotinin (1000x) & $1 \mathrm{mg} / \mathrm{ml}$ \\
$100 \mathrm{mM}$ in $100 \mathrm{mM} \mathrm{Mg}(\mathrm{OAc})_{2}, 20 \mathrm{mM}$ HEPES \\
ATP & $(\mathrm{pH} \mathrm{7.4)}$ \\
& $10 \%(\mathrm{w} / \mathrm{v})$ in DMSO \\
Digitonin & $1 \mathrm{M}$ \\
Dithiothreitol (DTT) & $0.1 \mathrm{mg} / \mathrm{ml}$ \\
Hoechst 33258 & $50 \mathrm{mg} / \mathrm{ml}$ \\
Kanamycin & $1 \mathrm{mg} / \mathrm{ml}$ von jedem in DMSO \\
Leupeptin/Pepstatin (1000x) & Penicillin $10000 \mathrm{U} / \mathrm{ml}$, Streptomycin $10 \mathrm{mg} / \mathrm{ml}$ \\
Penicillin/Steptomycin (1000x)
\end{tabular}

\subsection{Zelllinien}

\begin{tabular}{|c|c|}
\hline Zelllinie & Eigenschaft \\
\hline HeLaP4 & $\begin{array}{l}\text { HeLa-Zelllinie, die verschiedene für die HIV- } \\
\text { Infektion benötigte Oberflächenrezeptoren } \\
\text { exprimiert (CD4, CXCR4, CCR5) und das Gen } \\
\beta \text {-Galaktosidase unter der Kontrolle der HIV- } \\
1 \text { LTR enthält (Charneau et al., } 1994 \text { [140]). }\end{array}$ \\
\hline HelaNFAT adhärent & $\begin{array}{l}\text { Adhärente Hela-Zellinie, die stabil mit GFP- } \\
\text { NFAT transfiziert wurde (Hutten et al., } 2006 \\
\text { [51]). }\end{array}$ \\
\hline HelaNFAT spinner & $\begin{array}{l}\text { Spinner Hela-Zelllinie, die stabil mit GFP- } \\
\text { NFAT transfiziert wurde (Kehlenbach et al., } \\
1998[128] \text { ). }\end{array}$ \\
\hline
\end{tabular}




\subsection{Bakterien (E.coli)}

\begin{tabular}{|c|c|}
\hline Name & Eigenschaft \\
\hline BL21(DE3) & 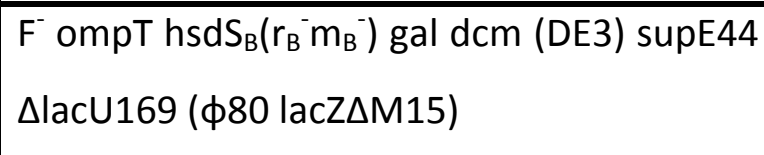 \\
\hline DH5a & hsdR17 recA1 end A1 gyrA96 thi-1 relA1 \\
\hline
\end{tabular}

\subsection{Technische Geräte}

\begin{tabular}{l|l} 
Gerät & Herkunft \\
\hline Appliskan & Thermo Scientific \\
Documentation system LAS $\mathbf{3 0 0 0}$ & Fujifilm \\
EmulsiFlex-C3 & Avestin Inc \\
FACS Canto' ${ }^{\text {III }}$ & BD Biosciences \\
Axioskop2 & Carl Zeiss \\
LSM 510 meta & Carl Zeiss \\
Sequenzierer, Genetic Analyzer $\mathbf{3 1 0 0}$ & Applied Biosystems \\
Spektralphotometer & Eppendorf \\
Thermocycler & Perkin Elmer, Biometra, Biotech \\
Tischzentrifuge & Eppendorf \\
Ultrazentrifuge & Beckman Coulter \\
UV-Cross-Linker & Biometra
\end{tabular}

\subsection{Software}

\begin{tabular}{l|l} 
Software & Herkunft \\
\hline AxioVision (LE) Rel. 4.5 & Zeiss \\
Chromas Lite 2.01 & Technelysium \\
Delta vision sofware & Applied Precision
\end{tabular}




\begin{tabular}{l|l} 
EndNoteX1 & Thomson Reuters \\
Image Reader LAS $\mathbf{3 0 0 0}$ & Fujifilm \\
LSM image browser & Carl Zeiss \\
LSM software & Carl Zeiss \\
Nucleid Acid Sequence Massager & http://www.attotron.com/cybertory/analy \\
& sis/seqMassager.htm \\
Photoshop ${ }^{\oplus}$ CS2 & Adobe
\end{tabular}

\subsection{1. zur Verfügung gestellte Vektoren}

\begin{tabular}{l|l} 
Name & Herkunft/Referenz \\
\hline pET28b & Novagen \\
pGEX-KG & Amersham \\
pEF-HA & O.Fackler \\
pMal-C2 & NEB \\
pEGFP-C1 & Clontech \\
pcDNA3.1(+)-Ha & Sarah Wälde \\
pmRFP-C1 & Clontech \\
pmRFP-N1 & Clontech
\end{tabular}

\subsection{2. zur Verfügung gestellte Plasmide}

\begin{tabular}{l|l|l} 
Name & Nummer & Herkunft/Referenz \\
\hline CRM1-HA & 532 & Christiane Spillner \\
NC2 $\beta-G F P_{2}$ & 502 & Kahle et al., 2009 [125] \\
Rev(47-116)-GFP2-cNLS & 423 & Hutten et al., 2008 [93] \\
Rev68-90-GFP2-M9core & 623 & Hutten et al., 2009 [94]
\end{tabular}




\subsection{Selbst klonierte Plasmide}

\begin{tabular}{|c|c|c|c|c|}
\hline Name & Nummer & Vektor & Primer & Restriktionsenzyme \\
\hline $\begin{array}{l}\text { MBP-NLP1 } \\
\mathrm{fl}\end{array}$ & 684 & pMal-C2 & G445, G446 & BamH1, HindIII \\
\hline GFP-NLP1 fl & 695 & pEGFP-C1 & G445, G446 & BamH1, Xba1 \\
\hline HA-NLP1 fl & 679 & pEF-HA & G445, G446 & BamH1, Xba1 \\
\hline NLP1 fl-HA & 866 & $\begin{array}{l}\text { pcDNA3.1(+)- } \\
\text { HA }\end{array}$ & G472, G773 & HindIII, BamH1 \\
\hline RFP-NLP1 fl & 698 & pmRFP-C1 & G445, G446 & BamH1, Xba1 \\
\hline NLP1 fl-RFP & 867 & pmRFP-N1 & G472, G773 & BamH1, Xba1 \\
\hline $\begin{array}{l}\text { GST-NLP1 } \\
1-204\end{array}$ & 683 & pGEX-KG & G445, G449 & BamH1, HindIII \\
\hline $\begin{array}{l}\text { GST-NLP1 } \\
1-165\end{array}$ & 859 & pGEX-KG & G565, G579 & BamH1, HindIII \\
\hline $\begin{array}{l}\text { His-NLP1 1- } \\
204\end{array}$ & 840 & pET28a & $\begin{array}{l}\text { ausgeschnitten } \\
\text { aus GST-NLP1 } \\
1-204\end{array}$ & BamH1, HindIII \\
\hline $\begin{array}{l}\text { GST-NLP1 } \\
205-423\end{array}$ & 680 & pGEX-KG & G448, G446 & BamH1, HindIII \\
\hline $\begin{array}{l}\text { GST-NLP1 } \\
165-423\end{array}$ & 825 & pGEX-KG & G763, G446 & BamH1, HindIII \\
\hline $\begin{array}{l}\text { GST-NLP1 } \\
130-230\end{array}$ & 852 & pGEX-KG & G643, G644 & BamH1, HindIII \\
\hline $\begin{array}{l}\text { GST-NLP1 } \\
165-204- \\
6 x H i s\end{array}$ & 862 & pGEX-KG & G763, G449 & BamH1, HindIII \\
\hline $\begin{array}{l}\text { MBP-NLP1 } \\
24-423\end{array}$ & 823 & pMal-C2 & G566, G446 & BamH1, HindIII \\
\hline $\begin{array}{l}\text { His- } \\
\text { Snurportin }\end{array}$ & 856 & pET30b & $\begin{array}{l}\text { ausgeschnitten } \\
\text { aus \#328 }\end{array}$ & Nco1, EcoR1 \\
\hline $\begin{array}{l}\text { GFP- } \\
\text { Snurportin }\end{array}$ & 857 & pEGFP-C1 & G769, G770 & Xho1. EcoR1 \\
\hline MBP-NC2 $\beta$ & 872 & pMal-C2 & G774, G775 & BamH1, HindIII \\
\hline GST-NC2 $\beta$ & 871 & pGEX-KG & G774, G775 & BamH1, HindIII \\
\hline
\end{tabular}


4.14. Durch „direkte in vitro Mutagenese“ erstellte Plasmide

\begin{tabular}{|c|c|c|c|}
\hline Name & Nummer & Oligo & Sequenz \\
\hline MBP-NLP1 ${ }_{165} \Delta_{204}$ & 854 & $\begin{array}{l}\text { G641, } \\
\text { G642 }\end{array}$ & $\begin{array}{l}\text { Ursprungsplasmid ist MBP- } \\
\text { NLP1 fl. Die Mutagenese } \\
\text { wurde mit der Phusion } \\
\text { durchgeführt (siehe Abschnitt } \\
\text { 5.1.10.). }\end{array}$ \\
\hline $\begin{array}{l}\text { MBP-NLP1 } \\
{ }_{165} \Delta_{204} \text { FGFG }_{14,15,95,96} \text { AAAA }\end{array}$ & 870 & $\begin{array}{l}\text { G714, } \\
\text { G715 } \\
\text { G716, } \\
\text { G717 }\end{array}$ & $\begin{array}{l}\text { Ursprungsplasmid ist MBP- } \\
\text { NLP1 }{ }_{165} \Delta_{204} . \text { Mit Hilfe des } \\
\text { QuickChange }{ }^{\circledR} \text { Site-Directed } \\
\text { Mutagenesis Kits von } \\
\text { Stratagene wurden zuerst die } \\
{\text { Aminosäuren } \mathrm{FG}_{14,15} \text { und dann }} \mathrm{FG}_{95,96} \text { zu Alaninen mutiert. }\end{array}$ \\
\hline
\end{tabular}

\subsection{Oligonukleotide für Klonierungen}

\begin{tabular}{|c|c|c|}
\hline Name & Nummer & Sequenz \\
\hline NLP1fl-BamH1-f & G445 & $\begin{array}{l}\text { TTTTGGATCCATGGCCATTTGTCAATTCTT } \\
\text { CCTTA }\end{array}$ \\
\hline NLP1fl-Hind3/Xba1-r & G446 & $\begin{array}{l}\text { TTTTAAGCTTTCTAGATTAAACATTTAGA } \\
\text { AGTTCCAGAGGTGG }\end{array}$ \\
\hline NLP1-204-Hind3/Xba-r & G449 & $\begin{array}{l}\text { TTTTAAGCTTTTCTAGAGAGCAAAGCTACT } \\
\text { TTAGTTG }\end{array}$ \\
\hline NLP1-205f-BamH1-f & G448 & TTTTGGATCCTCTGATGTAAAGATGGAG \\
\hline $\begin{array}{l}\text { NLP1pcDNA3.1(+)-HAf- } \\
\text { Hind3-f }\end{array}$ & G472 & $\begin{array}{l}\text { TTTTAAGCTTGATGGCCATTTGTCAATTC } \\
\text { TTCC }\end{array}$ \\
\hline $\begin{array}{l}\text { NLP1pcDNA3.1(+)-HAr- } \\
\text { Hind3-r }\end{array}$ & G773 & $\begin{array}{l}\text { TTTTGGATCCTTAACATTTAGAAGTTCCA } \\
\text { GAGG }\end{array}$ \\
\hline NLP1-165f-BamH1-f & G763 & TTTTGGATCCTTCTTAACCAGCAATAAC \\
\hline NLP1-24f-BamH1-f & G566 & TTTTTGGATCCGGTGCTAGGGGTGCAGG \\
\hline NLP1-230r-6xHis-Hind3-r & G643 & $\begin{array}{l}\text { TTTTAAGCTTTTAATGGTGATGGTGATGG } \\
\text { TGCGACATAAATGT }\end{array}$ \\
\hline NLP1-130f-BamH1-f & G644 & TTTGGATCCGGGCAGTGGATGTTTTC \\
\hline NLP1-204r-Spel-r & G764 & $\begin{array}{l}\text { TTTTACTAGTTTAGAGCAAAGCTACTTAG } \\
\text { TTG }\end{array}$ \\
\hline
\end{tabular}


Snurportin-Xho1-F

Snurportin-EcoR1-R

NC2 $\beta$-BamH1-f

NC2 $\beta$-BamH1-r
G769

G770

G774

G775
TTTTCTCGAGCTATGGAAGAGTTGAGTC AGG

TTTTTGAATTCATTCTCCATGAGGCATCC

TTTTTGGATCC ATGGCTTCCTCGTCTGGC

TTTTTAAGCTTCTAGATATCATCATCATCT TCTTC

\subsection{Oligonukleotide für Mutagenesen}

\begin{tabular}{|c|c|c|}
\hline Name & Nummer & Sequenz \\
\hline $\begin{array}{l}\text { MutageneseNLP1FG/AA14- } \\
\text { 15F } \\
\text { MutageneseNLP1FG/AA14- } \\
\text { 15R } \\
\text { MutageneseNLP1FG/AA96- } \\
\text { 97f } \\
\text { MutageneseNLP1FG/AA96- } \\
\text { 97R } \\
\text { NLP1-delta-165-204f } \\
\text { NLP1-delta-165-204r }\end{array}$ & $\begin{array}{l}\text { G714 } \\
\text { G715 } \\
\text { G716 } \\
\text { G717 } \\
\text { G641 } \\
\text { G642 }\end{array}$ & $\begin{array}{l}\text { CCTTCAAGGCCGGTGCCGCGCCGCCG } \\
\text { ATCGGTGCTGGAACG } \\
\text { CGTTCCAGCACCGATCGGCGGCGCGG } \\
\text { CACCGGCCTTGAAGG } \\
\text { CTAACAGGAAGGAAGGCGCCGCCTTG } \\
\text { TCTGAGAACCCATTTGC } \\
\text { GCAAATGGGTTCTCAGACAAGGCGGC } \\
\text { GCCTTCCTTCCTGTTAG } \\
\text { GCTTGAATACCATAACTTCTCTGATGT } \\
\text { AAAGGATGGA } \\
\text { TCCATCCTTTACATCAGAGAAGTTATG } \\
\text { GTATTCAAGC }\end{array}$ \\
\hline
\end{tabular}

4.17. Oligonukleotide für Sequenzierungen

\begin{tabular}{|c|c|c|}
\hline Name & Nummer & Sequenz \\
\hline HisF & 1000 & CATCACCATCACCATCAC \\
\hline pEF-HA vorwärts & 206 & $\begin{array}{l}\text { GCCATCTATTGCTTACATTTGCTTCTGA } \\
\text { CACAACTG }\end{array}$ \\
\hline pEF-HA rückwärts & 207 & $\begin{array}{l}\text { CCAGGGCATTAGCCACACCAGCCACC } \\
\text { ACTTTCTG }\end{array}$ \\
\hline pGEX5' & 499 & GGGCTGGCAAGCCACGTTTGGTG \\
\hline PGEX3' & 500 & CCGGGAGCTGCAGTGGTCAGAGG \\
\hline pMal5' & 1111 & GGTCGTCAGACTGTCGATGAAGCC \\
\hline pMal3' & 1112 & CGCCAGGGTTTTCCCAGTCACGAC \\
\hline T7-Terminator & 1176 & CTAGTTATTGCTCAGCGG \\
\hline
\end{tabular}




\subsection{Oligonukleotide für Fluoreszenz-in situ-Hybridisierung}

\begin{tabular}{l|l} 
Name & Sequenz \\
\hline$(T)_{40}$ & $\operatorname{Dig}-(T)_{40}$
\end{tabular}

\subsection{9. siRNAs}

Bei den in dieser Arbeit verwendeten siRNAs handelt es sich um Silencer ${ }^{\circledR}$ Select Predesigned siRNAs von Ambion.

\begin{tabular}{l|l|l|l} 
Name & siRNA ID & Sequenz 5' -3' $^{\prime}$ & Herkunft \\
\hline NLP1-siRNA8 & s21878 & AGGUAAUAAUAGACGUGGAtt & Ambion \\
NLP1-siRNA9 & S21879 & GAGCUUCAACUAACAGGAAtt & Ambion
\end{tabular}

\subsection{Selbst hergestellte Proteine}

Alle unten aufgeführten Proteine wurden von mir nach der jeweils angegebenen Referenz aufgereinigt.

\begin{tabular}{l|l|l} 
Name & Spezies & Referenz \\
\hline His-CRM1 & Mensch & Guan et al., 2000 [141] \\
GST-Ran & Mensch & Diese Arbeit \\
RanQ69L & Mensch & Melchior et al., 1995 [142] \\
MBP-NLP1 fl & Mensch & Diese Arbeit \\
GST-NLP1 1-204 & Mensch & Diese Arbeit \\
GST-NLP1 1-165 & Mensch & Diese Arbeit \\
His-NLP1 1-204 & Mensch & Diese Arbeit
\end{tabular}




\begin{tabular}{|c|c|c|}
\hline GST-NLP1 205-423 & Mensch & Diese Arbeit \\
\hline GST-NLP1 165-423 & Mensch & Diese Arbeit \\
\hline GST-NLP1 130-230 & Mensch & Diese Arbeit \\
\hline GST-NLP1 165-204 & Mensch & Diese Arbeit \\
\hline MBP-NLP1 24-423 & Mensch & Diese Arbeit \\
\hline MBP-NLP1 ${ }_{165} \Delta_{204}$ & Mensch & Diese Arbeit \\
\hline MBP-NLP1 & Mensch & Diese Arbeit \\
\hline${ }_{165} \Delta_{204} \mathrm{FGFG}_{14,15,95,96} \mathrm{AAAA}$ & & \\
\hline GST-Snurportin & Mensch & $\begin{array}{l}\text { angelehnt an Strasser et al., } 2004 \\
\text { [143] }\end{array}$ \\
\hline His-Snurportin & Mensch & Diese Arbeit \\
\hline GST-TAP & Mensch & Grüter et al., 1998 [144] \\
\hline MBP-NC2 $\beta$ & Mensch & Kahle et al., 2009 [125] \\
\hline $\begin{array}{l}\text { MBP-Nup214-C-Terminus } \\
\text { (AS1859-2090) }\end{array}$ & Mensch & Hutten et al., 2006 [51] \\
\hline GST-NC2 $\beta$ & Mensch & Kahle et al., 2009 [125] \\
\hline
\end{tabular}

\subsection{Zur Verfügung gestellte Proteine}

Die in der Liste unten aufgeführten Proteine wurden von Laborangehörigen nach den angegebenen Referenzen aufgereinigt und standen als allgemeiner Stock frei zur Verfügung.

\begin{tabular}{l|l|l} 
Name & Spezies & Referenz \\
\hline RanGAP & Maus & Mahajan et al., 1997 [90] \\
RanBP1 & Mahajan et al., 1997 [90] \\
$\begin{array}{l}\text { MBP-Nup88-C-Terminus } \\
\text { (AS 500-741) } \\
\text { HIV-Rev }\end{array}$ & Mensch & Hutten et al., 2006 [51] \\
Ran WT & HIV & Arnold et al, 2006 [108] \\
& Mensch & Melchior et al, $1995[142]$
\end{tabular}




\subsection{Primärantikörper}

\begin{tabular}{|c|c|c|c|}
\hline Name & Spezies & Herkunft & $\begin{array}{l}\text { Verdünnung ( } A) \text { WB, } \\
\text { B)IF) }\end{array}$ \\
\hline CRM1 & Ziege & Stefanie Roloff & $\begin{array}{l}\text { A) } 1: 5000 \\
\text { B) } 1: 1000\end{array}$ \\
\hline HA & Maus & Convance (Babco) & $\begin{array}{l}\text { A) } 1: 1000 \\
\text { B) } 1: 1000\end{array}$ \\
\hline RanGAP & Ziege & Melchior-Lab & A) 1:5000 \\
\hline Lamin A/C & Maus & BD Bioscience & A) 1:1000 \\
\hline NLP1 3754 & Kaninchen & Diese Arbeit & $\begin{array}{l}\text { A) } 1: 1500 \\
\text { B) } 1: 500\end{array}$ \\
\hline NLP1 3755 & Kaninchen & Diese Arbeit & $\begin{array}{l}\text { A) } 1: 2500 \\
\text { B) } 1: 3000\end{array}$ \\
\hline Nup214 & Kaninchen & Saskia Hutten & $\begin{array}{l}\text { A) } 1: 200 \\
\text { B) } 1: 200\end{array}$ \\
\hline Ran & Maus & BD Bioscience & $\begin{array}{l}\text { A) } 1: 5000 \\
\text { B) } 1: 2000\end{array}$ \\
\hline RanBP1 & Maus & BD Bioscience & A) $1: 250$ \\
\hline RanBP2 & Ziege & $\begin{array}{l}\text { Hutten et al., } 2008 \\
\text { [93] }\end{array}$ & B) $1: 1000$ \\
\hline RanBP3 & Maus & BD Bioscience & A) $1: 2500$ \\
\hline
\end{tabular}

\subsection{Sekundärantikörper}

Horseradish-Peroxidase gekoppelte Antikörper aus Esel gegen Maus, Kaninchen oder Ziege wurden für Westernblot-Analysen 1:5000 und ELISAs 1:2000 verdünnt eingesetzt.

In der Immunfluoreszenz wurden aus Esel gewonnene Antiköper gegen Maus, Ziege und Kaninchen, die Alexa488- und Alexa594-gekoppelt waren, in einer Verdünnung von 1:1000 - 1:2000 eingesetzt. 


\section{METHODEN}

\subsection{Molekularbiologische Methoden}

\subsubsection{Transformation chemisch kompetenter Bakterien}

Die chemisch-kompetenten gemachte Bakterien werden auf Eis aufgetaut und dann für 30 Minuten auf Eis mit der zu transformierenden DNA inkubiert. Nach einem Hitzeschock für 90 Sekunden bei $42^{\circ} \mathrm{C}$ und anschließendem Runterkühlen der Bakterien auf Eis für 2 Minuten, wird $400 \mu \mathrm{l}$ SOC-Medium zu den Zellen gegeben. Nach einer Inkubation von einer Stunde bei $37^{\circ} \mathrm{C}$ im Bakterienschüttler können die Zellen auf LB-Agarplatten inkubiert werden.

\subsubsection{Plasmid-Aufreinigung (Minipräparation)}

Geringe Plasmid-DNA-Mengen werden durch alkalische Lyse (Birnboim et al., 1979 [145]) und nachfolgende Präzipitation isoliert. Hierzu wird eine $2 \mathrm{ml}$ Übernachtkultur abzentrifugiert (1000 g, $1 \mathrm{~min})$ und in $200 \mu \mathrm{l}$ Puffer P1 resuspendiert. Die Lyse erfolgt durch Zugabe von $200 \mu$ l Lysierungspuffer P2 und nachfolgendes Invertieren für 5 min bei Raumtemperatur. Chromosomale DNA und Proteine werden danach durch Zugabe von $200 \mu$ l Neutralisationspuffer P3 für 5 min auf Eis gefällt. Durch Zentrifugation $(13,000 \mathrm{~g}, 30 \mathrm{~min})$ findet eine Trennung der löslichen Plasmide von den unlöslichen Komponenten (Chromosomale DNA und Proteine) statt. Zur Fällung der Plasmide wird $600 \mu \mathrm{l}$ des Überstandes mit $1 \mathrm{ml}$ eiskaltem 100\% Ethanol gemischt und die Plasmide $15 \mathrm{~min}$ bei $13000 \mathrm{~g}$ abzentrifugiert. Nach einem Waschschritt mit $70 \%$ (v/v) Ethanol wird das Plasmidpellet getrocknet und in $50 \mu \mathrm{lTE}$-Puffer aufgenommen.

Größere Plasmidmengen wurden mit Hilfe des NucleoBond ${ }^{\circledR}$ PC100 oder PC500 von Macherey\&Nagel gereinigt. 


\subsubsection{DNA-Konzentrationsmessung}

Die DNA-Konzentration wurde bei $\mathrm{OD}_{260}$ photometrisch gemessen. Das Verhältnis $\mathrm{OD}_{260}$ zu $\mathrm{OD}_{280}$ liefert dabei Informationen über die Reinheit der DNA. Der Quotient sollte zwischen 1,8 und 2 liegen.

\subsubsection{Agarosegelelektrophorese}

Um Plasmide oder DNA-Fragmente ihrer Größe nach aufzutrennen, wird die DNA mit 10x DNA-Probenpuffer versetzt und auf das mit Ethidiumbromid $(5 \mu \mathrm{g} / \mathrm{ml}$ ) versetzte Agarosegel aufgetragen. In dieser Arbeit wurden je nach Größe des DNAFragments 0.5-2 \% Agarosegele verwendet. Die Auftrennung der DNA-Fragmente erfolgt durch Anlegung einer Spannung von 80-140 V. Die Analyse erfolgt mit Hilfe von UV-Licht (Wellenlänge $365 \mathrm{~nm}$ ).

\subsubsection{Isolation von DNA aus Agarosegel}

Nachdem die DNA-Fragmente durch Agarosegelelektrophorese aufgetrennt sind, können die DNA-Banden ausgeschnitten und die DNA mit Hilfe des NucleoSpin ${ }^{\circledR}$ Extract II-Kits von Macherey\&Nagel gereinigt werden.

\subsubsection{DNA-Verdauung durch Endonucleasen}

Mit Hilfe von Restriktionsendonucleasen können Phosphodiesterbindungen der DNA hydrolytisch gespalten werden. Dabei erkennt das Enzym spezifische, palindromische Sequenzen, die für jedes Enzym unterschiedlich sind.

Zum Schneiden von PCR-Produkten und Plasmid-DNA werden je nach Herstellerangaben 1-8 U Enzym pro $1 \mu \mathrm{g}$ DNA eingesetzt und der angegebene Puffer 
verwendet. Die Reaktion erfolgt, wenn nicht anders angegeben, bei $37^{\circ} \mathrm{C}$ für $1-3$ Stunden.

\subsubsection{Ligation}

Mit Hilfe von DNA-Ligasen können 3'-Hydroxylgruppen und 5'-Phosphatgruppen von DNA-Strängen zu einer Phosphodiesterbindung verbunden werden.

In einem Reaktionsvolumen von $10 \mu$ l werden $1 \mathrm{U}$ T4-Ligase (Fermentas), Ligationspuffer (Fermentas), Insert und Vektor gemischt und 1 Stunde bei Raumtemperatur inkubiert. Das Verhältnis von Insert zu Vektor liegt hierbei bei 1:31:6. Nach der Ligation wird die Hälfte des Ligationsansatzes in kompetente $\mathrm{DH} 5 \alpha$ transformiert.

\subsubsection{Sequenzierung von Plasmiden}

Alle Plasmide, die durch PCR erstellt wurden, wurden mit Hilfe der Ketten-AbbruchReaktion nach Sanger et al 1977 [146] sequenziert. Die Reaktionen werden mit Hilfe des BigDye Terminator v1.1 cycle sequencing kit von Applied Biosystems durchgeführt. Hierzu werden ca. 200 ng Plasmid-DNA, 10 pmol Primer, $2 \mu \mathrm{l}$ Sequenzierungspuffer und $1 \mu \mathrm{l}$ Sequenzierungsmix gemischt und mit $\mathrm{H}_{2} \mathrm{O}$ auf $10 \mu \mathrm{l}$ aufgefüllt. Das PCR-Programm ist unten aufgeführt.

Anschließend muss der PCR-Ansatz gereinigt werden. Dazu wird dem PCR-Ansatz 1 $\mu \mathrm{l} 125$ mM EDTA, $1 \mu \mathrm{l} 3 \mathrm{M}$ Na-Acetat pH 5.2 und $50 \mu \mathrm{l}$ 100\% Ethanol hinzugefügt und für $20 \mathrm{~min}$ bei $13.000 \mathrm{~g}$ zentrifugiert. Das Pellet kann dann mit 70\% (v/v) Ethanol gewaschen werden. Nach Trocknen der DNA wird diese in $30 \mu \mathrm{l} \mathrm{H}_{2} \mathrm{O}$ aufgenommen. Die Sequenzierung erfolgt mittels "Genetic Analyser 3100“ der Firma Applied Biosystems im Göttinger Zentrum für Molekulare Biowissenschaften (GZMB). 


\begin{tabular}{l|l|l} 
Vorgang & Temperatur & Dauer \\
\hline Primäre DNA-Denaturierung & $96^{\circ} \mathrm{C}$ & $2 \mathrm{~min}$ \\
\hline Denaturierung & $96^{\circ} \mathrm{C}$ & $10 \mathrm{~s}$ \\
\hline Primer-Annealing & $55^{\circ} \mathrm{C}$ & $15 \mathrm{~s}$ \\
\hline Elongation & $60^{\circ} \mathrm{C}$ & $4 \mathrm{~min}$
\end{tabular}

\subsubsection{Polymerase-Kettenreaktion (PCR)}

Durch das Prinzip der Polymerase-Kettenreaktion, das auf K.B. Mullis et al , 1990 [147] zurückzuführen ist, ist eine Amplifikation spezifischer DNA-Fragmente möglich. Hierzu sind zwei Primer notwendig, die den Anfang und das Ende des Amplikons definieren.

Das Reaktionsvolumen einer typischen PCR beträgt $50 \mu \mathrm{l}$ und enthält 50-500 ng DNA-Template oder 1-2 $\mu \mathrm{l}$ cDNA, jeweils 20 pmol des Vorwärts- und RückwärtsPrimers, $200 \mu \mathrm{M}$ dNTPs und 1-2 U Polymerase ( Vent, Phusion, oder PAN ScriptDNA Polymerase). Annealing-Temperaturen wurden mit Hilfe von Online-Kalkulatoren berechnet (http://www.basic.northwestern.edu/biotools/oligocalc.html beim Gebrauch von Vent und PAN ScriptDNA Polymerase und https://www.finnzymes.fi/tm_determination.html bei der Phusion-Polymerase). Die Amplifikationszeit hängt von der Prozessivität der jeweiligen Polymerase ab (PAN ScriptDNA Polymerase und Vent 500 bp/min, Phusion 1 kb/15-30s). Ein typisches PCR-Programm ist unten dargestellt.

\begin{tabular}{l|l|l|l} 
Vorgang & Temperatur & Dauer \\
\hline Primäre DNA-Denaturierung & $96^{\circ} \mathrm{C}$ & $2 \mathrm{~min}$ \\
\hline Denaturierung & $96^{\circ} \mathrm{C}$ & $10 \mathrm{~s}$ & \multirow{2}{*}{ Zyklen } \\
\hline Primer-Annealing & $45-70^{\circ} \mathrm{C}$ & $15-30 \mathrm{~s}$ & \\
\hline Elongation & $72^{\circ} \mathrm{C}$ & $\begin{array}{l}\text { an Polymerase } \\
\text { angepasst }\end{array}$ & \\
\hline Abschluss-Elongation & $72^{\circ} \mathrm{C}$ & 10 min \\
\hline Kühlung & $4^{\circ} \mathrm{C}$ & $\infty$
\end{tabular}




\subsubsection{Gerichtete in vitro Mutagenese}

Zur Herstellung des MBP-NLP1 ${ }_{165} \Delta_{204}$-Konstrukts wurden revers-komplementäre Primer konstruiert, die den zu deletierenden Bereich umfassen. Als Matritze dient das Plasmid, in das die Mutation eingefügt werden soll.

Der Reaktionsansatz enthält 5 pmol jeden Primers, 5 nmol dNTPs, $10 \mu$ 5xPhusionPuffer, 200 ng DNA und $0.5 \mu$ l Phusion. Nachdem das PCR-Programm (siehe Tabelle unten) beendet ist, wird dem PCR-Ansatz DPN1 hinzugefügt, was zum Verdau der methylierten bakteriellen DNA führt. Nach dem DPN1-Verdau bei $37^{\circ} \mathrm{C}$ kann die DNA in kompetente Bakterien transformiert werden.

Zur Herstellung aller FG-Repeat-Mutationen wurde strikt nach dem Protokoll des QuickChange Site-Directed Mutagenesis Kits von Stratagene vorgegangen. Die Primer für diese Mutationen wurden ebenfalls so konstruiert, dass sie den Bereich umfassen, in dem der Basenaustausch stattfinden soll, sowie die neueingefügten anstelle der auszutauschenden Basen.

\begin{tabular}{l|l|l|l} 
Vorgang & Temperatur & \multicolumn{2}{|l}{ Dauer } \\
\cline { 1 - 3 } Primäre DNA-Denaturierung & $98^{\circ} \mathrm{C}$ & $30 \mathrm{~min}$ \\
\cline { 1 - 3 } Denaturierung & $98^{\circ} \mathrm{C}$ & $15 \mathrm{~s}$ & \multirow{2}{*}{30 Zyklen } \\
\cline { 1 - 3 } Primer-Annealing & $55^{\circ} \mathrm{C}$ & $30 \mathrm{~s}$ & \\
\hline Elongation & $72^{\circ} \mathrm{C}$ & $3 \mathrm{~min}$ & $12 \mathrm{~min}$
\end{tabular}

\subsection{Biochemische Methoden}

\subsubsection{Trennung von Proteinen mittels SDS-Polyacrylamid-Gelelektrophorese (SDS-} PAGE)

Die Trennung von Proteinen erfolgte nach der von Laemmli et al., 1970 [148] beschrieben Methode. Proteinproben werden mit Proteinprobenpuffer versetzt, für $5 \mathrm{~min}$ bei $95^{\circ} \mathrm{C}$ aufgekocht, um dann bei $25 \mathrm{~mA}$ der Größe nach im elektrischen Feld 
aufgetrennt zu werden. In dieser Arbeit wurden 10-12\% Gele, sowie Gradientengele (5-20\%) verwendet.

\subsubsection{Coomassiefärbung}

Durch die Coomassiefärbung ist es möglich Proteine im SDS-Gel sichtbar zu machen, da das Färbemittel Coomassie Brilliant Blue G-250 unspezifisch an kationische Aminosäuren bindet.

Um die Färbung durchzuführen, werden die Proteine im SDS-Gel 15 min bei RT fixiert (Coomassie-Fixierlösung) und dann solange mit der Coomassie-Färbelösung gefärbt, bis das gewünschte Ergebnis erreicht ist. Überschüssige Färbelösung kann durch mehrmaliges Waschen mit Wasser entfernt werden.

\subsubsection{Colloidale Coomassie-Färbung}

Eine sensitiviere Detektion von Proteinen wird durch die Anwendung der Colloidalen Coomassie-Färbung nach Neuhoff et al., 1988 [149] erreicht. Hierzu werden die SDS-Gele zunächst 1 Stunde mit der Colloidalen Coomassie-Fixierlösung fixiert, zweimal für 10 min bei RT mit Wasser gewaschen, um dann die Proteine über Nacht mit einem Gemisch aus 20\% Methanol und 80\% Colloidaler CoomassieFärbelösung anzufärben. Überschüssige Färbelösung kann dann mit Wasser entfernt werden.

\subsubsection{Proteintransfer mittels Western Blot mit anschließendem immunologischem Nachweis}

Mit Hilfe des Western Blots ist es möglich Proteine aus dem Polyacrylamidgel auf eine Membran bestehend aus Nitrozellulose zu transferieren (Towbin et al., 1979 [150]). Während dieser Arbeit wurde auschließlich die Nass-Blot-Methode 
verwendet. Bei dieser Blot-Methode wird das Acrylamidgel luftblasenfrei auf die Membran gelegt und beides wird in Filterpapier (Whatman) eingebettet (2 Papiere auf jeder Seite). Sowohl Filterpapiere als auch Membran wurden vorher im Western Blot-Puffer (WB-Puffer) äquiliebriert. Das Blot-Sandwich wird in eine "Blot-Cassette" gegeben, die dann in die mit WB-Puffer gefüllte Kammer eingesetzt wird. Dabei ist darauf zu achten, dass das Gel zur Kathode zeigt. Der Transfer findet dann bei $4^{\circ} \mathrm{C}$ für 75 min bei $400 \mathrm{~mA}$ statt.

Um erfolgreiches Blotten zu überprüfen, können die Proteine auf der Membran durch eine Ponceau S-Färbung sichtbar gemacht werden.

Nachfolgend wird die Membran in PBS-Tween gewaschen und mit PBS-Tween mit 5 \% Milchpulver für mindestens 30 min geblockt, um unspezifische Bindungen der Antikörper zu vermeiden. Übernacht und bei $4^{\circ} \mathrm{C}$ wird der erste Antikörper in wie im Materialteil beschriebener Verdünnung auf den Antikörper gegeben. Nach dreimaligem Waschen mit PBS-Tween für jeweils 5 min kann die Inkubation mit dem zweiten, HRP-gekoppelten Antikörper (Verdünnung 1:5000) für mindestens 1 Stunde bei RT stattfinden. Die Detektion des zweiten Antikörpers erfolgt nachdem der überschüssige Antikörper weggewaschen wurde, mit dem „ECL Western blotting analysis system“ von Pierce und einem Chemilumineszenz-Imaging System (LAS 2000).

\subsubsection{Expression rekombinanter Bakterien}

Wenn nicht anders angegeben, werden die mit den jeweiligen Plasmiden tranformierten Bakterien (BL21(DE3)) auf LB-Agar am Vortag der Expression ausgestrichen. Am nächsten Tag werden die Bakterien durch Abspühlen mit Medium in $2 \mathrm{I}$ LB-Medium gegeben und im Bakterienschüttler bei $37^{\circ} \mathrm{C}$ solange wachsen lassen, bis die exponentielle Wachstumsphase $\left(\mathrm{OD}_{600}\right.$ von 0.4-0.8) erreicht wird. Nach Erreichen von $\mathrm{OD}_{600} 0.6$ werden die Zellen mit $0.5 \mathrm{mM}$ IPTG für $4 \mathrm{~h}$ bei $25^{\circ} \mathrm{C}$ induziert.

Um die Bakterien zu ernten, werden sie für $15 \mathrm{~min}$ bei 4,000 g abzentrifugiert und können danach bei $-80^{\circ} \mathrm{C}$ gelagert werden. 


\subsubsection{Dialyse aufgereinigter Proteine}

Alle aufgereinigten Proteine werden, wenn nicht anders angegeben, über Nacht bei $4^{\circ} \mathrm{C}$ gegen Transportpuffer (+ $2 \mathrm{mM} \mathrm{DTT)} \mathrm{dialysiert.}$

\subsubsection{Reinigung MBP-fusionierter NLP1-Proteine}

Die Grundlage für diese Aufreinigung bildet das Reinigungsprotokoll von Rouzic et al., 2002 [99], das von mir modifiziert wurde.

Das Bakterien-Pellet wird im Wasserbad aufgetaut und in $10 \mathrm{ml}$ NLP1Aufschlusspuffer resuspendiert. Dann werden die Zellen mit Hilfe der EmulsiFlexC3 aufgeschlossen und bei 100,000 g für 30 min zentrifugiert. Der Überstand wird 1:5 mit NLP1-Verdünnungspuffer verdünnt und auf $1 \mathrm{ml}$ Amylose-Resin-Matrix, die vorher mit dem gleichen Puffer äquilibiriert wurde, gegeben. Die Bindung erfolgt für $1.5 \mathrm{~h}$ auf dem Drehrad bei $4^{\circ} \mathrm{C}$. Danach wird die Amylose-Resin-Matrix $3 \times 10 \mathrm{~min}$ mit NLP1-Waschpuffer gewaschen und die gebunden Proteine mit $10 \mathrm{mM}$ Maltose eluiert.

\subsubsection{Reinigung GST-fusionierter NLP1-Proteine}

Die Reinigung erfolgt wie bei den MBP-fusionierten NLP1-Proteinen. Anstatt Amylose-Resin wird hier Glutathion-Agarose verwendet und die Elution erfolgt mit 20 mM Gluthation, $\mathrm{pH}>8$.

\subsubsection{Reinigung von His-NLP1 1-204}

Das Pellet wird in 25 ml His-NLP-Aufschlusspuffer (50 mM Tris pH 8.0, 2 \% Triton, 2 $\mathrm{mM}$ DTT, $1 \mu \mathrm{g} / \mathrm{ml} \mathrm{AP/LP)}$ aufgenommen und die Bakterien danach durch die EmulsiFLex-C3 aufgeschlossen. Nach einer 100,000 g Zentrifugation für 20 min wird 
das Pellet, indem sich das unlösliche His-NLP 1-204 befindet, zweimal mit Hilfe eines Douncer-Homogenisators in je $25 \mathrm{ml}$ His-NLP-Resuspensionspuffer (50 mM Tris pH 8.0, $4 \mathrm{M}$ Harnstoff, $1 \mathrm{mM}$ DTT, $1 \mu \mathrm{g} / \mathrm{ml}$ AP/LP) resuspendiert und wieder bei 100,000 g abzentrifugiert. Das neuentstandene Pellet wird in $30 \mathrm{ml}$ His-NLPLösungspuffer (50 mM Tris pH 8.0, 8 M Harnstoff, $1 \mathrm{mM}$ DTT, $1 \mu \mathrm{g} / \mathrm{ml}$ AP/LP) aufgenommen, erneut mittels Douncer-Homogenisators resuspendiert und wieder 20 min bei 100,000 g zentrifugiert. Der Überstand wird nun für 1 Stunde auf zuvor äquilibrierte Ni-NTA-Agarose (Qiagen) gegeben. Nachdem die Agarose einmal mit His-NLP1-Lösungspuffer und zweimal mit His-NLP1-Lösungspuffer + 30 mM Imidazol gewaschen wurde, konnte das Protein mit 300 mM Imidazol eluiert werden. Dialysiert wurde über Nacht gegen PBS + 1 mM DTT.

\subsubsection{Reinigung von His-Snurportin1}

Das Pellet wurde in $50 \mathrm{ml}$ PBS mit $2 \mathrm{mM} \mathrm{DTT}, 1 \mu \mathrm{g} / \mathrm{ml}$ AP/LP aufgenommen und mittels EmulsiflexC3 aufgeschlossen. Nach 20 minütiger Zentrifugation (100,000 g) wurde der Überstand für $1.5 \mathrm{~h}$ auf zuvor äquilibrierte Ni-NTA-Agarose (Qiagen) gegeben. Nach drei Waschschritten mit PBS, 2 mM DTT, 30 mM Imidazol, 1 mg/ml

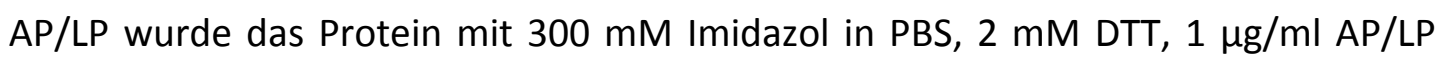
eluiert.

\subsubsection{Reinigung von GST-Ran}

Das Pellet wurde in $50 \mathrm{ml}$ PBS mit $2 \mathrm{mM}$ DTT, $1 \mu \mathrm{g} / \mathrm{ml}$ AP/LP aufgenommen und mittels EmulsiflexC3 aufgeschlossen. Nach 20 minütiger Zentrifugation (100,000 g) wurde der Überstand für $1.5 \mathrm{~h}$ auf zuvor äquilibrierte Gluthation-Sepharose (GEHealthcare) gegeben. Nach drei Waschschritten mit PBS, 2 mM DTT, 1 mg/ml AP/LP wurde das Protein mit $20 \mathrm{mM}$ Gluthation in PBS, $2 \mathrm{mM}$ DTT, $1 \mu \mathrm{g} / \mathrm{ml}$ AP/LP eluiert. 


\subsubsection{Reinigung von GST-NC2 $\beta$}

Die Reinigung von GST-NC2 $\beta$ wurde wie von Kahle et al., 2009 [125] beschrieben durchgeführt.

\subsubsection{Reinigung von GST-TAP}

Die Reinigung von GST-TAP wurde wie bei Grüter et al.,1998 [144] beschreiben durchgeführt.

\subsubsection{Reinigung von CRM1-His}

Die Reinigung von His-CRM1 wurde wie von Guan et al., 2000 [141] beschrieben durchgeführt.

\subsubsection{Reinigung von MBP-Nup214}

Die Reinigung von MBP-Nup214 wurde wie von Hutten et al., 2006 [51] beschreiben durchgeführt.

\subsubsection{Reinigung von RanQ69L}

Die Reinigung von RanQ69L wurde wie von Melchior et al, 1995 [142] beschrieben durchgeführt.

\subsubsection{7. in vitro $O$-Glykosylierung von GST-p62 und MBP-NLP1}

7.75 $\mu \mathrm{M}$ MBP-NLP1 oder 5.5 $\mu \mathrm{M}$ GST-p62 werden mit $0.8 \mu \mathrm{M}$ O-GlcNAc-Transferase (OGT) und $1 \mathrm{mM}$ UDP-N-Acetyl-Glucosamin (zur Verfügung gestellt von Aksana 
Labokha, MPI Göttingen) über Nacht bei RT inkubiert. Die Analyse erfolgte durch SDS-PAGE mit nachfolgender Coomassie-Färbung.

\subsubsection{Bindungsstudien mit MBP-oder GST-fusionierten Proteinen}

Für Bindungsstudien werden pro Ansatz $5 \mu \mathrm{g}$ der zu immobilisierenden Proteine an $20 \mu \mathrm{l}$ ihrer jeweiligen Matrix gebunden, die zuvor mit Transportpuffer $+1 \mu \mathrm{g} / \mathrm{ml}$ AP/LP, 2 mM DTT äquilibriert wurde. Für MBP-fusionierte Proteine wird $20 \mu \mathrm{l}$ Amylose-Resin und für GST-fusionierte Proteine wird Glutathion-Agarose verwendet. Die Immobilisation erfolgt für $1.5 \mathrm{~h}$ auf dem Drehrad bei $4^{\circ} \mathrm{C}$.

Ungebundenes Protein wird durch mehrmaliges Waschen mit kaltem Transportpuffer $+1 \mu \mathrm{g} / \mathrm{ml} \mathrm{AP/LP}, 2 \mathrm{mM}$ DTT entfernt. Durch das nachfolgende Blockieren der Matrix mit 1\% BSA (w/v) in Transportpuffer für 30 min bei $4^{\circ} \mathrm{C}$ soll unspezifisches Binden von Proteinen vermieden werden.

Die Bindungsreaktion findet in einem Volumen von $300 \mu$ Transportpuffer $1+1$ $\mu \mathrm{g} / \mathrm{ml}$ AP/LP, 2 mM DTT) statt. Hierzu werden $5 \mu \mathrm{g}$ der jeweiligen Bindungspartner zum immobilisierten Protein hinzugegeben und der Ansatz wird bei $4^{\circ} \mathrm{C}$ für $1.5 \mathrm{~h}$ auf dem Drehrad inkubiert. Um alle ungebundenen Proteine zu entfernen, wird der Ansatz mehrmals mit kaltem Transportpuffer gewaschen. Die gebundenen Proteine können dann durch Zugabe von $50 \mu$ l Proteinprobenpuffer eluiert und durch SDSPAGE und nachfolgende Colloidale Coomassie-Färbung analysiert werden.

\subsubsection{Enzymgekoppelter Immunadsorptionstest (ELISA, Engvall et al, 1971 [151])}

Die Immobilisierung von $300 \mathrm{ng}(120 \mathrm{nM})$ GST-Ran an eine 96well Platte mit Proteaseinhibitoren findet über Nacht in Transportpuffer bei $4^{\circ} \mathrm{C}$ statt. Am nächsten Morgen wird ungebundenes Protein durch Waschen mit TP-Puffer $+3 \%$ BSA entfernt, GST-Ran mit GTP/GDP beladen (nach Kehlenbach et al., 1999 [50]) und dabei unspezifische Bindungsstellen mit 3\% BSA in TPB geblockt ( alternativ kann auch nach der Ran-Beladung für 30 min mit 3\% BSA geblockt werden). Einmal 
Waschen mit TP-Puffer $+3 \%$ BSA entfernt ungebundene Nucleotide. Die nachfolgende Bindungsreaktion findet für 75 min bei RT in einem Volumen von 50 $\mu$ statt. Jeder Ansatz entält 300 ng (70 nM) MBP-NLP1 und ansteigende Mengen an His-CRM1 (0, 1, 2.5, 5, 20, 50 nM). Einige Ansätze enthalten zusätzlich 300 ng (120 nM) His-Snurportin.

Nach dreimaligem Waschen mit TP-Puffer + 3\% BSA kann die Antikörperdetektion von gebundenem MBP-NLP1 durch den Kaninchen-Antikörper a-NLP1 3754 (Verdünnung, 1:5000, eine Stunde bei RT) und nachfolgendem HRP-gekoppeltemAntikörper gegen Kaninichen aus Esel (Verdünnung 1:2000, eine Stunde bei RT) erfolgen. Ungebundene Antikörper werden durch mehrmaliges Waschen mit TPPuffer entfernt. Die Analyse erfolgt mit Hilfe des „TMB Substrate Reagent Sets“ von Millipore und Messen der $\mathrm{OD}_{420}$ mittels „Platten-Leser“ (Appliskan von Thermo Scientific).

\subsubsection{Beladung von Ran mit GTP/GDP oder $\left[\gamma^{32} \mathrm{P}\right] \mathrm{GTP}$}

Die Beladung von Ran findet wie bei Kehlenbach et al., 1999 [50] beschrieben, statt. Durch Zugabe von 15 mM EDTA und und einem Überschuss des gewünschten Nucleotids (5 mM) zum Ran-Protein wird zunächst der Ran-Nucleotid-Komplex aufgelöst (20 min RT), um dann durch Zugabe von $40 \mathrm{mM} \mathrm{MgCl}$ erneut gebildet zu werden (15 min auf Eis).

Zur Beladung von Ran mit radioaktivem $\left[\gamma^{32}\right.$ P]GTP wird Ran verwendet, das zuvor schon mit GTP beladen war, da GDP eine höhere Affinität zu Ran besitz als GDP. Somit wird die Effizienz des Austausches von GTP zu $\left[\gamma^{32} \mathrm{P}\right]$ GTP erhöht. Nicht gebundenens GTP bzw [ $\gamma^{32}$ P]GTP kann mit Hilfe einer PD-10-Säule entfernt werden.

\subsubsection{RanGAP1-Assay}

Die RanGAP-Assays wurden wie in Askjaer et al., 1999 [106] durchgeführt. Im Reaktionsansatz $(60 \mu \mathrm{l})$ befinden sich $430 \mathrm{nM}$ CRM1, $500 \mathrm{nM}$ Ran[r $\left.{ }^{32} \mathrm{P}\right] \mathrm{GTP}$ und 
ansteigende Mengen der angegebenen Nucleoporine (MBP-NLP1 (1-423), MBPNup214-C-Terminus (AS1859-2090), Nup-88-C-Terminus (AS 500-741)). Nach 20 minütiger Komplexformation bei RT wird für weitere 10 min 16 nM RanGAP1 hinzugegeben. Die Reaktion wird durch Zugabe von $1 \mathrm{ml}$ Stopplösung (7\% (w/v) Aktivkohle, $10 \%$ (v/v) Ethanol, $100 \mathrm{mM} \mathrm{HCl}, 10 \mathrm{mM} \mathrm{Na}_{2} \mathrm{H}_{2} \mathrm{PO}_{4}$ ) abgestoppt. Durch anschließendes Zentrifugieren für 4 Minuten bei $13,000 \mathrm{~g}$ werden die Proteinkomponenten abgetrennt. Die Menge des freigesetzten radioaktiven $\gamma^{32} \mathrm{P}$ im Überstand wird durch Szintillationsmessung ermittelt. Die GTP-Hydrolyse wird in Prozent angegeben, wobei 100\% GTP-Hydrolyse dem Ansatz entspricht, der kein Nucleoporin enthält.

\subsubsection{Affinitäts-Aufreinigung polyclonaler Antikörper}

Von mir aufgereinigtes His-NLP1 1-204 wurde zur Immunisierung zweier Kaninchen durch die Firma BioGenes verwendet. Die Aufreinigung der Antikörper aus den gelieferten Seren erfolgt wie folgt: Zuerst wird rekombinantes MBP-NLP1 über Nacht gegen Carbonatpuffer $\left(0.2 \mathrm{M} \mathrm{NaHCO}_{3} \mathrm{pH}\right.$ 9.8) dialysiert und anschließend für 4 Stunden bei RT an CNBr-Matrix gekoppelt (1 mg MBP-NLP1/ml Matrix). Um die Effizienz der Kopplung zu überprüfen, wird die optische Dichte bei $280 \mathrm{~nm}$ vor und nach dem Koppeln gemessen. Die Matrix wird zweimal mit Carbonatpuffer gewaschen und dann eine Stunde mit 100 mM Ethanolamin geblockt. Nach weiteren drei Waschschritten mit $500 \mathrm{mM} \mathrm{NaCl}$ in PBS kann die Affinitätsaufreinigung erfolgen. $750 \mu \mathrm{l}$ der MBP-NLP1-gekoppelten Beads werden über Nacht mit $10 \mathrm{ml}$ Serum verdünnt mit $30 \mathrm{ml}$ PBS, bei $4^{\circ} \mathrm{C}$ inkubiert. Am nächsten Morgen wird die Matrix zweimal mit PBS $+500 \mathrm{mM} \mathrm{NaCl}$ gewaschen, in eine Säule gefüllt und solange weiter gewaschen, bis im Durchfluss kein Protein mehr nachzuweisen ist. Die Antikörper werden mit Elutionspuffer (200 mM Essigsäure $\mathrm{pH}$ 2.7, $500 \mathrm{mM} \mathrm{NaCl}$ ) eluiert, wobei $500 \mu \mathrm{l}$ Fraktionen gesammelt und schnell mit $1 \mathrm{M}$ Tris Base neutralisiert (100 $\mu \mathrm{l} /$ Fraktion) werden. Mittels PonceauFärbung werden die Fraktionen ermittelt, die den Antikörper enthalten. Diese Fraktionen werden vereinigt, eingeengt auf ca. $500 \mu \mathrm{l}$ und der Puffer gegen PBS 
ausgetauscht. Anschließend werden die Antikörper mit einem Volumen 87\% Glycerol (v/v) versetzt und bei $-20^{\circ} \mathrm{C}$ gelagert.

\begin{tabular}{|l|l|l|}
\hline Name des Antikörpers & Verdünnung im WB & Verdünnung in IF \\
\hline NLP1 3754 & $1: 2000$ & $1: 500$ \\
\hline NLP1 3755 & $1: 2500$ & $1: 3000$ \\
\hline
\end{tabular}

\subsection{Zellbiologische Methoden}

\subsubsection{Kultivierung adhärent-wachsender HeLa-Zellen}

Adhärent-wachsender HeLa-Zellen werden auf $10 \mathrm{~cm}$ Platten in „Dulbecco's modified Eagle Medium“ (DMEM) mit 10\% (v/v) fetalem Kälberserum (FCS) und 2 $\mathrm{mM}$ Glutamin in einem humiden Inkubator mit $5 \% \mathrm{CO}_{2}$ bei $37^{\circ} \mathrm{C}$ gehalten. Kurz bevor die Zellen konfluent werden, werden sie 1:10 aufgeteilt. Hierzu werden sie zunächst mit PBS gewaschen, mit Trypsin/EDTA abgelöst und mit frischem Medium verdünnt.

\subsubsection{Beschichten der Deckgläschen mit Poly-L-Lysin}

Um die Adhärenz von HeLa-Zellen auf Deckgläschen zu verbessern, werden diese mit Poly-L-Lysin beschichtet. Nachdem die Deckgläschen mit Isopropanol entfettet sind, wird jedes Slide mit einem Tropfen 0.01\% Poly-L-Lysin (v/v) beschichtet. Nach 30 min werden die Deckgläschen einmal mit Wasser gewaschen und getrocknet. Durch Behandlung mit UV-Strahlung $\left(3 \mathrm{~min}\right.$ mit $\left.0.12 \mathrm{~J} / \mathrm{cm}^{2}\right)$ werden die Deckgläschen sterilisiert und sind somit Zellkultur geeignet. 


\subsubsection{Transiente Transfektion mittels Calcium-Phosphat-Methode nach Ausubel et al., 1994 [152]}

Die zu transfizierenden Zellen befinden sich in $500 \mu$ DMEM/24 well. 0.75-1 $\mu \mathrm{g}$ der zu transfizierenden DNA wird in ein steriles $1.5 \mathrm{ml}$ Eppendorfgefäß gegeben und durch Vortexen mit $20 \mu \mathrm{l} 250 \mathrm{mM} \mathrm{CaCl}_{2}$ gemischt. Als nächstes wird $20 \mu \mathrm{l} 2 \mathrm{xHBS}$ pH 6.93 hinzugegeben und $10 \mathrm{~s}$ gevortext. Nach einer Inkubation von 20-30 min wird der gesamte Transfektionsansatz über Nacht auf die Zellen gegeben. Am nächsten Tag werden die Zellen zweimal mit PBS gewaschen und neues Medium hinzugegeben.

\subsubsection{Transiente Transfektion mittels Polyfect}

Transiente Transfektion von HeLa-Zellen mittels Polyfekt (Qiagen) wurde gemäß Herstellerangaben durchgeführt.

\subsection{5. Überexpression und Detektion fluoreszierender Proteine}

HeLa-Zellen werden auf Poly-L-Lysin beschichteten $12 \mathrm{~mm}$ Deckgläschen ausgesät und dann wie oben angegeben transfiziert und für 24-48 h weiterkultiviert. Um die Zellen zu fixieren, werden sie zweimal mit PBS gewaschen und dann mit 3.7\% (v/v) Formaldehyd in PBS für 15 min fixiert. Um die Zellkerne anzufärben, kann der Formaldehydlösung Hoechst 33258 (Verdünnung 1:10.000) hinzugefügt werden. Danach werden die Zellen dreimal für 5 min mit PBS gewaschen, getrocknet und im Histogel-Mounting Medium (Linaris) eingebettet.

Zur Auswertung diente entweder das Fluoreszenz-Mikroskop „Axioskop II“ von Zeiss oder das konfokale Mikroskop „Zeiss LSM 510 Meta Konfokal Mikroskop“ sowie die Software AxioVision(LE)Rel.IV.5. 


\subsubsection{Indirekte Immunfluoreszenz}

HeLa-Zellen werden auf Poly-L-Lysin-beschichteten $12 \mathrm{~mm}$ Deckgläschen ausgesät, transfiziert und für 24-48 $\mathrm{h}$ weiter kultiviert. Wie oben beschrieben, werden die Zellen 15 min mit 3.7\% (v/v) Formaldehyd fixiert und einmal mit PBS gewaschen. Um die Membranen der Zellen für die Antikörper durchgängig zu machen, werden die Zellen 5 min mit 0.5\% (v/v) Triton permeabilisiert. Das Triton wird danach durch Waschen mit PBS entfernt. Um unspezifische Bindungen der Antikörper zu vermeiden, werden die Zellen für 15 min mit 1\% BSA in PBS geblockt. Nach dem Blocken kann der erste Antikörper (Verdünnung wie im Materialteil beschrieben) für eine Stunde bei RT auf die Zellen gegeben werden. Nach drei anschließenden Waschschritten für je 5 min mit 1\% BSA in PBS kann die Detektion des ersten Antikörpers durch den zweiten, Alexa-gekoppelten Antikörper (Verdünnung 1:1000 $-1: 2000$, in PBS + 1\% BSA) für eine Stunde bei RT erfolgen. Durch Waschen mit PBS werden alle ungebundenen Antikörper entfernt (dreimal für 5 min). Nun können die Zellen getrocknet und im Histogel (Linaris) eingedeckelt werden. Die Analyse erfolgt wie bei der Detektion fluoreszierender Proteine.

\subsubsection{Fluoreszenz-in situ-Hybridisierung (FISH) (Gall et al., 1969 [153]) in}

\section{Kombination mit Immunfluoreszenz}

Die Fluoreszenz-in situ-Hybridisierung macht es möglich, spezifische RNA-Moleküle in der Zelle zu lokalisieren. In dieser Arbeit wurde eine Digoxygenin-gekoppelte Sonde $(\mathrm{dT})_{40}$ verwendet, die gegen den „Poly-A-Schwanz" von mRNAs gerichtet ist. Somit kann mit dieser Detektion die Lokalisation des gesamten poly(A)-mRNA-Pools betrachtet werden.

Alle zu dieser Färbung erforderlichen Lösungen werden mit DEPC behandelt um RNasen zu inaktivieren. Hierzu wird über Nacht 0.1\% DEPC zu den Puffern gegeben und anschließend autoklaviert.

Die auf beschichteten Deckgläschen gewachsenen Zellen werden mit 3.7\% Formaldehyd für 15 min bei RT fixiert und danach mit $0.5 \%(v / v)$ Triton in in PBS 
permeabilisiert. Zur Äquilibrierung werden die Zellen mit 2xSCC/25\% (v/v) Formamid für 5 min inkubiert. Danach kann die Hybridisierung der Sonde $(1 \mathrm{ng} / \mathrm{ml}$ Hybridisierungspuffer) für $2 \mathrm{~h}$ bei $37^{\circ} \mathrm{C}$ in einer feuchten Kammer durchgeführt werden. Anschließend werden die Zellen zweimal mit 2xSCC und 25\% Formamid für je $15 \mathrm{~min}$ bei $37^{\circ} \mathrm{C}$, einmal für 15 min mit $0.5 x$ SCC bei RT und einmal mit $0.5 \%(v / v)$ Triton in PBS gewaschen. Danach kann die Detektion der Sonde mittels Immunfärbung stattfinden. Bei dem zweiten Antikörper handelt es sich um ein Fluorescein-Isothiocyanat (FITC)-gekoppelten Schaf anti-Digoxygenin-Fab-Fragment (Roche), der 1:300 eingesetzt wird.

\subsubsection{Transfekion von siRNAs mit Oligofectamin (Invitrogen) in HeLaP4-Zellen}

Zur Transfektion von in dieser Arbeit verwendeten siRNAs, die gegen NLP1 gerichtet sind, werden HeLa-Zellen in 24well-Platten, die mit Poly-L-Lysin beschichtetem Deckgläschen bestückt sind, so ausgesät, dass sie zum Zeitpunkt der Transfektion ca. 30\% konfluent sind. Die Transfektion erfolgt wie im Protokoll von Invitrogen angegeben. Es wird pro 24 well $100 \mathrm{nM}$ siRNA verwendet. $12 \mathrm{~h}$ nach der Transfektion findet ein Mediumwechsel statt. Zu diesem Zeitpunkt können die Zellen mit Plasmiden transfiziert werden. $48 \mathrm{~h}$ nach der siRNA-Transfektion ist die Depletion von NLP1 optimal, was durch Westernblot-Analyse überprüft werden kann.

\subsubsection{In vivo Exportassay von GFP-NFAT (nnuclear factor of activated t-cells)}

Stabiltransfizierte GFP-NFAT-Zellen (Hutten et al., 2006 [51]) wurden auf Poly-LysinDeckgläschen ausgesät und NLP1 durch siRNA-Transfektion depletiert.

Am Vortag des Versuchs wird die Expression von GFP-NFAT durch Zugabe von $1 \mu \mathrm{M}$ Trichostatin A (TSA) induziert. Am nächsten Morgen findet ein Mediumwechsel mit $1 \mu \mathrm{M}$ lonomycin in DMEM statt, was eine Dephosphorylierung und somit den Import von GFP-NFAT zur Folge hat. Um den Export genauer zu untersuchen, wird 
nach 30 min das lonomycin gründlich mit DMEM weggewaschen, so dass GFP-NFAT erneut phosphoryliert und der Export von GFP-NFAT stattfinden kann. Die Zellen werden dafür mit DMEM für $1 \mathrm{~h}$ inkubiert. Durch anschließende Fixierung der Zellen mit 3.7\% Formaldehyd wird der Export abgestoppt. Die Analyse erfolgt mikroskopisch. Hierbei wird von jeweils 100 Zellen pro Ansatz die Lokalisation von GFP-NFAT bestimmt.

\subsubsection{In vitro Exportassay nach Kehlenbach et al., 1998 [128]}

Stabil-transfizierte GFP-NFAT-Zellen (HeLa NFAT Spinner, Kehlenbach et al., 1998 [128]) werden am Vortrag mit $1 \mu \mathrm{M}$ TSA induziert. Am nächsten Tag wird der Import von GFP-NFAT durch Zugabe von $1 \mu \mathrm{M}$ Ionomycin für $30 \mathrm{~min}$ im Inkubator induziert. Die Zellen werden mittels Trypsin von der Platte abgelöst, einmal mit eiskaltem PBS $+10 \%$ FCS und einmal mit eiskaltem PBS gewaschen, bevor sie mit $0.01 \%$ Digitonin in Transportpuffer für 5 min auf Eis permeabilisiert werden. Alle cytosolischen Faktoren werden durch zweimal Waschen mit kaltem Transportpuffer entfernt. Nun werden rekombinante Exportfaktoren (1.5 $\mu \mathrm{M}$ Ran, 225 nM CRM1, $4.5 \mu \mathrm{M}$ MBPNLP1) in verschiedenen Kombinationen sowie ein ATP-regenerierendes System (1 mM ATP, $2.8 \mathrm{mM}$ Creatinphosphat, $0.4 \mathrm{U}$ Creatinphosphokinase) und ca. $1 \mu \mathrm{M}$ NFAT-Oligodimer (5`AGAGGAAAATTTGTTTCATA) zu den permeabilisierten Zellen (100,000 pro Probe) gegeben. Der Export findet in Transportpuffer mit $2.5 \mathrm{mg} / \mathrm{ml}$ BSA bei $30^{\circ}$ oder $4^{\circ} \mathrm{C}$ statt. Zu den angegebenen Zeitpunkten werden den Ansätzen Proben entnommen, bei denen der Export sofort durch Verdünnen mit eiskaltem Transportpuffer abgestoppt wird. Die Auswertung des Versuchs erfolgt mittels Durchflusszytometrie. Um verschiedene Ansätze vergleichen zu können, wurde die zum Zeitpunkt 0 min gemessene Fluoreszenz auf $100 \%$ gesetzt und alle nachfolgenden Werte darauf normalisiert. 


\subsubsection{FLIP (fluorescence loss in photobleaching)}

Um Export-Kinetiken von Shuttle-Konstrukten unter verschiedenen Bedingungen zu vergleichen, werden FLIP-Experimente durchgeführt (abgewandelt aus Hilliard et al., 2010 [154]). Hierzu werden HeLa-Zellen auf beschichtete Deckgläschen ausgesät und transfiziert.

Die Experimente werden mit dem „LSM 510 Meta Konfokal Mikroskop“ von Zeiss mit einem „LCl Plan-Neofluar63x/1.3 Imm Korr DIC Objektiv“ durchgeführt und finden bei $37^{\circ} \mathrm{C}$ in $\mathrm{CO}_{2}$-unabhängigem Medium statt. Hierzu wird ein Bereich mit festgelegter Größe (ROI1) im Cytoplasma der zu untersuchenden Zelle 200 bis 400 mal durch den 488nm Argon-Laser mit 100\% Intensität geblichen und nach jedem

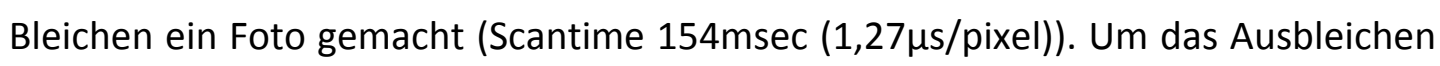
der Fluoreszenz durch das Bildermachen zu vermeiden, wird die Laserintensität auf 1.1\% gesetzt. Vor dem ersten Bleichen werden zur Äquilibrierung 20 Fotos gemacht. Für jeden Zeitpunkt wird mit Hilfe der ROI-Funktion (Region Of Interest) der LSMSoftware die Fluoreszenz verschiedener Bereiche gemessen. ROI1 ist der gebleichte Bereich, ROI2 der Zellkern der geblichenen Zelle, ROI3 ein Bereich einer ReferenzZelle, die sich in der Nähe der geblichenen Zelle befindet und ROI4 ist der Hintergrund. Die Fluoreszenzintensität des Kerns wird dann wie folgt berechnet: Fluoreszenz $\mathrm{K}_{\text {Kern }}=(\mathrm{ROI2}-\mathrm{ROI} 4) /(\mathrm{ROI3}-\mathrm{ROI} 4)$. Um verschiedene Zellen miteinander vergleichen zu können, werden die „Prä-Bleich-Fluoreszenzen“ auf 1 normalisiert. In der untenstehenden Liste sind die Daten der verschiedenen Experimente aufgeführt.

\begin{tabular}{l|l|l} 
Experiment & $\begin{array}{l}\text { Anzahl der } \\
\text { Bilder }\end{array}$ & $\begin{array}{l}\text { Zeit zwischen den } \\
\text { Bildern }\end{array}$ \\
\hline GFP-Snurportin mit RFP-NLP1 Cotransfektion & 300 & $521 \mathrm{~ms}$ \\
\hline NC2ß-GFP 2 und NLP1-Depletion & 200 & $512 \mathrm{~ms}$ \\
\hline GFP-NLP1 und NC2ß-GFP $2+/-L M B$ & 150 & ca. 2 s
\end{tabular}


5.3.12. FRAP (fluorescence recovery after photobleaching) (abgewandelt aus Köster et al., 2006 [155])

Mit Hilfe von FRAP lässt sich eine Aussage über die Mobilität eines Proteins in einem bestimmten Zellkompartiment machen.

FRAP findet wie beim FLIP-Experiment bei $37^{\circ} \mathrm{C}$ in $\mathrm{CO}_{2}$-unabhängigen Medium mit Hilfe des „LSM 510 Meta Konfokal Mikroskop“ von Zeiss statt.

Nachdem zur Äquilibrierung 20 Bilder gemacht wurden, findet ein einmaliges Bleichen (ROI1) in einem definierten Bereich im Zellkern statt. Danach werden weitere 380 Bilder gemacht (154 ms/Bild) und jedes Mal die Fluoreszenz in ROI1, in einer Referenz-Zelle (ROI2) und des Hintergrundes (ROI3) gemessen. Die Berechnung der Werte wurde mittels LSM-Software und Microsoft Exel durchgeführt. 
A

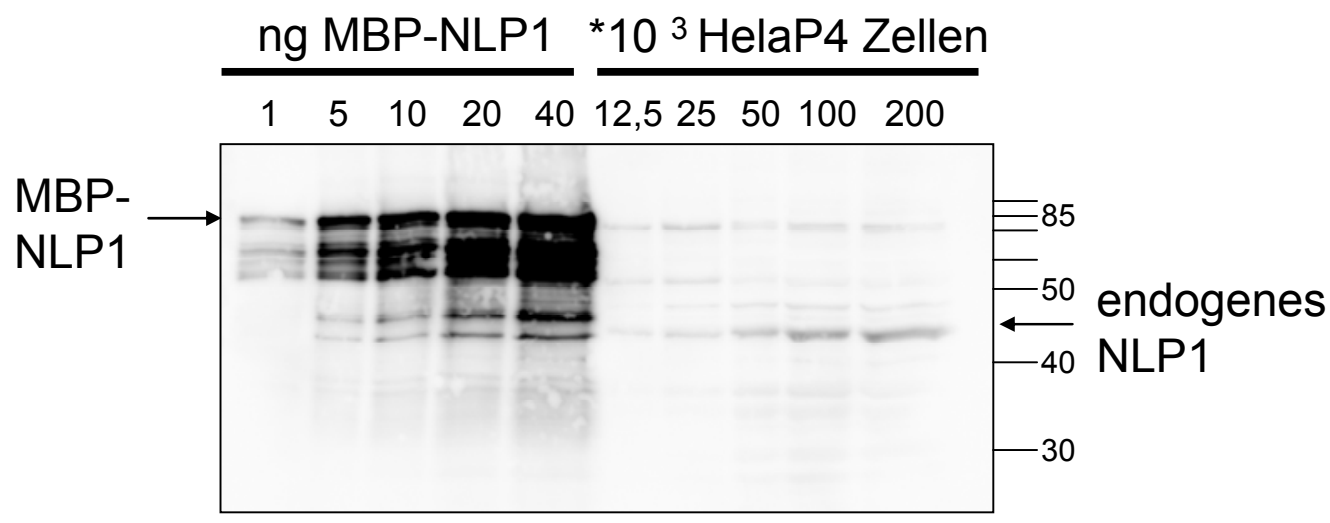

B

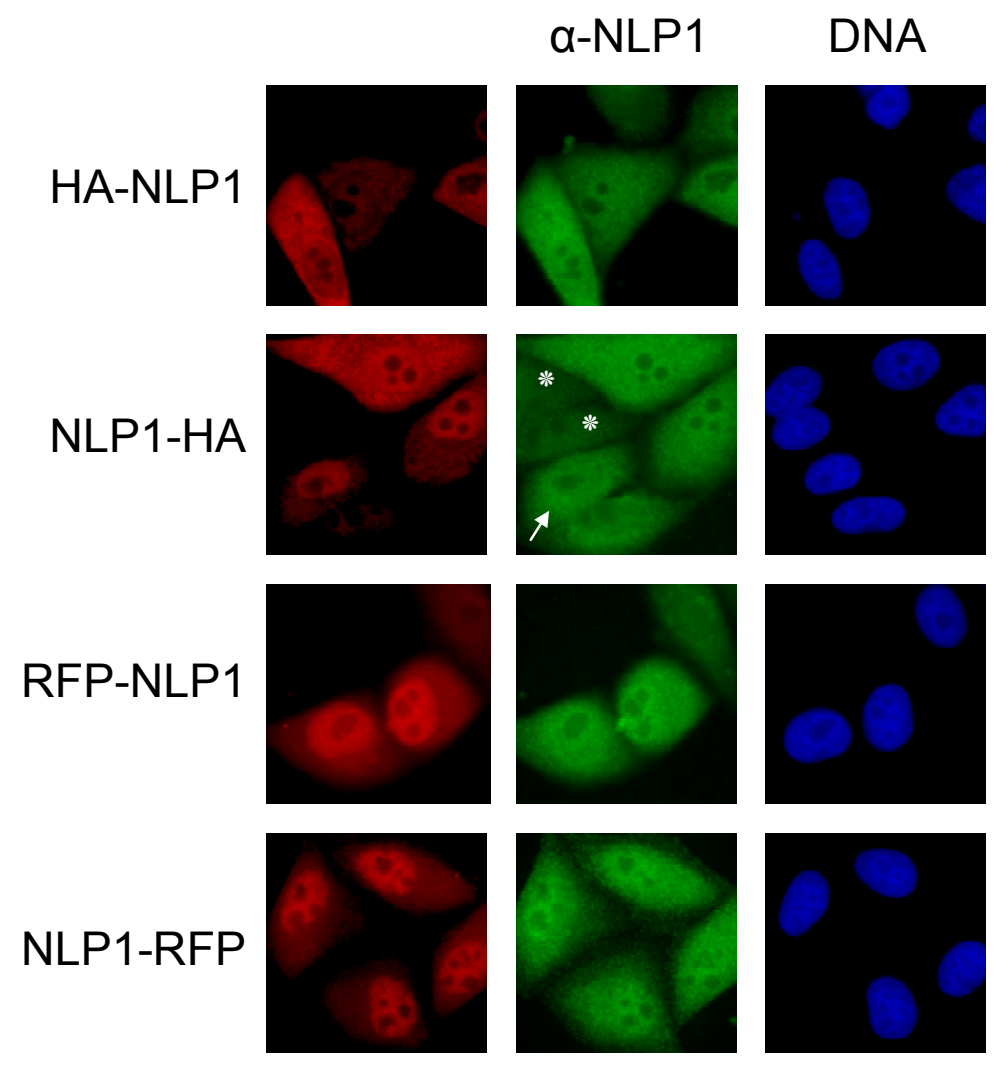

Abb. S1 A) Western Blot-Detektion von rekombinantem MBP-NLP1 und endogenem NLP1 Verschiedene Mengen MBP-NLP1 (1, 5, 10, 20, $40 \mu \mathrm{g})$ sowie eine ansteigende Anzahl von HeLa-P4Zellen wurden auf ein SDS-Gel aufgetragen und die Proteine der Größe nach elektrophoretisch aufgetrennt. Die Detektion erfolgte durch Immunoblot-Analyse mit $\alpha$-NLP1 3754-Antikörper (1:2000). B) Immunofluoreszenz von überexprimiertem NLP1 HeLa-Zellen wurden mit HA-NLP1, NLP1-HA, RFP-NLP1 sowie NLP1-RFP transfiziert und die Lokalsisation sowohl von endogenem als auch von überexprimiertem NLP1 durch indirekte Immunufluoreszenz mit $\alpha$-NLP1 3754 (1:500) analysiert. Die Sterne zeigen Zellen, die nicht transfiziert sind. Der Pfeil zeigt eine Zelle, die mit NLPHA transfiziert ist. 


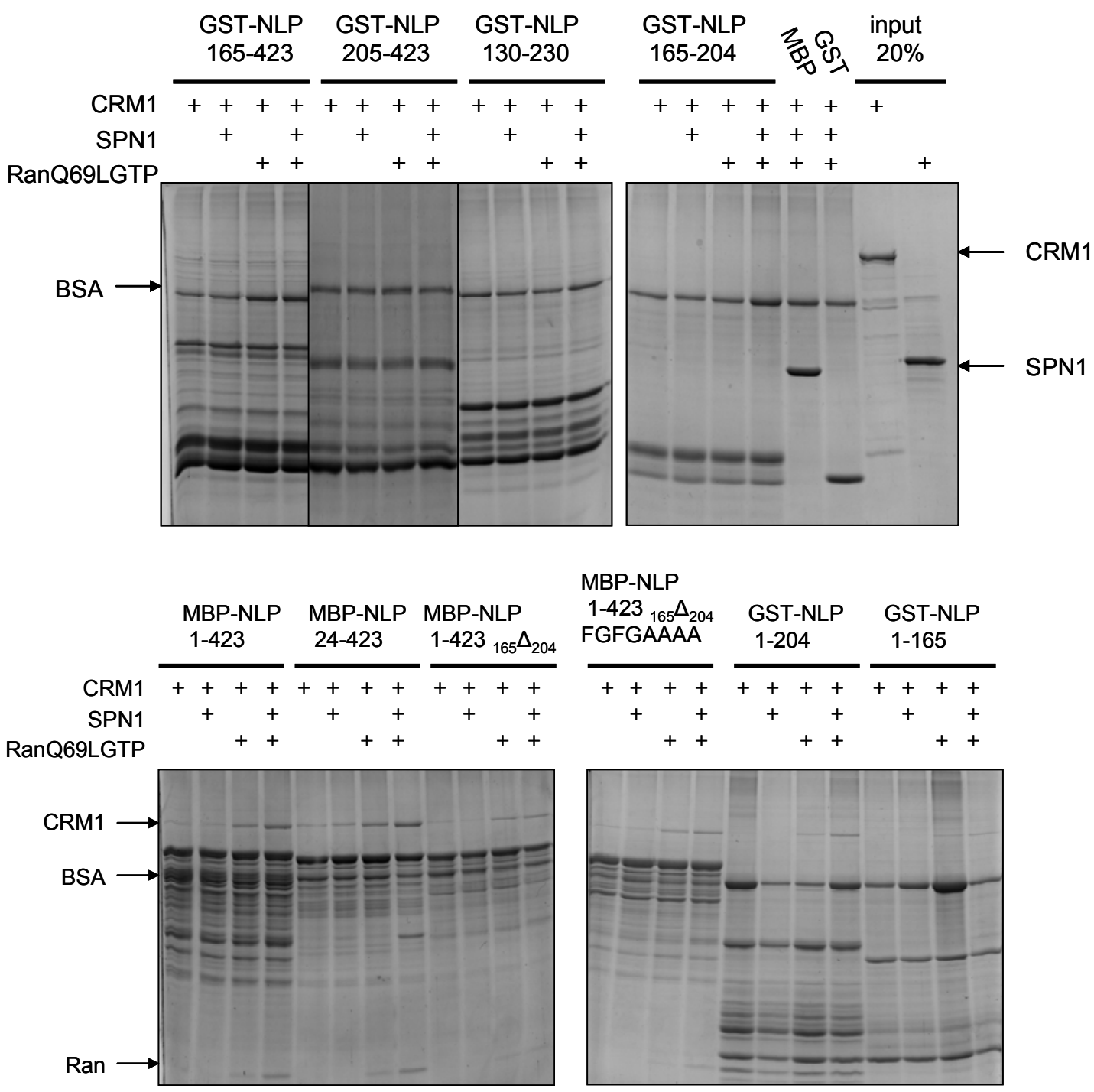

Abb. S2A Identifizierung der CRM1-Binderegion in NLP1 $5 \mu \mathrm{g}$ der jeweiligen NLP1-Fragmente (sowie GST oder MBP als Kontrolle) wurden an ihre entsprechende Matrix gebunden und in verschiedenen Kombinationen mit $5 \mu \mathrm{g}$ His-CRM1, $5 \mu \mathrm{g}$ His-Snurportin1 und ca. $5 \mu \mathrm{g}$ RanQ69LGTP inkubiert. Die gebundenen Proteine wurden mit Proteinprobenpuffer eluiert und durch SDS-PAGE und nachfolgende Coomassie-Färbung analysiert. 

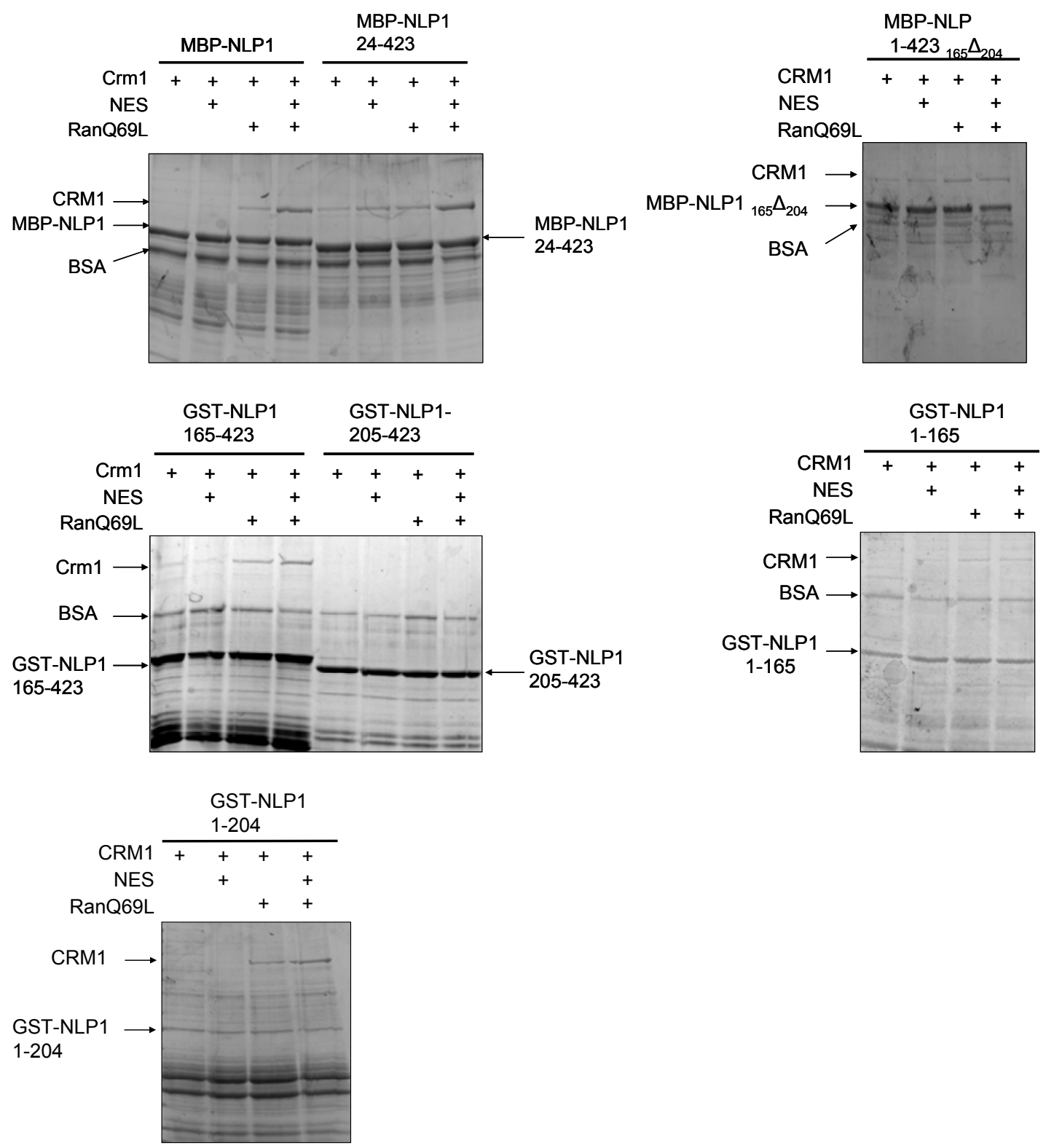

Abb. S2B Identifizierung der CRM1-Binderegion in NLP1 $5 \mu \mathrm{g}$ der jeweiligen NLP1-Fragmente wurden an ihre entsprechende Matrix gebunden und in verschiedenen Kombinationen mit $5 \mu \mathrm{g}$ HisCRM1, NES-Peptid und ca. $5 \mu \mathrm{g}$ RanQ69LGTP inkubiert (das NES-Peptid (CVDEMTKKFGTLTIHDTEK) stammt aus NS2 protein of minute virus of mice (Askjaer et al., 1999 [106]). Die gebundenen Proteine wurden mit Proteinprobenpuffer eluiert und durch SDS-PAGE und nachfolgende Coomassie-Färbung analysiert. 
A
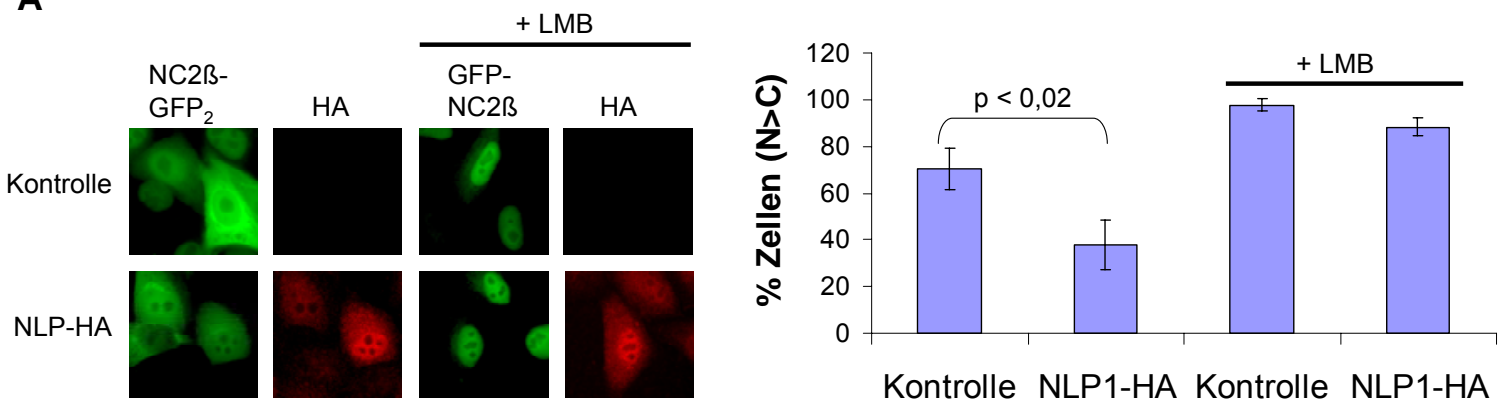

B
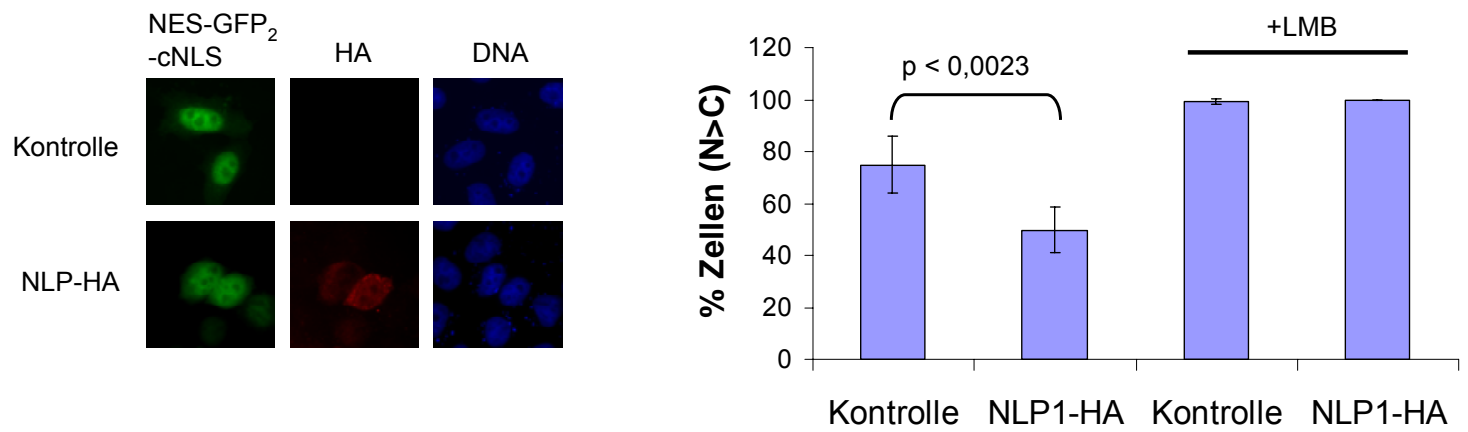

Abb. S4 Die subzelluläre Lokalisation von NC2ß-GFP $P_{2}$ und eines artifiziellen Shuttle-Konstrukts (Rev(47-116)-GFP2-cNLS) wird durch Überexpression von NLP1-HA ins Cytoplasma verlagert. HeLaZellen werden mit den Reporterproteinen NC2ß-GFP 2 (A) oder Rev(47-116)-GFP2-cNLS (B) und NLP1HA (bzw. HA zur Kontrolle) cotransfiziert. Nach $48 \mathrm{~h}$ wurden die HA-Konstrukte durch indirekte Immunfluoreszenz angefärbt. Die Analyse erfolgte durch Fluoreszenzmikroskopie und Auszählen (Die Bilder der Kontrolle in A sind sind dieselben wie in Abb. 2.15.A, da es sich hier um einen Versuch handelt). Der Graph gibt in Prozent an, wieviele der analysierten Zellen eine eindeutige Kernlokalisation $(\mathrm{N}>\mathrm{C})$ von $\mathrm{NC} 2 \mathrm{~B}_{-} \mathrm{GFP}_{2}$ zeigen. Pro Transfektionsansatz wurden mehr als 100 Zellen analysiert. Zur Kontrolle wurden die Zellen für 2,5 h mit $5 \mathrm{nM}$ LMB behandelt. Die Fehlerbalken geben die Standardabweichungen von mindestens drei unabhängigen Experimenten an. Die p-Werte wurden Hilfe des Student's T-Tests ermittelt.

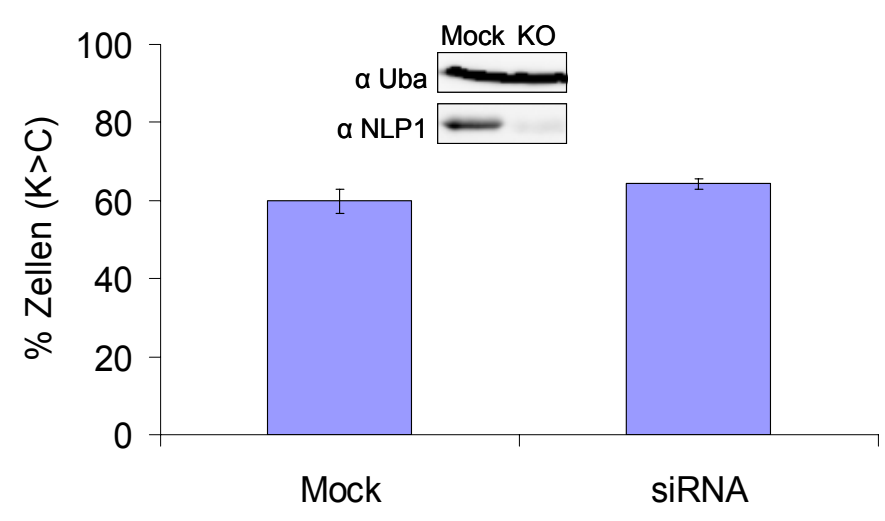

Abb. S5 NLP1 Depletion hat keinen Einfluss auf das „steady state-Verhalten“ von NLP1. HeLaP4 wurden mit $12 \mathrm{~h}$ mit siRNA behandelt und dann für $48 \mathrm{~h}$ mit NC2ß-GFP2-transfiziert. Die Analyse erfolgte durch Fluoreszenzmikroskopie und Auszählen. Die Qualität der Depletion wurde mittels WesternBlot analysiert. 


\subsection{Proteinsequenz von NLP1}

1 MAICQFFLQG RCRFGDRCWN EHPGARGAGG

31 GRQQPQQQPS GNNRRGWNTT SQRYSNVIQP

61 SSFSKSTPWG GSRDQEKPYF SSFDSGASTN

91 RKEGFGLSEN PFASLSPDEQ KDEKKLLEGI

121 VKDMEVWESS GQWMFSVYSP VKKKPNISGF

151 TDISPEELRL EYHNFLTSNN LQSYLNSVQR

181 LINQWRNRVN ELKSLNISTK VALLSDVKDG

211 VNQAAPAFGF GSSQAATFMS PGFPVNNSSS

241 DNAQNFSFKT NSGFAAASSG SPAGFGSSPA

271 FGAAASTSSG ISTSAPAFGF GKPEVTSAAS

301 FSFKSPAASS FGSPGFSGLP ASLATGPVRA

331 PVAPAFGGGS SVAGFGSPGS HSHTAFSKPS

361 SDTFGNSSIS TSLSASSSII ATDNVLFTPR

391 DKLTVEELEQ FQSKKFTLGK IPLKPPPLEL

421 LNV 


\section{Abkürzungen}

\subsection{Symbole für Aminosäuren}

$\begin{array}{ll}\text { A } & \text { Alanin } \\ \text { C } & \text { Cystein } \\ \text { E } & \text { Aspartat } \\ \text { F } & \text { Glutamat } \\ \text { G } & \text { Phenylalanin } \\ \text { H } & \text { Glycin } \\ \text { I } & \text { Histidin } \\ \text { K } & \text { Isoleucin } \\ \text { L } & \text { Lysin } \\ \text { M } & \text { Leucin } \\ \text { N } & \text { Methionin } \\ \text { P } & \text { Asparagin } \\ \text { Q } & \text { Prolin } \\ \text { R } & \text { Glutamin } \\ \text { S } & \text { Arginin } \\ \text { T } & \text { Serin } \\ \text { V } & \text { Threonin } \\ \text { W } & \text { Valin } \\ \text { Tryptophan }\end{array}$




\subsection{Allgemeine Abkürzungen}

\begin{tabular}{|c|c|}
\hline Abb. & Abbildung \\
\hline AP & Aprotinin \\
\hline ATP & Adenosintriphosphat \\
\hline BSA & Bovine serum albumin \\
\hline CRM1 & Chromosome Reion Maintenance 1 \\
\hline C-terminal & carboxyterminal \\
\hline $\mathrm{Da}$ & Dalton \\
\hline DEAE & Diethylaminoethyl \\
\hline DEPC & Diethylpyrocarbonat \\
\hline DMEM & $\begin{array}{l}\text { Dulbecco`s Modification of Eagle`s Minimum Es- } \\
\text { sential Medium }\end{array}$ \\
\hline DNA & Desoxyribonukeinsäure \\
\hline dNTPs & 2`-Desoxyribonukleosidtriphosphate \\
\hline DTT & 1,4-Dithiotreitol \\
\hline ECL & Enhanced Chemoluminescence \\
\hline E.coli & Escherichia coli \\
\hline EDTA & Ethylendiamintetraessigsäure \\
\hline FG & Phenylalanin-Glycin \\
\hline g & Erdbeschleunigung \\
\hline GDP & Guanosindiphosphat \\
\hline GFP & Green Fluorescent Protein \\
\hline GTP & Guanosintriphosphat \\
\hline h & Stunde \\
\hline HEPES & $\mathrm{N}$-(2-Hydroxyethyl)piperazin- $\mathrm{N}^{\prime}$-ethansulfonsäure \\
\hline HIV & Human Immunodeficiency virus \\
\hline hnRNP & Heterogenes nukleäres Ribonukleoprotein \\
\hline IBB & Importin $\beta$ Bindedomäne \\
\hline IPTG & Isopropyl-beta-D-thiogalactosidase \\
\hline J & Joule \\
\hline kb & Kilobase \\
\hline
\end{tabular}




\begin{tabular}{|c|c|}
\hline kDA & Kilodalton \\
\hline I & Liter \\
\hline LB & Luria Bertani \\
\hline LMB & Leptomycin B \\
\hline LP & Leupeptin \\
\hline m & milli \\
\hline M & Mega \\
\hline M & Molar \\
\hline $\mathrm{mA}$ & Milliampère \\
\hline MBP & Maltose-Bindeprotein \\
\hline $\min$ & Minute \\
\hline mg & Milligram \\
\hline $\mathrm{ml}$ & Milliliter \\
\hline $\mathrm{mM}$ & Millimolar \\
\hline mol & Mol \\
\hline mRNA & Messenger RNA \\
\hline$\mu \mathrm{l}$ & Mikroliter \\
\hline$\mu g$ & Mikrogramm \\
\hline NES & Nuklear Export Signal \\
\hline NFAT & nuclear factor of activated T-cells \\
\hline ng & Nanogramm \\
\hline NLS & Nuclear Localisation Signal \\
\hline $\mathrm{nM}$ & Nanomolar \\
\hline $\mathrm{nm}$ & Nanometer \\
\hline NPC & Nuclear Pore Complex \\
\hline NTA & Nitrilotriacetic Acid \\
\hline NTF2 & Nuclear Transport Factor2 \\
\hline Nup & Nucleoporin \\
\hline OD & Optische Dichte \\
\hline PAGE & Polyacrylamid-Gelelektrophorese \\
\hline PBS & Phosphate Buffered Saline \\
\hline PCR & Polymerase Kettenreaktion \\
\hline
\end{tabular}




\begin{tabular}{|c|c|}
\hline Ran & Ras related nuclear protein \\
\hline RanBP1 & Ran Bining Protein 1 \\
\hline RanGAP1 & RanGTPase Activating Protein1 \\
\hline Ran GEF & Ran Guanosine Nucleotide Exchange Factor \\
\hline RCC1 & Regulator of Chromosome Condensation 1 \\
\hline RFP & Red Fluorescent Protein \\
\hline RNA & Ribonukleinsäure \\
\hline RNase & Ribonuklease \\
\hline rRNA & Ribosomale RNA \\
\hline RT & Raumtemperatur \\
\hline $\mathbf{s}$ & Sekunde \\
\hline SDS & Natrium-Dodecylsulfat \\
\hline SV40 & Simian Virus 40 \\
\hline SSC & Standard Saline Citrate \\
\hline TAP & $\begin{array}{l}\text { Tip-(Herpesvirus saimiri tyrosine-kinase-interacting- } \\
\text { protein) associated protein }\end{array}$ \\
\hline TE & Tris/EDTA \\
\hline TEMED & $\mathrm{N}, \mathrm{N}, \mathrm{N}, \mathrm{N}-$-Tetramethylethylendiamin \\
\hline Tris & Tris(hydroymethyl)aminomethan \\
\hline tRNA & Transfer RNA \\
\hline TSA & Trichostatin A \\
\hline$\mu g$ & Mikrogramm \\
\hline$\mu l$ & Mikroliter \\
\hline$\mu \mathrm{M}$ & Mikromolar \\
\hline $\mathbf{U}$ & Enzymeinheit (Unit) \\
\hline UsnRNA & Uracil-rich small-nuclear-RNA \\
\hline WB & Western Blot \\
\hline WGA & Wheat Germ Agglutinin \\
\hline
\end{tabular}




\section{LITERATURVERZEICHNIS}

1. Fried H, Kutay U: Nucleocytoplasmic transport: taking an inventory. Cell Mol Life Sci 2003, 60(8):1659-1688.

2. Weis K: Regulating access to the genome: nucleocytoplasmic transport throughout the cell cycle. Cell 2003, 112:441-451.

3. Mosammaparast N, Pemberton LF: Karyopherins: from nuclear-transport mediators to nuclear-function regulators. Trends Cell Biol 2004, 14(10):547556.

4. Cook A, Bono F, Jinek M, Conti E: Structural biology of nucleocytoplasmic transport. Annu Rev Biochem 2007, 76:647-671.

5. Wente SR, Rout MP: The nuclear pore complex and nuclear transport. Cold Spring Harb Perspect Biol, 2(10):a000562.

6. Pemberton LF, Paschal BM: Mechanisms of receptor-mediated nuclear import and nuclear export. Traffic 2005, 6(3):187-198.

7. Andrade MA, Petosa C, O'Donoghue SI, Muller CW, Bork P: Comparison of ARM and HEAT protein repeats. $J \mathrm{Mol}$ Biol 2001, 309(1):1-18.

8. Andrade MA, Bork P: HEAT repeats in the Huntington's disease protein. Nat Genet 1995, 11(2):115-116.

9. Dingwall C, Sharnick SV, Laskey RA: A polypeptide domain that specifies migration of nucleoplasmin into the nucleus. Cell 1982, 30:449-458.

10. Kalderon D, Roberts BL, Richardson WD, Smith AE: A short amino acid sequence able to specify nuclear location. Cell 1984, 39(3 Pt 2):499-509.

11. Robbins J, Dilworth SM, Laskey RA, Dingwall C: Two interdependent basic domains in nucleoplasmic nuclear targeting sequence: identification of a class of bipartide nuclear targeting sequence. Cell 1988, 64:615-623.

12. Huber J, Cronshagen U, Kadokura M, Marshallsay C, Wada T, Sekine M, Luhrmann R: Snurportin1, an m3G-cap-specific nuclear import receptor with a novel domain structure. Embo J 1998, 17(14):4114-4126.

13. Michael WM, Choi M, Dreyfuss G: A nuclear export signal in hnRNP A1: a signal-mediated, temperature- dependent nuclear protein export pathway. Cell 1995, 83(3):415-422.

14. Siomi H, Dreyfuss G: A nuclear localization domain in the hnRNP A1 protein. J Cell Biol 1995, 129(3):551-560.

15. Pollard VW, Michael WM, Nakielny S, Siomi MC, Wang F, Dreyfuss G: A novel receptor-mediated nuclear protein import pathway. Cell 1996, 86(6):985994.

16. Bonifaci N, Moroianu J, Radu A, Blobel G: Karyopherin beta2 mediates nuclear import of a mRNA binding protein. Proc Natl Acad Sci U S A 1997, 94(10):5055-5060.

17. Fornerod M, Ohno M, Yoshida M, Mattaj IW: CRM1 is an export receptor for leucine-rich nuclear export signals. Cell 1997, 90(6):1051-1060.

18. Stade K, Ford CS, Guthrie C, Weis K: Exportin 1 (Crm1p) is an essential nuclear export factor. Cell 1997, 90(6):1041-1050.

19. Hutten S: Untersuchungen zur Funktion der cytoplasmatischen Nukleoporine Nup214 and Nup358 im nukleocytoplasmatischen Transport. Göttingen: Ernst-August-Universität zu Göttingen; 2007. 
20. Hutten S, Kehlenbach RH: CRM1-mediated nuclear export: to the pore and beyond. Trends Cell Biol 2007, 17(4):193-201. Epub 2007 Feb 2020.

21. Ohno M, Segref A, Bachi A, Wilm M, Mattaj IW: PHAX, a mediator of $U$ snRNA nuclear export whose activity is regulated by phosphorylation. Cell 2000, 101(2):187-198.

22. Groom HC, Anderson EC, Lever AM: Rev: beyond nuclear export. J Gen Virol 2009, 90(Pt 6):1303-1318.

23. Thomas F, Kutay U: Biogenesis and nuclear export of ribosomal subunits in higher eukaryotes depend on the CRM1 export pathway. J Cell Sci 2003, 116(Pt 12):2409-2419.

24. Kutay U, Bischoff FR, Kostka S, Kraft R, Görlich D: Export of importin alpha from the nucleus is mediated by a specific nuclear transport factor. Cell 1997, 90(6):1061-1071.

25. Cook AG, Conti E: Nuclear export complexes in the frame. Curr Opin Struct Biol, 20(2):247-252.

26. Stewart M: Nuclear export of mRNA. Trends Biochem Sci, 35(11):609-617.

27. Rexach $M$, Blobel $\mathrm{G}$ : Protein import into nuclei: association and dissociation reactions involving transport substrate, transport factors, and nucleoporins. Cell 1995, 83(5):683-692.

28. Görlich D, Mattaj IW: Nucleocytoplasmic transport. Science 1996, 271(5255):1513-1518.

29. Bischoff FR, Klebe C, Kretschmer J, Wittinghofer A, Ponstingl H: RanGAP1 induces GTPase activity of nuclear Ras-related Ran. Proc Natl Acad Sci U S A 1994, 91(7):2587-2591.

30. Bischoff FR, Ponstingl H: Catalysis of guanine nucleotide exchange on Ran by the mitotic regulator RCC1. Nature 1991, 354(6348):80-82.

31. Klebe C, Bischoff FR, Ponstingl H, Wittinghofer A: Interaction of the nuclear GTP-binding protein Ran with its regulatory proteins RCC1 and RanGAP1. Biochemistry 1995, 34(2):639-647.

32. Nemergut ME, Mizzen CA, Stukenberg T, Allis CD, Macara IG: Chromatin docking and exchange activity enhancement of RCC1 by histones H2A and H2B. Science 2001, 292(5521):1540-1543.

33. Monecke T, Guttler T, Neumann P, Dickmanns A, Gorlich D, Ficner R: Crystal structure of the nuclear export receptor CRM1 in complex with Snurportin1 and RanGTP. Science 2009, 324(5930):1087-1091.

34. Dong X, Biswas A, Suel KE, Jackson LK, Martinez R, Gu H, Chook YM: Structural basis for leucine-rich nuclear export signal recognition by CRM1. Nature 2009, 1:1.

35. Guttler T, Madl T, Neumann P, Deichsel D, Corsini L, Monecke T, Ficner R, Sattler M, Gorlich D: NES consensus redefined by structures of PKI-type and Rev-type nuclear export signals bound to CRM1. Nat Struct Mol Biol, 17(11):1367-1376.

36. Kudo N, Matsumori N, Taoka H, Fujiwara D, Schreiner EP, Wolff B, Yoshida $M$, Horinouchi S: Leptomycin B inactivates CRM1/exportin 1 by covalent modification at a cysteine residue in the central conserved region. Proc Natl Acad Sci U S A 1999, 96(16):9112-9117.

37. Kudo N, Wolff B, Sekimoto T, Schreiner EP, Yoneda Y, Yanagida M, Horinouchi S, Yoshida M: Leptomycin B inhibition of signal-mediated 
nuclear export by direct binding to CRM1. Exp Cell Res 1998, 242(2):540547.

38. Fischer U, Huber J, Boelens WC, Mattaj IW, Lührmann R: The HIV-1 Rev activation domain is a nuclear export signal that accesses an export pathway used by specific cellular RNAs. Cell 1995, 82(3):475-483.

39. Wen W, Meinkoth JL, Tsien RY, Taylor SS: Identification of a signal for rapid export of proteins from the nucleus. Cell 1995, 82(3):463-473.

40. Engelsma D, Bernad R, Calafat J, Fornerod M: Supraphysiological nuclear export signals bind CRM1 independently of RanGTP and arrest at Nup358. EMBO J 2004, 23(18):3643-3652.

41. Kutay $U$, Güttinger S: Leucine-rich nuclear-export signals: born to be weak. Trends Cell Biol 2005, 15(3):121-124.

42. Paraskeva E, Izaurralde E, Bischoff FR, Huber J, Kutay U, Hartmann E, Luhrmann R, Gorlich D: CRM1-mediated recycling of snurportin 1 to the cytoplasm. J Cell Biol 1999, 145(2):255-264.

43. Nemergut ME, Lindsay ME, Brownawell AM, Macara IG: Ran-binding protein 3 links Crm1 to the Ran guanine nucleotide exchange factor. J Biol Chem 2002, 277(20):17385-17388. Epub 12002 Apr 17383.

44. Lindsay ME, Holaska JM, Welch K, Paschal BM, Macara IG: Ran-binding protein 3 is a cofactor for $\mathrm{Crm1-mediated} \mathrm{nuclear} \mathrm{protein} \mathrm{export.} \mathrm{J} \mathrm{Cell} \mathrm{Biol}$ 2001, 153(7):1391-1402.

45. Englmeier L, Fornerod M, Bischoff FR, Petosa C, Mattaj IW, Kutay U: RanBP3 influences interactions between CRM1 and its nuclear protein export substrates. EMBO Rep 2001, 2(10):926-932. Epub 2001 Sep 2024.

46. Oka M, Asally M, Yasuda Y, Ogawa Y, Tachibana T, Yoneda Y: The Mobile FG Nucleoporin Nup98 Is a Cofactor for Crm1-dependent Protein Export. Mol Biol Cell, 2010:7.

47. Ben-Efraim I, Frosst PD, Gerace L: Karyopherin binding interactions and nuclear import mechanism of nuclear pore complex protein Tpr. BMC Cell Biol 2009, 10:74.

48. Kraemer D, Wozniak RW, Blobel G, Radu A: The human CAN protein, a putative oncogene product associated with myeloid leukemogenesis, is a nuclear pore complex protein that faces the cytoplasm. Proc Natl Acad Sci USA 1994, 91(4):1519-1523.

49. Fornerod M, van Deursen J, van Baal S, Reynolds A, Davis D, Murti KG, Fransen J, Grosveld G: The human homologue of yeast CRM1 is in a dynamic subcomplex with CAN/Nup214 and a novel nuclear pore component Nup88. EMBO (Eur Mol Biol Organ) J 1997, 16(4):807-816.

50. Kehlenbach RH, Dickmanns A, Kehlenbach A, Guan T, Gerace L: A role for RanBP1 in the release of CRM1 from the nuclear pore complex in a terminal step of nuclear export. J Cell Biol 1999, 145:645-657.

51. Hutten S, Kehlenbach RH: Nup214 is required for CRM1-dependent nuclear protein export in vivo. Mol Cell Biol 2006, 26(18):6772-6785.

52. Bernad R, Engelsma D, Sanderson H, Pickersgill H, Fornerod M: Nup214Nup88 nucleoporin subcomplex is required for CRM1-mediated $60 \mathrm{~S}$ preribosomal nuclear export. J Biol Chem 2006, 281(28):19378-19386. Epub 12006 May 19374. 
53. Koyama $M$, Matsuura $Y$ : An allosteric mechanism to displace nuclear export cargo from CRM1 and RanGTP by RanBP1. EMBO J, 29(12):2002-2013.

54. Stewart M: Molecular mechanism of the nuclear protein import cycle. Nat Rev Mol Cell Biol 2007, 8(3):195-208. Epub 2007 Feb 2007.

55. Maul GG, Deaven L: Quantitative determination of nuclear pore complexes in cycling cells with differing DNA content. J Cell Biol 1977, 73(3):748-760.

56. Cordes VC, Reidenbach S, Franke WW: High content of a nuclear pore complex protein in cytoplasmic annulate lamellae of Xenopus oocytes. Eur J Cell Biol 1995, 68(3):240-255.

57. Fahrenkrog B, Stoffler D, Aebi U: Nuclear pore complex architecture and functional dynamics. Curr Top Microbiol Immunol 2001, 259:95-117.

58. Terry LJ, Wente SR: Flexible gates: dynamic topologies and functions for FG nucleoporins in nucleocytoplasmic transport. Eukaryot Cell 2009, 8(12):1814-1827. Epub 2009 Oct 1812.

59. Wälde $S$, Kehlenbach R: The Part and the Whole: functions of nucleoporins in nucleocytoplasmic transport. Trends in Cell Biology 2010, in press.

60. Rout MP, Aitchison JD, Suprapto A, Hjertaas K, Zhao Y, Chait BT: The yeast nuclear pore complex: composition, architecture, and transport mechanism. J Cell Biol 2000, 148(4):635-651.

61. Cronshaw JM, Krutchinsky AN, Zhang W, Chait BT, Matunis MJ: Proteomic analysis of the mammalian nuclear pore complex. J Cell Biol 2002, 158(5):915-927.

62. Grote $M$, Kubitscheck $U$, Reichelt R, Peters R: Mapping of nucleoporins to the center of the nuclear pore complex by post-embedding immunogold electron microscopy. J Cell Sci 1995, 108 ( Pt 9):2963-2972.

63. Bayliss R, Littlewood T, Stewart M: Structural basis for the interaction between FxFG nucleoporin repeats and importin-beta in nuclear trafficking. Cell 2000, 102(1):99-108.

64. Denning DP, Patel SS, Uversky V, Fink AL, Rexach M: Disorder in the nuclear pore complex: the FG repeat regions of nucleoporins are natively unfolded. Proc Natl Acad Sci U S A 2003, 100(5):2450-2455. Epub 2003 Feb 2425.

65. Fahrenkrog B, Maco B, Fager AM, Koser J, Sauder U, Ullman KS, Aebi U: Domain-specific antibodies reveal multiple-site topology of Nup153 within the nuclear pore complex. J Struct Biol 2002, 140(1-3):254-267.

66. Fahrenkrog B, Aebi U: The nuclear pore complex: nucleocytoplasmic transport and beyond. Nat Rev Mol Cell Biol 2003, 4(10):757-766.

67. Paulillo SM, Phillips EM, Koser J, Sauder U, Ullman KS, Powers MA, Fahrenkrog B: Nucleoporin domain topology is linked to the transport status of the nuclear pore complex. J Mol Biol 2005, 351(4):784-798.

68. Bayliss R, Ribbeck K, Akin D, Kent HM, Feldherr CM, Gorlich D, Stewart M: Interaction between NTF2 and xFxFG-containing nucleoporins is required to mediate nuclear import of RanGDP. J Mol Biol 1999, 293(3):579-593.

69. Bayliss R, Littlewood T, Strawn LA, Wente SR, Stewart M: GLFG and FxFG nucleoporins bind to overlapping sites on importin-beta. J Biol Chem 2002, 277(52):50597-50606.

70. Fribourg S, Braun IC, Izaurralde E, Conti E: Structural basis for the recognition of a nucleoporin FG repeat by the NTF2-like domain of the TAP/p15 mRNA nuclear export factor. Mol Cell 2001, 8(3):645-656. 
71. Grant RP, Neuhaus D, Stewart M: Structural basis for the interaction between the Tap/NXF1 UBA domain and FG nucleoporins at 1A resolution. $J \mathrm{Mol}$ Biol 2003, 326(3):849-858.

72. Liu SM, Stewart M: Structural basis for the high-affinity binding of nucleoporin Nup1p to the Saccharomyces cerevisiae importin-beta homologue, Kap95p. J Mol Biol 2005, 349(3):515-525.

73. Brohawn SG, Partridge JR, Whittle JR, Schwartz TU: The nuclear pore complex has entered the atomic age. Structure 2009, 17(9):1156-1168.

74. Elad N, Maimon T, Frenkiel-Krispin D, Lim RY, Medalia O: Structural analysis of the nuclear pore complex by integrated approaches. Curr Opin Struct Biol 2009, 19(2):226-232. Epub 2009 Mar 2025.

75. Suntharalingam M, Wente SR: Peering through the pore: nuclear pore complex structure, assembly, and function. Dev Cell 2003, 4(6):775-789.

76. Peters R: Translocation through the nuclear pore: Kaps pave the way. Bioessays 2009, 31(4):466-477.

77. Frey S, Richter RP, Görlich D: FG-rich repeats of nuclear pore proteins form a three-dimensional meshwork with hydrogel-like properties. Science 2006, 314(5800):815-817.

78. Frey S, Görlich D: A saturated FG-repeat hydrogel can reproduce the permeability properties of nuclear pore complexes. Cell 2007, 130(3):512523.

79. Frey S, Görlich D: FG/FxFG as well as GLFG repeats form a selective permeability barrier with self-healing properties. Embo J 2009, 28(17):2554-2567. Epub 2009 Aug 2513.

80. Ribbeck K, Görlich D: The permeability barrier of nuclear pore complexes appears to operate via hydrophobic exclusion. Embo J 2002, 21(11):26642671.

81. Rout MP, Aitchison JD, Magnasco MO, Chait BT: Virtual gating and nuclear transport: the hole picture. Trends Cell Biol 2003, 13(12):622-628.

82. Lim RY, Huang NP, Koser J, Deng J, Lau KH, Schwarz-Herion K, Fahrenkrog B, Aebi U: Flexible phenylalanine-glycine nucleoporins as entropic barriers to nucleocytoplasmic transport. Proc Natl Acad Sci U S A 2006, 103(25):95129517. Epub 2006 Jun 9512.

83. Matsuura $Y$, Stewart M: Nup50/Npap60 function in nuclear protein import complex disassembly and importin recycling. Embo J 2005, 24(21):36813689. Epub 2005 Oct 3613.

84. Walther TC, Fornerod M, Pickersgill H, Goldberg M, Allen TD, Mattaj IW: The nucleoporin Nup153 is required for nuclear pore basket formation, nuclear pore complex anchoring and import of a subset of nuclear proteins. Embo J 2001, 20(20):5703-5714.

85. Fontoura BM, Blobel G, Yaseen NR: The nucleoporin Nup98 is a site for GDP/GTP exchange on ran and termination of karyopherin beta 2mediated nuclear import. J Biol Chem 2000, 275(40):31289-31296.

86. Wu J, Matunis MJ, Kraemer D, Blobel G, Coutavas E: Nup358, a cytoplasmically exposed nucleoporin with peptide repeats, Ran-GTP binding sites, zinc fingers, a cyclophilin A homologous domain, and a leucine-rich region. J Biol Chem 1995, 270(23):14209-14213. 
87. Singh $B B$, Patel $H H$, Roepman $R$, Schick $D$, Ferreira PA: The zinc finger cluster domain of RanBP2 is a specific docking site for the nuclear export factor, exportin-1. J Biol Chem 1999, 274(52):37370-37378.

88. Delphin C, Guan T, Melchior F, Gerace L: RanGTP Targets p97 to RanBP2, a filamentous protein localized at the cytoplasmic periphery of the nuclear pore complex. Mol Biol Cell 1997, 8(12):2379-2390.

89. Yaseen NR, Blobel G: Two distinct classes of Ran-binding sites on the nucleoporin Nup-358. Proc Natl Acad Sci U S A 1999, 96(10):5516-5521.

90. Mahajan R, Delphin C, Guan T, Gerace L, Melchior F: A small ubiquitinrelated polypeptide involved in targeting RanGAP1 to nuclear pore complex protein RanBP2. Cell 1997, 88(1):97-107.

91. Matunis MJ, Wu J, Blobel G: SUMO-1 modification and its role in targeting the Ran GTPase-activating protein, RanGAP1, to the nuclear pore complex. J Cell Biol 1998, 140(3):499-509.

92. Walther TC, Pickersgill HS, Cordes VC, Goldberg MW, Allen TD, Mattaj IW, Fornerod $\mathrm{M}$ : The cytoplasmic filaments of the nuclear pore complex are dispensable for selective nuclear protein import. J Cell Biol 2002, 158(1):6377.

93. Hutten S, Flotho A, Melchior F, Kehlenbach RH: The Nup358-RanGAP complex is required for efficient importin $\{$ alpha\}/\{beta\}-dependent nuclear import. Mol Biol Cell 2008, 19(5):2300-2310. Epub 2008 Feb 2327.

94. Hutten S, Wälde S, Spillner C, Hauber J, Kehlenbach RH: The nuclear pore component Nup358 promotes transportin-dependent nuclear import. J Cell Sci 2009, 122(Pt 8):1100-1110. Epub 2009 Mar 1119.

95. Van Laer L, Van Camp G, van Zuijlen D, Green ED, Verstreken M, Schatteman I, Van de Heyning P, Balemans W, Coucke P, Greinwald JH et al: Refined mapping of a gene for autosomal dominant progressive sensorineural hearing loss (DFNA5) to a 2-cM region, and exclusion of a candidate gene that is expressed in the cochlea. Eur J Hum Genet 1997, 5(6):397-405.

96. Farjot $G$, Sergeant A, Mikaelian I: A new nucleoporin-like protein interacts with both HIV-1 Rev nuclear export signal and CRM-1. J Biol Chem 1999, 274(24):17309-17317.

97. Strahm Y, Fahrenkrog B, Zenklusen D, Rychner E, Kantor J, Rosbach M, Stutz F: The RNA export factor Gle1p is located on the cytoplasmic fibrils of the NPC and physically interacts with the FG-nucleoporin Rip1p, the DEAD-box protein Rat8p/Dbp5p and a new protein Ymr 255p. Embo J 1999, 18(20):5761-5777.

98. Kendirgi F, Rexer DJ, Alcazar-Roman AR, Onishko HM, Wente SR: Interaction between the shuttling mRNA export factor Gle1 and the nucleoporin hCG1: a conserved mechanism in the export of Hsp70 mRNA. Mol Biol Cell 2005, 16(9):4304-4315. Epub 2005 Jul 4306.

99. Le Rouzic E, Mousnier A, Rustum C, Stutz F, Hallberg E, Dargemont C, Benichou S: Docking of HIV-1 Vpr to the nuclear envelope is mediated by the interaction with the nucleoporin hCG1. J Biol Chem 2002, 277(47):45091-45098. Epub 42002 Sep 45012.

100. Saavedra CA, Hammell CM, Heath CV, Cole CN: Yeast heat shock mRNAs are exported through a distinct pathway defined by Rip1p. Genes Dev 1997, 11(21):2845-2856. 
101. Rollenhagen $\mathrm{C}$, Hodge $\mathrm{CA}$, Cole $\mathrm{CN}$ : The nuclear pore complex and the DEAD box protein Rat8p/Dbp5p have nonessential features which appear to facilitate mRNA export following heat shock. Mol Cell Biol 2004, 24(11):4869-4879.

102. Vainberg IE, Dower K, Rosbash M: Nuclear export of heat shock and nonheat-shock mRNA occurs via similar pathways. Mol Cell Biol 2000, 20(11):3996-4005.

103. Katahira J, Strasser K, Podtelejnikov A, Mann M, Jung JU, Hurt E: The Mex67p-mediated nuclear mRNA export pathway is conserved from yeast to human. Embo J 1999, 18(9):2593-2609.

104. Stutz F, Neville M, Rosbash M: Identification of a novel nuclear poreassociated protein as a functional target of the HIV-1 Rev protein in yeast. Cell 1995, 82(3):495-506.

105. Floer M, Blobel G: Putative reaction intermediates in Crm1-mediated nuclear protein export. J Biol Chem 1999, 274(23):16279-16286.

106. Askjaer P, Bachi A, Wilm M, Bischoff FR, Weeks DL, Ogniewski V, Ohno M, Niehrs C, Kjems J, Mattaj IW et al: RanGTP-regulated interactions of CRM1 with nucleoporins and a shuttling DEAD-box helicase. Mol Cell Biol 1999, 19(9):6276-6285.

107. Fischer U, Meyer S, Teufel M, Heckel C, Lührmann R, Rautmann G: Evidence that HIV-1 Rev directly promotes the nuclear export of unspliced RNA. EMBO J 1994, 13:4105-4112.

108. Arnold M, Nath A, Hauber J, Kehlenbach RH: Multiple importins function as nuclear transport receptors for the Rev protein of human immunodeficiency virus type 1. J Biol Chem 2006, 281(30):20883-20890. Epub 22006 May 20816.

109. Henderson BR, Percipalle P: Interactions between HIV Rev and nuclear import and export factors: the Rev nuclear localisation signal mediates specific binding to human importin-beta. J Mol Biol 1997, 274(5):693-707.

110. Kehlenbach RH, Assheuer R, Kehlenbach A, Becker J, Gerace L: Stimulation of nuclear export and inhibition of nuclear import by a Ran mutant deficient in binding to Ran-binding protein 1. J Biol Chem 2001, 276(17):14524-14531.

111. Bernad R, van der Velde H, Fornerod M, Pickersgill H: Nup358/RanBP2 attaches to the nuclear pore complex via association with Nup88 and Nup214/CAN and plays a supporting role in CRM1-mediated nuclear protein export. Mol Cell Biol 2004, 24(6):2373-2384.

112. Bachi A, Braun IC, Rodrigues JP, Pante N, Ribbeck K, von Kobbe C, Kutay U, Wilm M, Gorlich D, Carmo-Fonseca M et al: The C-terminal domain of TAP interacts with the nuclear pore complex and promotes export of specific CTE-bearing RNA substrates. RNA 2000, 6(1):136-158.

113. Wiegand HL, Coburn GA, Zeng Y, Kang Y, Bogerd HP, Cullen BR: Formation of Tap/NXT1 heterodimers activates Tap-dependent nuclear mRNA export by enhancing recruitment to nuclear pore complexes. Mol Cell Biol 2002, 22(1):245-256.

114. Katahira J, Straesser K, Saiwaki T, Yoneda Y, Hurt E: Complex formation between Tap and $\mathrm{p} 15$ affects binding to FG-repeat nucleoporins and nucleocytoplasmic shuttling. J Biol Chem 2002, 277(11):9242-9246. 
115. Goppelt A, Stelzer G, Lottspeich F, Meisterernst M: A mechanism for repression of class II gene transcription through specific binding of NC2 to TBP-promoter complexes via heterodimeric histone fold domains. EMBO J 1996, 15(12):3105-3116.

116. Mermelstein F, Yeung K, Cao J, Inostroza JA, Erdjument-Bromage H, Eagelson $\mathrm{K}$, Landsman $\mathrm{D}$, Levitt $\mathrm{P}$, Tempst $\mathrm{P}$, Reinberg $\mathrm{D}$ : Requirement of a corepressor for Dr1-mediated repression of transcription. Genes Dev 1996, 10(8):1033-1048.

117. Kamada K, Shu F, Chen H, Malik S, Stelzer G, Roeder RG, Meisterernst M, Burley SK: Crystal structure of negative cofactor 2 recognizing the TBP-DNA transcription complex. Cell 2001, 106(1):71-81.

118. Inostroza JA, Mermelstein FH, Ha I, Lane WS, Reinberg D: Dr1, a TATAbinding protein-associated phosphoprotein and inhibitor of class II gene transcription. Cell 1992, 70(3):477-489.

119. Meisterernst M, Roeder RG: Family of proteins that interact with TFIID and regulate promoter activity. Cell 1991, 67(3):557-567.

120. Cang $\mathrm{Y}$, Prelich $\mathrm{G}$ : Direct stimulation of transcription by negative cofactor 2 (NC2) through TATA-binding protein (TBP). Proc Natl Acad Sci U S A 2002, 99(20):12727-12732.

121. Castano E, Gross P, Wang Z, Roeder RG, Oelgeschlager T: The C-terminal domain-phosphorylated IIO form of RNA polymerase II is associated with the transcription repressor NC2 (Dr1/DRAP1) and is required for transcription activation in human nuclear extracts. Proc Natl Acad Sci U S A 2000, 97(13):7184-7189.

122. Willy PJ, Kobayashi R, Kadonaga JT: A basal transcription factor that activates or represses transcription. Science 2000, 290(5493):982-985.

123. Geisberg JV, Holstege FC, Young RA, Struhl K: Yeast NC2 associates with the RNA polymerase II preinitiation complex and selectively affects transcription in vivo. Mol Cell Biol 2001, 21(8):2736-2742.

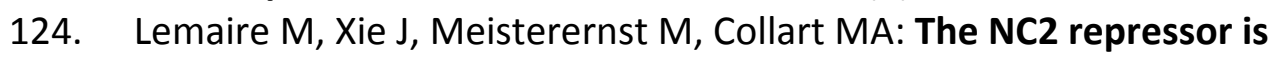
dispensable in yeast mutated for the Sin4p component of the holoenzyme and plays roles similar to Mot1p in vivo. Mol Microbiol 2000, 36(1):163-173.

125. Kahle J, Piaia E, Neimanis S, Meisterernst M, Doenecke D: Regulation of nuclear import and export of negative cofactor 2. J Biol Chem 2009, 284(14):9382-9393. Epub 2009 Feb 9389.

126. Beals CR, Clipstone NA, Ho SN, Crabtree GR: Nuclear localization of NF-ATc by a calcineurin-dependent, cyclosporin- sensitive intramolecular interaction. Genes Dev 1997, 11(7):824-834.

127. Beals CR, Sheridan CM, Turck CW, Gardner P, Crabtree GR: Nuclear export of NF-ATc enhanced by glycogen synthase kinase-3. Science 1997, 275(5308):1930-1934.

128. Kehlenbach RH, Dickmanns A, Gerace L: Nucleocytoplasmic shuttling factors including Ran and CRM1 mediate nuclear export of NFAT in vitro. J Cell Biol 1998, 141(4):863-874.

129. Shibasaki F, Price ER, Milan D, McKeon F: Role of kinases and the phosphatase calcineurin in the nuclear shuttling of transcription factor NFAT4. Nature 1996, 382(6589):370-373. 
130. Liang SH, Clarke MF: Regulation of p53 localization. Eur J Biochem 2001, 268(10):2779-2783.

131. Cai X, Liu X: Inhibition of Thr-55 phosphorylation restores p53 nuclear localization and sensitizes cancer cells to DNA damage. Proc Natl Acad Sci U S A 2008, 105(44):16958-16963.

132. Geyer RK, Yu ZK, Maki CG: The MDM2 RING-finger domain is required to promote p53 nuclear export. Nat Cell Biol 2000, 2(9):569-573.

133. Li M, Brooks CL, Wu-Baer F, Chen D, Baer R, Gu W: Mono- versus polyubiquitination: differential control of p53 fate by Mdm2. Science 2003, 302(5652):1972-1975.

134. Alt JR, Cleveland JL, Hannink M, Diehl JA: Phosphorylation-dependent regulation of cyclin D1 nuclear export and cyclin D1-dependent cellular transformation. Genes Dev 2000, 14(24):3102-3114.

135. Diehl JA, Cheng M, Roussel MF, Sherr CJ: Glycogen synthase kinase-3beta regulates cyclin D1 proteolysis and subcellular localization. Genes Dev 1998, 12(22):3499-3511.

136. Choudhary C, Kumar C, Gnad F, Nielsen ML, Rehman M, Walther TC, Olsen $\mathrm{JV}$, Mann M: Lysine acetylation targets protein complexes and co-regulates major cellular functions. Science 2009, 325(5942):834-840.

137. Le Rouzic E, Mousnier A, Rustum C, Stutz F, Hallberg E, Dargemont C, Benichou S: Docking of HIV-1 Vpr to the nuclear envelope is mediated by the interaction with the nucleoporin hCG1. J Biol Chem 2002, 277(47):45091-45098.

138. Holt GD, Snow CM, Senior A, Haltiwanger RS, Gerace L, Hart GW: Nuclear pore complex glycoproteins contain cytoplasmically disposed O- linked Nacetylglucosamine. J Cell Biol 1987, 104(5):1157-1164.

139. Langer K, Dian C, Rybin V, Muller CW, Petosa C: Insights into the Function of the CRM1 Cofactor RanBP3 from the Structure of Its Ran-Binding Domain. PLoS One, 6(2):e17011.

140. Charneau P, Mirambeau G, Roux P, Paulous S, Buc H, Clavel F: HIV-1 reverse transcription. A termination step at the center of the genome. $J \mathrm{Mol} B \mathrm{BiO}$ 1994, 241(5):651-662.

141. Guan T, Kehlenbach RH, Schirmer EC, Kehlenbach A, Fan F, Clurman BE, Arnheim N, Gerace L: Nup50, a nucleoplasmically oriented nucleoporin with a role in nuclear protein export. Mol Cell Biol 2000, 20(15):5619-5630.

142. Melchior F, Guan T, Yokoyama N, Nishimoto T, Gerace L: GTP hydrolysis by Ran occurs at the nuclear pore complex in an early step of protein import. $J$ Cell Biol 1995, 131(3):571-581.

143. Strasser A, Dickmanns A, Schmidt U, Penka E, Urlaub H, Sekine M, Luhrmann $\mathrm{R}$, Ficner R: Purification, crystallization and preliminary crystallographic data of the $\mathrm{m} 3 \mathrm{G}$ cap-binding domain of human snRNP import factor snurportin 1. Acta Crystallogr D Biol Crystallogr 2004, 60(Pt 9):1628-1631. Epub 2004 Aug 1626.

144. Grüter P, Tabernero C, von Kobbe C, Schmitt C, Saavedra C, Bachi A, Wilm M, Felber BK, Izaurralde E: TAP, the human homolog of Mex67p, mediates CTEdependent RNA export from the nucleus. Mol Cell 1998, 1(5):649-659.

145. Birnboim HC, Doly J: A rapid alkaline extraction procedure for screening recombinant plasmid DNA. Nucleic Acids Res 1979, 7(6):1513-1523. 
146. Sanger F, Nicklen S, Coulson AR: DNA sequencing with chain-terminating inhibitors. Proc Natl Acad Sci U S A 1977, 74(12):5463-5467.

147. Mullis KB: Target amplification for DNA analysis by the polymerase chain reaction. Ann Biol Clin (Paris) 1990, 48(8):579-582.

148. Laemmli UK: Cleavage of structural proteins during the assembly of the head of bacteriophage T4. Nature 1970, 227(5259):680-685.

149. Neuhoff V, Arold N, Taube D, Ehrhardt W: Improved staining of proteins in polyacrylamide gels including isoelectric focusing gels with clear background at nanogram sensitivity using Coomassie Brilliant Blue G-250 and R-250. Electrophoresis 1988, 9(6):255-262.

150. Towbin H, Staehelin T, Gordon J: Electrophoretic transfer of proteins from polyacrylamide gels to nitrocellulose sheets: procedure and some applications. Proc Natl Acad Sci U S A 1979, 76(9):4350-4354.

151. Engvall E, Perlmann P: Enzyme-linked immunosorbent assay (ELISA). Quantitative assay of immunoglobulin G. Immunochemistry 1971, 8(9):871874.

152. Ausubel FM, Brent R, Kingston RE, Moore DD, Seidman JG, Smith JA, Struhl K: Current protocols in molecular biology. New York: Greene Publishing Associates and Wiley-Interscience 1994.

153. Gall JG, Pardue ML: Formation and detection of RNA-DNA hybrid molecules in cytological preparations. Proc Natl Acad Sci U S A 1969, 63(2):378-383.

154. Hilliard M, Frohnert C, Spillner C, Marcone S, Nath A, Lampe T, Fitzgerald DJ, Kehlenbach $\mathrm{RH}$ : The anti-inflammatory prostaglandin 15-deoxydelta(12,14)-PGJ2 inhibits CRM1-dependent nuclear protein export. J Biol Chem, 285(29):22202-22210.

155. Koster M, Frahm T, Hauser H: Nucleocytoplasmic shuttling revealed by FRAP and FLIP technologies. Curr Opin Biotechnol 2005, 16(1):28-34. 


\section{CURRICULUM VITAE}

Name:

Geburtstag:

Geburtsort:

Staatsangehörigkeit:

Schulische Ausbildung

$1986-1990$

$1990-1992$

$1992-1999$

21.6.1999

$1999-2001$

29.6.2001

\section{Hochschulstudium}

$10.2001-05.2007$

$05.2006-05.2007$

Seit 06.2007
Inga Mareike Waldmann

21.6.1980

Aurich

deutsch
Grundschule Holtrop

Orientierungsstufe Großefehn

Gymnasium Ulricianum Aurich

Abitur

Berufsfachschule für Biologisch-Technische Assistenz Abschluss der Ausbildung zur BTA

Studium der Biologie an der Georg-August-Universität Göttingen.

Diplomarbeit,„Untersuchungen zum Import des Transkriptionsfaktors c-Jun in den Zellkern" in der Arbeitsgruppe von PD Dr. Ralph Kehlenbach, Abteilung Biochemie 1 der Universität Göttingen.

Doktorarbeit „Die Funktion von NLP1 im CRM1abhängigen Protein-Export aus dem Zellkern" in der Arbeitsgruppe von PD Dr. Ralph Kehlenbach, Abteilung Biochemie 1 der Universität Göttingen. 


\section{Veröffentlichungen:}

Waldmann I., Wälde S., Kehlenbach RH. Nuclear import of c-Jun is mediated by multiple transport receptors. J Biol Chem. 2007 Sep 21;282(38):27685-92

Waldmann I., Spillner C., Kehlenbach RH. The nucleoporin like protein NLP1/hCG1 promotes CRM1-dependent nuclear protein export (eingereicht im März 2011 (Journal of Cell Science)). 


\section{DANKSAGUNG}

Ganz herzlich bedanken möchte ich mich bei Dr. Ralph Kehlenbach für ein spannendes und zudem auch häufig herausforderndes Projekt und für seine Unterstützung während der Höhen und Tiefen dieser Doktorarbeit.

Ein besonderer Dank gilt Prof. Dr. Ralf Ficner für die Übernahme des Korreferats. Gleichfalls danke ich Prof. Dr. Detlef Doenecke, Prof. Dr. Blanche Schwappach, Dr. Dieter Klopfenstein und Dr. Michael Thumm, die sich als Mitglieder des Prüfungskomitees zur Verfügung gestellt haben.

Danke an meine lieben Kollegen Steffi, Conny, Sarah, Ketan, Annegret, Ulrike und Ruth für die angenehme Atmosphäre im Labor.

Ein besonders großes Dankeschön geht an Christiane, die mich so tatkräftig im Labor unterstützt hat und an die Korrekturleser dieser Arbeit, Herrn Doenecke, Ralph, Frank und Marie!

Sehr viel Spaß hatte ich während dieser Doktorarbeit mit Lennart und Marie, was mir das Laborleben etwas versüßt hat! Vielen Dank Euch für das ein oder andere „Entspannungskäffchen“ und „Bier um vier“ :)!

Mein größter Dank geht an meine Familie, Frank und meine Freunde, die gerade in schweren Zeiten für mich da waren, mich immer wieder aufgebaut und zum Weitermachen animiert haben! 